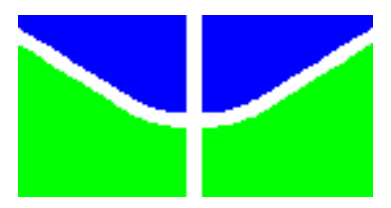

UNIVERSIDADE DE BRASÍLIA

Instituto de Química

Programa de Pós-Graduação em Química

DEFESA DE MESTRADO

\title{
ESTUDO TEÓRICO DOS ASPECTOS MECANÍSTICOS DO REARRANJO DO TIPO MCLAFFERTY
}

LAÍS DE SOUSA BARBOSA

ORIENTADOR: PROF. Dr. KLEBER CARLOS MUNDIM COORIENTADOR: PROF. Dr. DAVÍ ALEXSANDRO CARDOSO FERREIRA

Brasília, DF

2016 


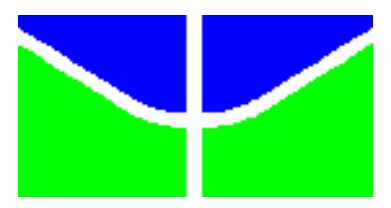

UNIVERSIDADE DE BRASÍLIA

Instituto de Química

Programa de Pós-Graduação em Química

\section{LAÍS DE SOUSA BARBOSA}

Defesa de Mestrado apresentada ao Programa de Pós-Graduação em Química da Universidade de Brasília como requisito para obtenção do título de Mestre em Química.

ORIENTADOR: PROF. Dr. KLEBER CARLOS MUNDIM COORIENTADOR: PROF. Dr. DAVÍ ALEXSANDRO CARDOSO FERREIRA

Brasília, DF

2016 


\section{FOLHA DE APROVAÇÃO}

Comunicamos a aprovação da Defesa de Dissertação de Mestrado do (a) Aluno (o) Laís de Sousa Barbosa, intitulada "Estudo Teórico dos Aspectos Mecanísticos do Rearranjo do Tipo Mclafferty", apresentado no (a) auditório Láuro Morhy do Instituto de Química (IQ) da Universidade de Brasília em 05 de agosto de 2016.

Prof. Dr. Kleber Carlos Mundim Presidente (IQ/ UnB)

Prof $^{a}$. Dr ${ }^{a}$. Maria Suely Pedrosa Mundim

Membro Titular (IF/ UnB)

Prof. Dr. Rafael Oliveira Rocha

Membro Titular (IQ/UnB)

Prof. Dr. Wender Alves da Silva

Membro Suplente (IQ/UnB)

Brasília, 2016. 


\section{RESUMO}

Neste trabalho foi explorado, a partir de uma análise químico-quântica, o rearranjo do tipo McLafferty - modelo mecanístico bastante aplicado na interpretação de surgimento de intermediários no espectro de massa - para os sistemas do 1-nitropropano, 2-pentanona e butirofenona. Esta exploração teórica, através da combinação dos métodos M06/6311G(d,p)//UHF/LanL2MB, permitiu a construção de um perfil termodinâmico, cinético e eletrônico do referido rearranjo, onde constatou-se que o rearranjo clássico é improvável, cinética e termodinamicamente, quando comparado ao mecanismo em etapas. Através de análises QTAIM foi verificado que o processo de fragmentação depende diretamente da natureza do substituinte $\mathrm{X}$, onde quanto maior a natureza retiradora do grupo, mais instável é o intermediário formado. Esta tendência topologicamente observada, reflete no comportamento cinético e termodinâmico do rearranjo do tipo McLafferty.

PALAVRAS CHAVE: McLafferty, QTAIM, NBO, Fragmentação, Espectrometria de Massas, Rearranjo Concertado, Rearranjo em Etapas. 


\begin{abstract}
In this work we explored, from a quantum-chemical analysis, a McLafferty rearrangement type - mechanistic model widely applied in the interpretation of intermediate rises in the mass spectrum - for systems 1-nitropropane, 2-pentanone and butyrophenone. This theoretical exploration, through the M06/6-311G(d, p)//UHF/LanL2MB, allowed the thermodynamical, kinetical and electronic profile of the rearrangement, where it was found that the classical rearrangement is unlikely, thermodynamically and kinetically, compared to the stepwise mechanism. Through the QTAIM analysis it was found that the fragmentation process depends directly of the substituent $\mathrm{X}$ nature, where the higher withdrawing nature of the group, lead to the more unstable intermediate. This topological observed trend reflects the kinetic and thermodynamic behavior of the type McLafferty rearrangement.
\end{abstract}

KEYWORDS: McLafferty, QTAIM, NBO, Fragmentation, Mass Spectrometry, Rearrangement Concerted, Stepwise Rearrangement. 


\section{AGRADECIMENTOS}

- Ao meu orientador Kleber Carlos Mundim por sua orientação, discussões e preocupação com a qualidade da minha formação.

- A todos os meus professores pela contribuição na minha formação acadêmica durante o mestrado, em especial aos Professores José Roberto Politi, Edgardo Garcia e Ângelo Machado.

- À minha madrinha Elisabete que sempre me ajudou, incentivou e se preocupou com os meus estudos.

- Aos colegas de laboratório, LMSC.

- Aos meus amigos pela força, apoio e momentos de descontração em momentos de dificuldade, em especial, à Raiiiissa, Arsênio, Tania, Lais e minha prima Mariana.

- Aos meus familiares agradeço com muito carinho, em especial meus pais (Maurício e Silvia) e minha irmã Nara por todo o apoio, incentivo e a base que sempre me proporcionaram para a vida e em especial meus estudos.

- Finalmente, agradeço com todo o meu carinho, aos meus amigos Sara e Davi, que desde o início deste mestrado sempre me apoiaram e acreditaram na minha capacidade, proporcionando o meu crescimento não só na área acadêmica, mas como também um crescimento pessoal, em relação a maturidade e aspectos gerais da vida. Muito obrigada por tudo!!! Vocês são amigos para uma vida inteira e que merecem o que há de melhor nessa vida, principalmente se for o melhor cachorro quente de Brasília.

- Aos professores Ângelo Machado, Maria Suely P. Mundim e Rafael Rocha por aceitar participar das bancas examinadoras de qualificação e defesa desta dissertação de mestrado e por todas as contribuições.

- Aos órgãos de fomento: CAPES, pela bolsa que me permitiu desenvolver esse trabalho, CNPq e FAPDF. 


\section{LISTA DE FIGURAS}

Figura 1. 1 Componentes de um Espectro de Massa. Fonte: Ref. 6 ............................ 11 Figura 1. 2 Estruturas analisadas Erro! Indicador não definido. Figura 2. 1 Exemplo de Segmentação $\alpha$. Fonte: adaptado da ref.20. 20

Figura 2. 2 Exemplo de Segmentação Indutiva. Fonte: adaptado da ref.20 ................. 20 Figura 2. 3 Exemplo de Segmentação de duas Ligações. Fonte:adaptado da ref.20.... 21 Figura 2. 4 Exemplo de Fragmentação Retro Diels-Alder. Fonte: adaptado da ref.20. 21 Figura 2. 5 Rearranjo do Tipo McLafferty. Fonte: adaptado da ref.20.

Figura 4. 1. Mecanismo geral para fragmentação do 1-Nitropropano, 2-Penanona e Butirofenona

Figura 4. 2. Representação das estruturas do $\mathrm{PrNO}_{2}$ com suas respectivas relações massa/carga Fonte: autor.

Figura 4. 3. Coordenada de reação para a fragmentação do sistema a (1-nitropropano). Fonte: autor. 34

Figura 4. 4. Energia Potencial Relativa da formação de complexo do tipo van der Waals. Fonte: autor

Figura 4. 5. Representação das estruturas da 2-Pentanona com suas respectivas relações massa/carga Fonte: autor. 36

Figura 4. 6. Coordenada de reação para a fragmentação do sistema b (2-pentanona). Fonte: autor.

Figura 4. 7. Representação das estruturas da Butirofenona com suas respectivas relações massa/carga Fonte: autor.

Figura 4. 8. Coordenada de reação para a fragmentação do sistema c (Butirofenona). Fonte: autor. 39

Figura 4. 9. Coordenada Intrínseca de Reação (IRC) para a transferência de hidrogênio radicalar no sistema c (Butirofenona) a partir do 3.1.cTS. 40

Figura 4. 10. Representação geral da geometria de estado de transição do rearranjo do tipo McLafferty (a), do orbital ligante (b) e do orbital p semi preenchido (c) do átomo de carbono$\gamma$ (isocontorno $=0.062208$ ). Fonte: autor 42

Figura 4. 11. Representação estrutural do estado de transição 3.3aTS (a) e da densidade de spin do sistema (região em vermelho representa probabilidade de se encontrar elétron desemparelhado; isocontorno $=0.069442$ ). Fonte: autor.

Figura 4. 12. Representação geral da geometria de estado de transição do rearranjo do tipo McLafferty (a), do orbital ligante (b) e do orbital p semi preenchido (c) do átomo de carbono$\gamma$ (isocontorno $=0.062208)$. Fonte: autor. 44

Figura 4. 13. Representação estrutural do estado de transição 3.cTS e da densidade de spin do sistema (região em vermelho representa probabilidade de se encontrar elétron desemparelhado; isocontorno $=0.069442$ ). Fonte: autor 44

Figura 4. 14. Representação estrutural do estado de transição 3.1cTS e da densidade de spin do sistema (região em vermelho representa probabilidade de se encontrar elétron desemparelhado; isocontorno $=0.069442$ ). Fonte: autor 
Figura 4. 15. Representação estrutural do estado de transição 3.3cTS e da densidade de spin do sistema (região em vermelho representa probabilidade de se encontrar elétron desemparelhado; isocontorno $=0.069442$ ). Fonte: autor

Figura 4. 16. Representação das estruturas do 1- Nitropropano com seus pontos críticos de ligação (BCP) e tabela com os respectivos valores; densidade $(\rho)$, laplaciana de densidade $(\nabla 2 \rho)$, eliplicidade $(\varepsilon)$ e potencial químico $(\mathrm{V})$. 46

Figura 4. 17. Representação das estruturas do 2- Pentanona com seus pontos críticos de ligação (BCP) e tabela com os respectivos valores; densidade $(\rho)$, laplaciana de densidade $(\nabla 2 \rho)$, eliplicidade $(\varepsilon)$ e potencial químico $(\mathrm{V})$.

Figura 4. 18. Representação das estruturas da Butirofenona com seus pontos críticos de ligação (BCP) e tabela com os respectivos valores; densidade $(\rho)$, laplaciana de densidade $(\nabla 2 \rho)$, eliplicidade $(\varepsilon)$ e potencial químico $(\mathrm{V})$. 48

Figura A. 1. Representação do sistema butirofenona com seus respectivos produtos de fragmentação. (Fonte: Adaptado da ref. 44) 52

Figura A. 2. Coordenada de fragmentação caminho 1 53

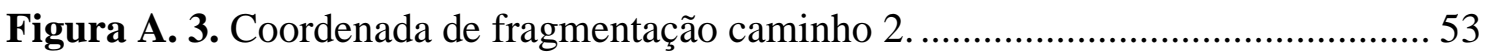

Figura A. 4. Coordenada de fragmentação caminho 3 ............................................... 54

Figura A. 5. Coordenada de fragmentação caminho 1 ................................................ 55

Figura A. 6. Coordenada Intrínseca de Reação (IRC) para a transferência de hidrogênio

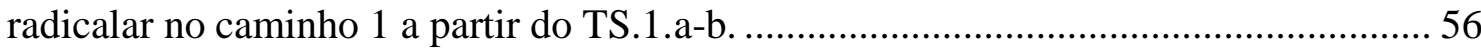

Figura A. 7. Coordenada de fragmentação caminho 3 ........................................... 57

Figura A. 8. Proposta alternativa de coordenada de reação ......................................... 58

Figura A. 9. Proposta alternativa de coordenada de fragmentação - Caminho de fragmentação concertado e "em etapas". 58

Figura A. 10. Coordenada de fragmentação - Proposta alternativa de coordenada de fragmentação - Caminho de fragmentação concertado e "em etapas".

Figura A. 11. Mecanísmo de Fragmentação do $\mathrm{PrNO}_{2}$. Fonte: autor...............................6 60

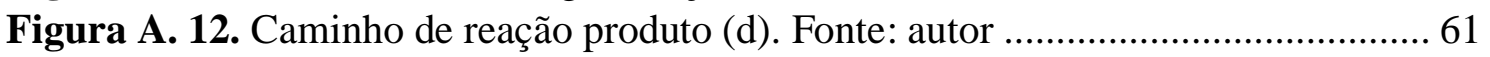

Figura A. 13. Energia Potencial Relativa da formação de complexo do tipo van der Waals.

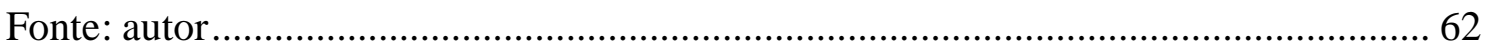

Figura A. 14. Caminho de Reação Produto (e). Fonte: autor ....................................... 63

Figura A. 15. Comparação entre os caminhos de fragmentação que levam aos fragmentos e e

d. Fonte: autor. 63 


\section{LISTA DE ABREVIATURAS E SIGLAS}

ABO - Aproximação de Born-Oppenheimer

BCP - Bond Critical Point - Ponto crítico de ligação

CID - Collision-Induced Dissociation - Dissociação Induzida por Colisão

CI - Ionização Química

DFT - Teoria do Funcional da Densidade

$\mathrm{EE}^{+}$- Ílons com número par de elétrons

EI - Ionização por Elétrons c

ESI - Ionização por Eletrospray

FAB - Bombardeamento de átomos rápidos

GGA - Generalized Gradient Approximation

HFR- Hartree-Fock-Roothaan

HF- Hartree-Fock

LDA - Local Density Approximation

MALDI ionização por dessorção a laser assistido por matriz

NBO Orbitais Naturais de Ligação

$\mathrm{OE}^{\cdot+}$ - Íons com número ímpar de elétrons

$\mathrm{OE}^{\bullet+}$ - Íons com número ímpar de elétrons

QTAIM Teoria Quântica de Átomos em Moléculas

RMN Ressonância magnética nuclear

SIMS espectrometria de massas de íons secundário

SCF-Self Consistent Field

vdW complexo de van der Waals 


\section{SUMÁRIO}

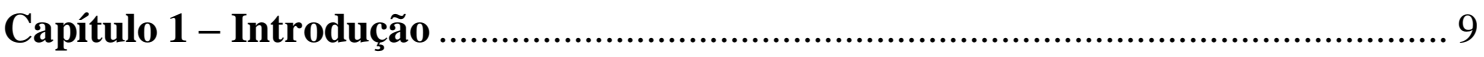

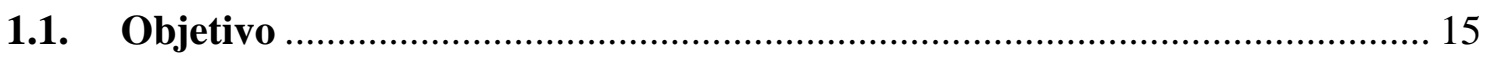

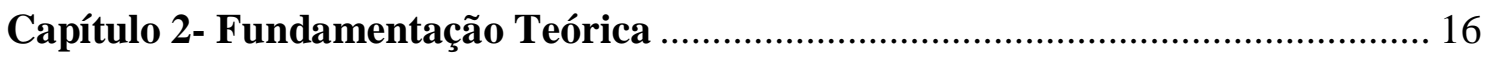

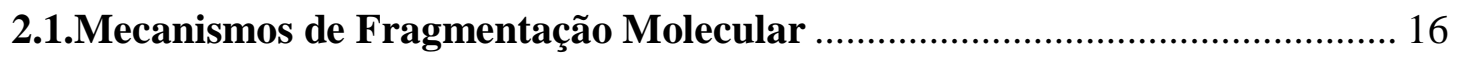

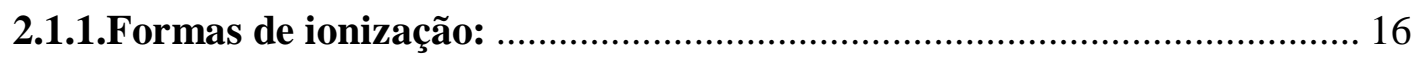

2.1.2. Mecanismos dissociativos de sistemas simples e complexos ................... 18

2.1.3. Rearranjo do tipo McLafferty ........................................................... 21

Capítulo 3. Métodos de Estrutura Eletrônicas ....................................................... 22

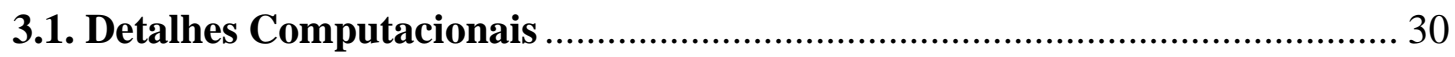

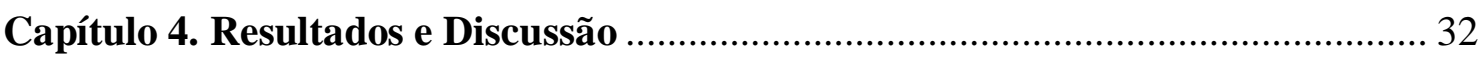

4.1. Análise Cinética e Termodinâmica do Rearranjo do tipo McLafferty ......... 32

4.2. Análise de estrutura eletrônica do Rearranjo do Tipo McLafferty .............. 41

4.2.1. Análises NBO, QTAIM, densidade de spin e índices multicêntricos do Rearranjo do Tipo McLafferty ................................................................... 41

4.2.2. Análise Topológica QTAIM do efeito do substituinte nos sistemas estudados 45

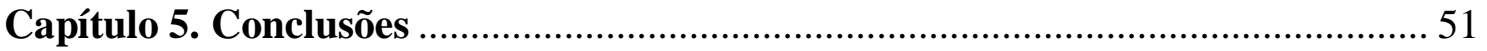

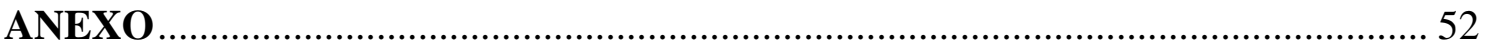

A.1 - Proposta de Mecanismo Completo de Fragmentação da Butirofenona ..... 52

A.2 - Proposta de Mecanismo Completo de Fragmentação do 1-Nitropropano. 59

Referências 


\section{Capítulo 1 - Introdução}

A Química é considerada uma ciência central, sendo interligada à diversos ramos da ciências tais como a Física, Biologia, Farmácia, Geologia, Nutrição, dentre outras. ${ }^{1}$ Uma das áreas de grande importância na Química é a de identificação e caracterização de compostos, que se utiliza dos mais variados métodos físicos para caracterização desses substâncias; a etapa analítica é de fundamental importância para o desenvolvimento de pesquisas nas mais diversas áreas da Química. ${ }^{2}$ Através da ampliação dos conceitos já estabelecidos na Química, aliados aos dados experimentais de caracterização, é possível o entendimento dos fenômenos em nível molecular e atômico; assim, a partir destes resultados é possível interpretar o fenômeno observado macroscopicamente. Sendo assim, a melhor compreensão de fenômenos químicos passa pela caracterização e estudo aprofundado dos mecanismos pelas quais essas transformações ocorrem. ${ }^{3}$

Para a realização destes estudos se faz necessário compreender a estrutura da matéria, em escala atômica, através de modelos modernos aliados a técnicas experimentais baseadas em espectroscopia. Ao passar dos anos, os modelos atômicos foram substancialmente reelaborados e aprimorados, conduzindo a propostas que proporcionaram melhores descrições de diversos fenômenos até então incompreendidos, tais como o comportamento dualístico da luz ${ }^{4}$, efeito fotoelétrico ${ }^{5}$ e, mais recentemente, a descrição topológica de átomos e moléculas ${ }^{6}$; criando, com isso, uma linha de evolução dos modelos atômicos desde a primeira discussão sobre a natureza atômica por Demócrito, passando pelo modelo de Dalton, Thomson ${ }^{7}$, Rutherford $^{8}$, Bohr $^{9}$ até o modelo quântico atual ${ }^{10}$ (o qual incorpora conceitos como quantum de energia, acompanhados dos conceitos de indeterminismo, dualidade onda/partícula, função de onda e densidade de probabilidade $^{4,11}$ ) que foi essencialmente desenvolvido a partir da equação de Schrödinger ${ }^{10}$.

Os conhecimentos construídos ao longo deste período foram de grande importância para a aceitação do modelo quântico atual. Além disso, os experimentos realizados para comprovação e consequente desenvolvimento desses modelos, aplicados ao estudo de átomos e moléculas, reescreveram a história da espectroscopia (atômica e molecular), área do conhecimento que se baseia no fenômeno de interação entre a radiação e matéria e os fenômenos decorrentes de tal interação. ${ }^{12}$

Já é sabido que a luz apresenta natureza dual ${ }^{4}$, podendo ser descrita através de duas teorias que se complementam, a teoria ondulatória e corpuscular. Assim, a luz pode ser descrita 
como uma energia que se propaga como onda eletromagnética (demonstrada por Maxwell ${ }^{13}$ ) e, ao mesmo tempo, interagir com a matéria como partícula (comprovada pelo experimento do efeito fotoelétrico ${ }^{13-14}$ ). Uma vez que a luz apresenta também natureza de onda eletromagnética, ela pode exibir diferentes energias associadas a depender comprimentos de onda assumido, o que dá origem ao seu espectro eletromagnético característico. Esse espectro eletromagnético, que contempla todos os comprimentos de onda da luz, pode ser particionado em regiões com uma determinada faixa de energia (como exemplo a região de micro-ondas, do infravermelho, ultravioleta visível, raios-X, dentre outras). Dessa forma, é possível observar que comprimentos de onda diferentes proporcionam perturbações características, tornando tal sinal espectroscópico único na descrição de átomos, moléculas ou grupos funcionais. A exemplo, absorção de energia no espectro do infravermelho leva ao estiramento de ligações químicas, com características únicas a depender do grupo que absorve a radiação; ou como a retirada de elétrons resultando na fragmentação de moléculas no espectro de massa, cujas razões massa/carga obtidas dependem da estabilidade relativa dos intermediários formados. Utilizando esses conceitos, foram desenvolvidas diversas técnicas espectroscópicas que podem ser utilizadas para caracterização e identificação de estruturas moleculares, a partir de uma vasta catalogação de dados das respostas dessas moléculas após a interação com a luz. Algumas dessas técnicas são a espectroscopia no infravermelho, de ressonância magnética nuclear, de ultravioleta, espectrometria de massa, dentre outras. ${ }^{13 a, 15}$

Dentre os variados métodos de análise citados acima, a espectrometria de massas tem sido um instrumento importante para análise de moléculas orgânicas e biológicas; pois possibilita, através da análise do padrão de fragmentação da molécula e aliada ao banco de dados espectrais e/ou outras técnicas espectroscópicas, a caracterização e até identificação de vários compostos ${ }^{15 b, 16}$. A espectrometria de massas é uma técnica analítica baseada na formação de íons gasosos de uma amostra que são separados pela razão massa/carga (m/z), caracterizando-se, de forma simplificada, como uma dissociação induzida por colisão (CIDCollision-Induced Dissociation). Compreender os mecanismos de reações de fragmentação é de fundamental importância para elucidar o espectro de massa CID e, consequentemente, determinar a composição de amostras tomando como ponto de partida os intermediários catiônicos e /ou radicalares formados ${ }^{15 b, 17}$.

Esta técnica é frequentemente aplicada em diferentes áreas do conhecimento, tais como: na indústria de biotecnologia e farmacêutica, no sequenciamento de proteínas e no 
desenvolvimento de novos compostos químicos de interesse farmacológico, dentre outros. É utilizada, ainda, para o monitoramento da qualidade de água, dos recursos naturais e no monitoramento da qualidade das reservas de petróleo nas áreas de ciências ambientais e geologia. $^{15 b}$

Há diversos modelos de espectrômetros de massa. Em química os espectrômetros de massa normalmente utilizados são padronizados e operam em com calibrações que abrangem uma faixa relativamente elevada de compostos. ${ }^{18}$ Comumente um espectrômetro de massa possui cinco componentes (Figura1.1). O primeiro componente é chamado de unidade de entrada da amostra, compartimento onde a amostra é submetida a condições de pressão muito baixas para que seja iniciado o processo de fragmentação. Após essa unidade de entrada a amostra é conduzida a uma fonte de ionização, onde as moléculas são transformadas em íons gasosos. Estes íons são acelerados por um campo eletromagnético e são direcionados ao analisador de massa, que separa os íons em função de sua massa/carga; o grau de complexidade deste analisador é o que caracteriza o tipo de espectrômetro de massa em uso. ${ }^{15 \mathrm{~b}}$ Em seguida, após passar pelo analisador de massa, os íons são contados pelo detector e são registrados por um sistema de aquisição de dados, conectado a um computador. Finalmente, o espectro de massa é determinado, relacionando o número de íons detectados e populações relativas com suas razões massa/carga. ${ }^{15 \mathrm{~b}, 18-19}$

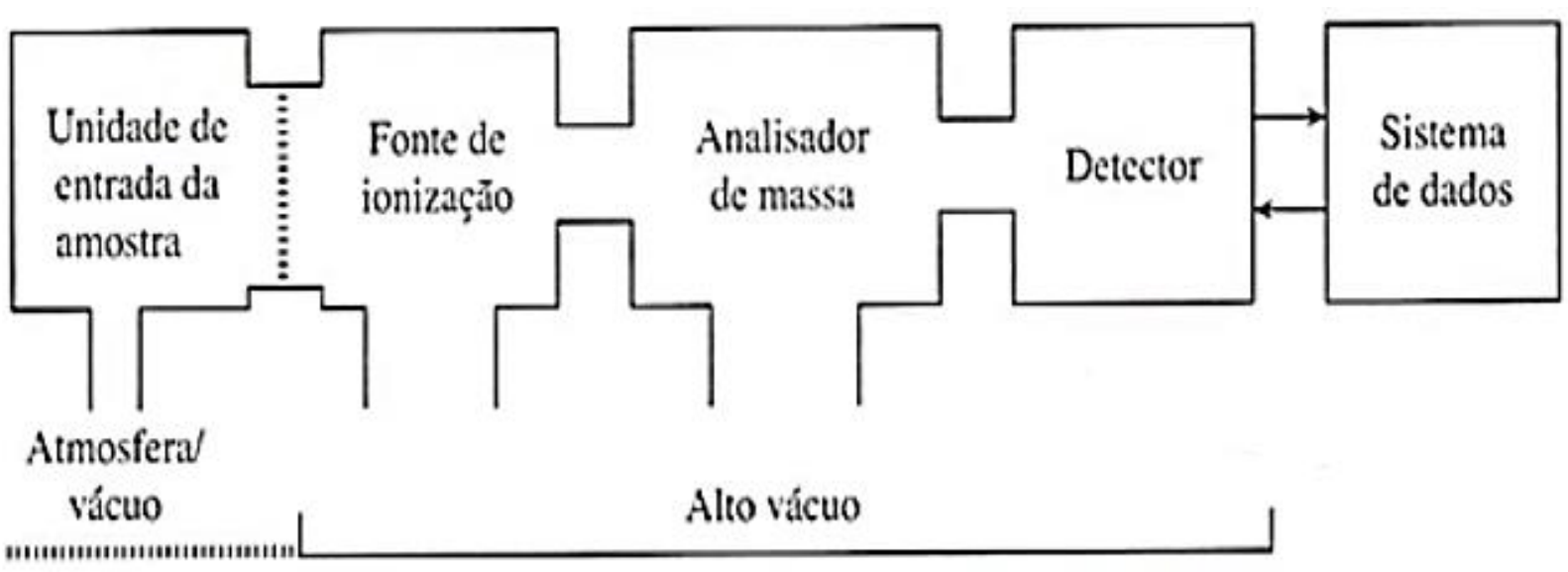

Figura 1. 1 Componentes de um Espectro de Massa. Fonte: Ref. 6

Na espectrometria de massa há diversos modelos mecanísticos de fragmentação, porém dentre elas são identificados cinco tipos mais comuns, a fragmentação de segmentação $\alpha$, a de segmentação indutiva, a segmentação de duas ligações, a segmentação retro Diels-Alder e Rearranjo de McLafferty. ${ }^{15 b, 17}$ 
Um dos mais destacados modelos mecanísticos de rearranjos usados na interpretação espectrométrica é o rearranjo do tipo McLafferty; entretanto, a sua descrição mescanística não está totalmente elucidada. Nos livros-texto mais comuns de espectrometria de massas, como por exemplo, o Fundamentals of contemporary mass spectrometry ${ }^{20}$, Interpretation of mass spectra $^{17 b}$ e o Introduction to spectroscopy ${ }^{15 a}$ esta rearranjo é apresentado como um mecanismo concertado, ocorrendo diretamente através da transferência intramolecular de um átomo de hidrogênio de um fragmento $\mathrm{X}-\mathrm{H}$ da posição- $\gamma$, referente à região onde originalmente a carga se encontra, para o fragmento carregado positivamente carregado; vale salientar que este mecanismo se restringe a fragmentos carregados e/ou radicalares. ${ }^{15 b}$, 16a, 17-18, 20-21

Porém, a ideia de mecanismo concertado começou a ser contestada em alguns trabalhos, ${ }^{21 b}, 22$ nos quais a abordagem, a partir análises experimentais e/ou teóricas, do rearranjo do tipo McLafferty sugere que este pode ocorrer em etapas (comumente relatado em artigos como stepwise mechanism, ou seja, literalmente um mecanismo "passo a passo").

Pesquisadores fazem uso da espectrometria de massas para identificar e caracterizar substâncias, através de propriedades físico-químicas dos intermediários que aparecem a partir da fragmentação molecular e, hipoteticamente, tomando modelos de estados de transição que possibilitem a interpretação da escolha de um ou outro caminho de fragmentação. Por outro lado, muitas relações $\mathrm{m} / \mathrm{z}$ podem surgir ambiguamente num dado espectro de massas (isômeros constitucionais) conforme a deslocalização dos elétrons em determinadas estruturas, podendo levar o pesquisador à conclusões e interpretações errôneas do fenômeno de fragmentação. Com o avanço da Química Teórica, muitos desses problemas podem, agora, ser contornados via simulação de processos de fragmentação e rearranjo molecular durante tal fenômeno de fragmentação. Neste contexto, os métodos computacionais permitem abrir novos caminhos para uma melhor descrição desses processos reativos, que podem levar à diversas rotas de fragmentação. ${ }^{15 b, 17 b, 21 \mathrm{e}}$

Com isso, aplicando a modelagem quântica a sistemas que passam por rearranjo do tipo McLafferty, pode-se obter uma descrição mais acurada do ponto de vista atômico-molecular do referido rearranjo, possibilitando uma melhor elucidação mecanística quanto o uso de técnicas experimentais for insuficiente para a interpretação/caracterização da fragmentação.

Neste trabalho foram analisados três sistemas, o 1-Nitropropano, 2-Pentanona e Butirofenona ${ }^{16 a, 23}$; cujos os mecanismos de fragmentação apresentam em comum a ocorrência 
do rearranjo do tipo McLafferty. Neste contexto, foram analisados dois possíveis caminhos de fragmentação do tipo McLafferty: concertado e em etapas. Para ambos os mecanismos, foram realizadas análises termodinâmica, cinética e eletrônica. Uma análise mais completa de todo o mecanismo que envolve os sistemas 1-Nitropropano e Butirofenona se encontra no Anexo 1. Nas Figuras 1.2, 1.3 e 1.4 temos os espectros de massa experimentais ${ }^{24}$ destas substâncias.

Para o estudo dos três sistemas analisados foram utilizados métodos de cálculos teóricos que possibilitam uma descrição mais acurada dos parâmetros avaliados neste trabalho; assim, através do estudo termodinâmico e eletrônico do sistema tem-se uma descrição completa do rearranjo do tipo McLafferty.

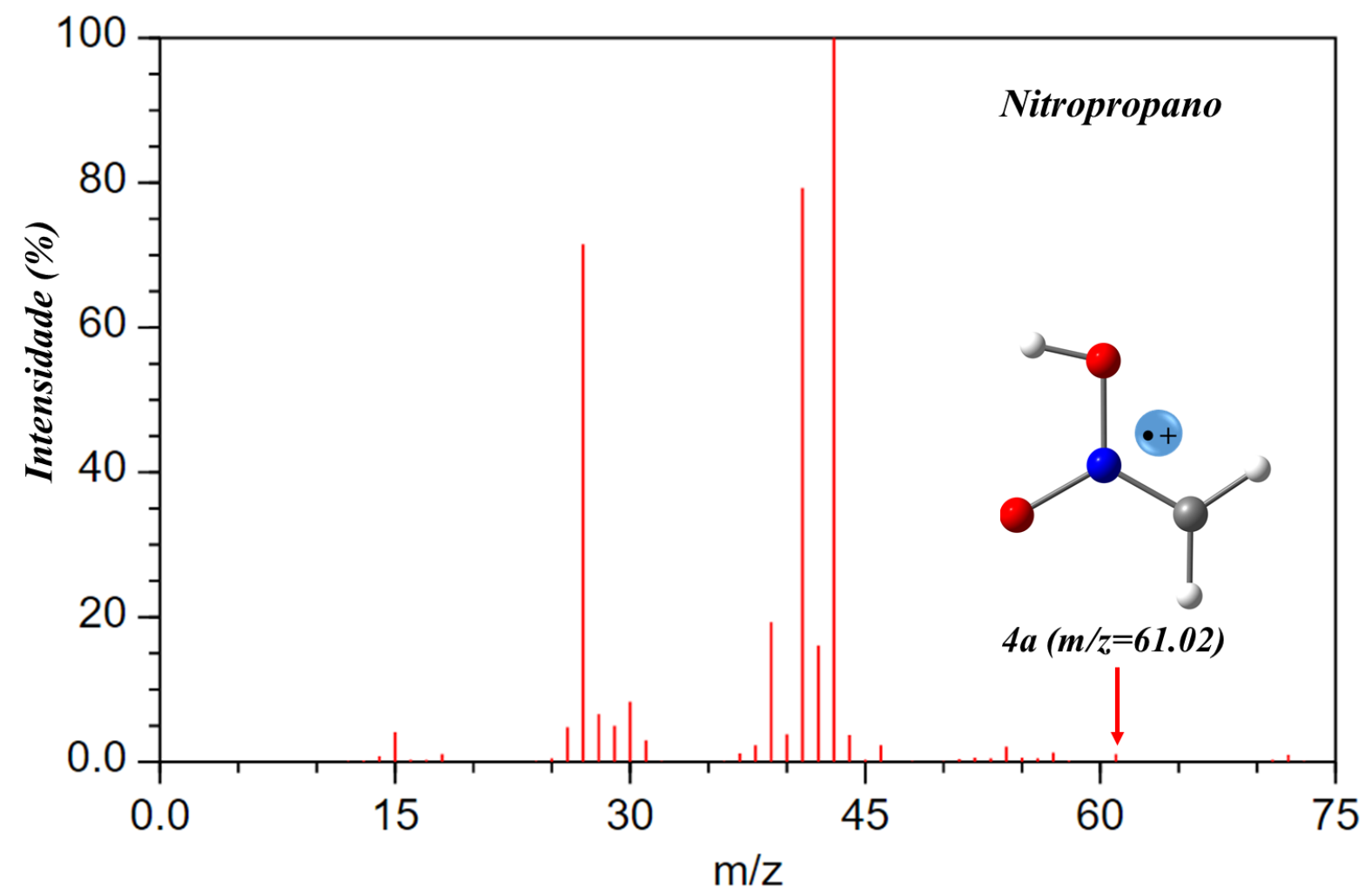

Figura 1. 2. Espectro de massa experimental 1-Nitropropano 


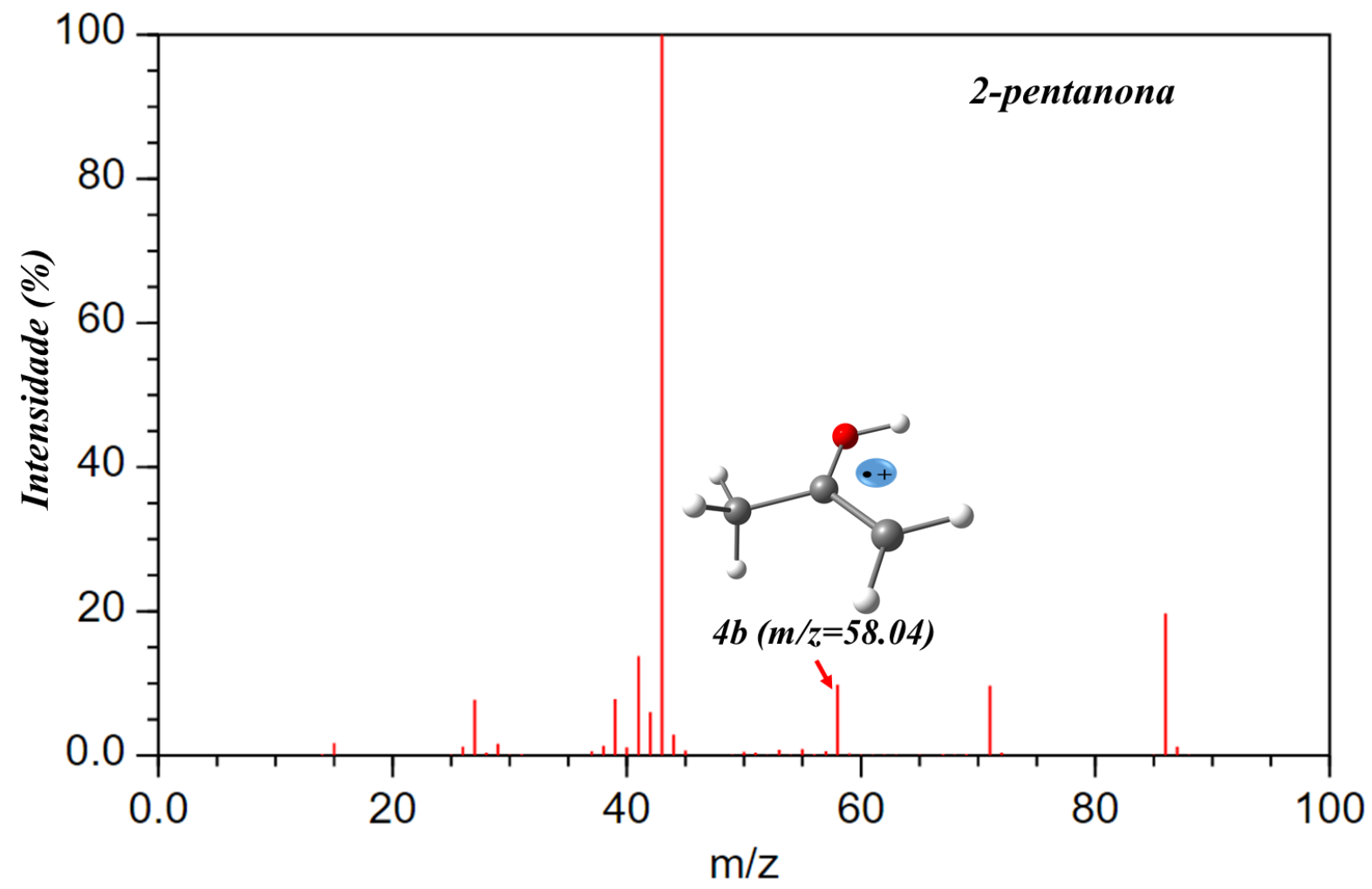

Figura 1. 3. Espectro de massa experimental 2-Pentanona

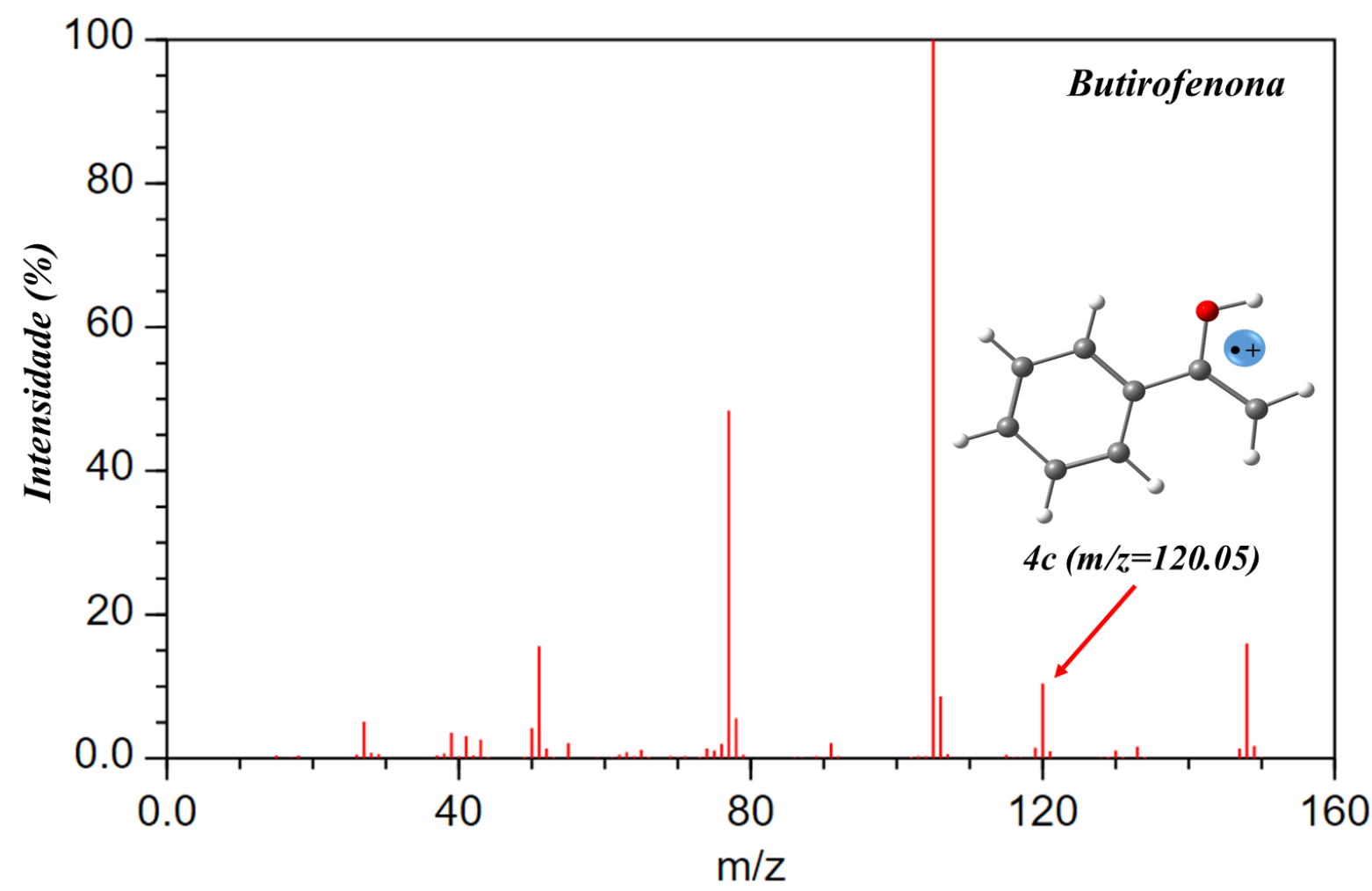

Figura 1. 4. Espectro de massa experimental Butirofenona 


\subsection{Objetivo}

Este trabalho tem como objetivo geral explorar teoricamente o rearranjo do tipo McLafferty para três sistemas distintos, o 1-nitropropano, 2-pentanona e a butirofenona; determinando inicialmente um padrão químico-quântico do comportamento reativo dos intermediários neste estágio de fragmentação molecular e partir deste padrão caracterizar os caminhos de fragmentação observados (via espectrometria de massas) já disponibilizados na literatura.

Como objetivo específico, proporcionar, através de modelos químico-quânticos, a compreensão mecanística do rearranjo do tipo McLafferty durante a fragmentação molecular, indicando os efeitos de grupo sobre a velocidade e facilidade de ocorrência de rearranjo durante a fragmentação do 1-nitropropano, 2-pentanona e butirofenona.

Além disso este trabalho visa criar um padrão de investigação teórica, através de explorações termodinâmica e de estrutura eletrônica (por meio de análises NBO, QTAIM e índices multicêntricos), para comparação de efeito do substituinte em substratos que podem sofrer o rearranjo do tipo McLafferty no processo de fragmentação molecular. 


\section{Capítulo 2- Fundamentação Teórica}

\subsection{Mecanismos de Fragmentação Molecular}

\subsubsection{Formas de ionização:}

Conforme descrito na introdução, ao se utilizar a técnica de espectrometria de massa, a substância em análise passa por uma etapa de ionização antes de seguir para o analisador de massas no qual, a partir de um método adequado de ionização da amostra, a mesma será transformada em íons gasosos. ${ }^{15 b, 17}$

A formação destes íons pode ser descrita através de três tipos de processos: a remoção/adição de um elétron formando íons radicais $\left(\mathrm{M}^{{ }^{++}}\right.$ou $\left.\mathrm{M}^{*-}\right)$; protonação/desprotonação (reações ácido/base) formando moléculas protonadas ou desprotonadas $\left([\mathrm{M}-\mathrm{H}]^{+} /[\mathrm{M}]^{-}\right)$; e cationização/anionização, resultando na formação de moléculas carregadas $\left([\mathrm{M}]^{+} \mathrm{ou}[\mathrm{M}]^{-}\right)$. Estes processos químicos são os principais, encontrados na grande maioria dos métodos de ionização. ${ }^{6}$

Dentro do tema de espectrometria de massa há quatro métodos gerais de ionização de amostra; a Ionização por Elétrons (EI), Ionização Química (CI), Técnicas de Ionização por Dessorção (SIMS, FAB e MALDI) e Ionização por Eletrospray (ESI). A escolha entre estes métodos deve ser feita baseada nas propriedades químicas e físicas das substâncias analisadas e na transferência de energia que ocorre durante o processo de ionização ${ }^{15 b, 17,25}$.

A Ionização por Elétrons (EI) e a Ionização Química (CI), são as técnicas mais tradicionais. Para a utilização destas técnicas, é necessário que o composto seja volatilizado e depois ionizado, limitando assim essas duas técnicas a compostos voláteis, termolábeis e com baixo peso molecular, impedindo a análise de muitas biomoléculas ${ }^{15 b}$, 17-18, 25-26.

$\mathrm{Na}$ EI, a partir de um filamento aquecido, é emitido um feixe de elétrons de alta energia; esse feixe atinge o fluxo de moléculas da amostra inserida no espectrômetro. A colisão, entre os elétrons e as moléculas, gera um íon radical devido à retirada de um elétron da amostra. Através de uma placa com potencial elétrico repulsivo, os íons formados são direcionados por um campo eletromagnético, onde são acelerados. Após passarem por fendas colimadoras, forma-se um feixe uniforme de íons, sendo encaminhados para o analisador de massa. Em alguns espectrômetros é possível inverter a polaridade das placas aceleradoras e repelentes, 
tornando-se possível a análise tanto de cátions quanto de ânions. O feixe padrão utilizado nesta técnica é de 70 eV. ${ }^{15 b}$, 16a, 17a, 19-20, 25b, 25c

A técnica de EI apresenta vantagens e desvantagens. Embora essa técnica de ionização permita a formação de um número expressivo de íons moleculares, alguns destes íons podem apresentar um tempo de vida muito curto, dificultando a identificação nestes casos. ${ }^{15 b}$, 16a, 17a, 19$20,21 \mathrm{~d}$

Um exemplo da aplicação desta técnica encontra-se no trabalho experimental de Nibbering ${ }^{23 a}$ onde foi estudo a fragmentação do sistema 1-nitropropano, no qual foi utilizado a EI; porém esta técnica não foi suficiente para realizar uma análise completa, de maneira que a amostra foi submetida ainda à uma purificação em cromatografia gasosa e depois analisado por ressonância magnética nuclear (RMN). ${ }^{23 a}$, 23b, 27

$\mathrm{Na}$ ionização química (CI), a colisão ocorre entre as moléculas do analito com um fluxo de íons moleculares. A ionização pode ocorrer por diversos mecanismos, por exemplo, transferência de prótons, elétrons e formação de adutos. Os reagentes ionizantes mais comuns são metano, amônia, isobutano e metanol. Alternando o gás reagente, é possível mudar a seletividade de ionização e fragmentação dos íons. A escolha do gás é feita a partir da afinidade protônica entre o gás e a amostra, para garantir uma melhor ionização e não causar muitas fragmentações que atrapalhem a análise. Um gás com afinidade protônica adequada resultará em um espectro com um número maior de íons moleculares intactos e um número menor de íons fragmentados. A principal vantagem desta técnica, se a afinidade for analisada e o gás for aplicado corretamente, é a produção de íons moleculares quase intactos, possibilitando obter uma melhor detecção destes. ${ }^{15 b, 16 a, 17 a, 20,25 b, 25 c}$

Como as técnicas de ionização EI e CI são limitadas para compostos de baixo peso molecular, surgiram outras técnicas de ionização que englobam moléculas com alto peso molecular e não voláteis. Como exemplo temos as Técnicas de Ionização por Dessorção (SIMS, FAB e MALDI) e Ionização por Eletrospray (ESI). ${ }^{15 b}$, 16a, 17a, 19-20, 25 b, $25 c$

A ionização por Dessorção engloba três métodos, espectrometria de massas de íons secundário (SIMS), bombardeamento de átomos rápidos (FAB) e ionização por dessorção a laser assistido por matriz (MALDI). Nesta técnica, a amostra é dissolvida ou dispersa em uma matriz (não volátil, relativamente inerte e um eletrólito que permita a formação dos íons). Em 
seguida, a amostra passa por um feixe de íons de alta energia (SIMS), por um feixe de átomos neutros (FAB), ou por um feixe de fótons de alta intensidade (MALDI). A colisão obtida entre a amostra e os íons/fótons/átomos, dependendo do método, faz com que as moléculas analisadas sejam ionizadas, expelidas e aceleradas para o analisador de massa, conforme as outras técnicas. ${ }^{15 b, 16 a, 17 a, 20,25 b, 25 c}$

A ESI tornou-se umas das técnicas mais utilizadas atualmente devido à sua aplicação para analisar biomoléculas com alto peso molecular, compostos pouco estáveis e não voláteis. A técnica, em geral, baseia-se em duas etapas, a dispersão de gotas altamente carregadas e aplicadas condições para que ocorra a evaporação. ${ }^{15 b, 16 a, 17 a, 20,25 b, 25 c}$

Nesta técnica a amostra é borrifada, através de um tubo capilar, dentro de uma câmara aquecida com uma pressão aproximada da pressão atmosférica. $\mathrm{O}$ tubo capilar tem um potencial de alta voltagem em sua superfície, podendo ser negativo ou positivo, forçando um processo de oxirredução, formando pequenas gotículas carregadas que serão dispersas dentro da câmara de ionização. Essas gotículas passam por um gás de secagem, com isso, conforme aumenta a densidade de carga de cada gotícula, as forças repulsivas eletrostáticas excedem a tensão superficial, e assim, a gotícula que tinha sofrido uma deformação, divide-se em gotículas menores. Este processo ocorre até que os íons da amostra sejam deixados em fase gasosa. ${ }^{15 b}$, $16 \mathrm{a}, 17 \mathrm{a}, 20,25 \mathrm{~b}, 25 \mathrm{c}$

Este tipo de ionização apresenta várias vantagens tais como a alta sensibilidade e seletividade, a facilidade de uso e consumo da amostra. Uma característica importante deste método é a capacidade de produzir íons multiplamente carregados, possibilitando, então, a redução da razão massa/carga e, por isso, consegue-se analisar moléculas com alto peso molecular. ${ }^{15 b, 17-19,21 d, 23 a, 25-26}$ Agora que foram expostos os métodos de ionização, serão abordados os aspectos mecanísticos dos rearranjos envolvendo íons formados.

\subsubsection{Mecanismos dissociativos de sistemas simples e complexos}

Como dito anteriormente, a partir de uma análise geral em um espectro de massa, a substância inicialmente passa por um bombardeamento de elétrons de alta energia, podendo ocorrer através de vários métodos de ionização, culminando num cátion radical. Após este choque entre elétrons e molécula, forma-se o íon molecular, que se encontra em um estado vibracional altamente excitado, devido à energia adquirida após a colisão. Este íon molecular 
pode estar em um estado mais instável, proporcionando a fragmentação do mesmo em sistemas moleculares menores e mais estáveis. O tempo de vida do íon irá direcionar para uma possível fragmentação ou não. Se o tempo de vida for $>10^{-5} \mathrm{~s}$, o íon permanecerá intacto e será detectado no analisador de massa. Já se for $<10^{-5} \mathrm{~s}$, ele irá sofrer fragmentações até se estabilizar. Como em um composto os íons formados apresentam tempos de vida distintos nota-se no espectro, além do pico de íon molecular (primeiro íon formado e detectado), picos relacionados com os diversos outros sistemas intermediários posteriormente gerados. 15b, 16a, 17a, 20, 25b, 25c

Em geral, os compostos que sofrem fragmentação seguem algumas características conhecidas tornando possível, em alguns casos, prever os mecanismos que geram os fragmentos. Uma característica importante é a natureza do íon molecular, que é um cátion

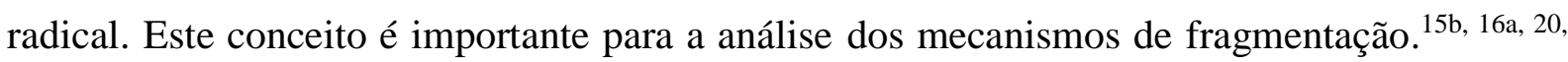
21d, 23a, 25-26

As reações de fragmentação podem ser classificadas de dois tipos; as que sofrem uma simples clivagem na ligação e as reações que passam por rearranjos moleculares. Estes padrões de fragmentação mais conhecidos seguem a regra de Stevenson ${ }^{15 b}$, de evento inicial de ionização, segmentação $\alpha$, segmentação indutiva, segmentação de duas ligações, segmentação de Diels-Alder e rearranjos do tipo McLafferty. ${ }^{15 b, 16 a, 20-21,23 a, 25 a}$

O evento inicial de ionização baseia-se na escolha do elétron que será ejetado da amostra, que sofrerá o processo de ionização. Os elétrons que serão retirados após a colisão são os encontrados nos orbitais moleculares de maior energia potencial. Tendo, com isso, uma ordem de remoção de elétrons que pode ser seguida para facilitar a visualização. (Orbital não ligante - orbital $\pi$ - orbital $\sigma) .{ }^{15 b, 16 a, 20,21 \mathrm{f}}$

Os íons fragmentados são formados através de processos unimoleculares, devido à condição de baixa pressão imposta na câmara de ionização e esses processos energeticamente mais favoráveis geram a maioria dos íons fragmentos. A regra de Stevenson afirma que o processo de fragmentação leva à formação de íons mais estáveis. Além desta busca por estabilidade, existem outras propriedades físico-químicas que podem ajudar a prever outros possíveis mecanismos de fragmentação, como eletronegatividade, polarizabilidade, ressonância e entre outras. ${ }^{15 b, 16 a, 20,21 f}$ 
A partir desses dados, pode-se afirmar que uma fragmentação se baseia na formação de um fragmento eletricamente neutro e um carregado, de modo que é possível prever um mecanismo de fragmentação para uma dada molécula. ${ }^{15 b}$, 16a, 20, $21 \mathrm{f}$

Seguindo a regra de Stevenson, um íon molecular radicalar pode ser fragmentado por mecanismos de segmentação. ${ }^{15 b, 16 a, 20,21 f}$ Com isso, o modo de fragmentação mais comum segue o método de segmentação de ligação, e, através da regra de Stevenson, tem-se uma ordem de formação de fragmentação, considerando o maior radical alquila como sendo o primeiro a ser fragmentado. ${ }^{15 b}$

$$
\mathrm{H}_{3} \mathrm{C}^{+}<\mathrm{RCH}_{2}<\mathrm{R}_{2} \mathrm{CH}^{+}<\mathrm{R}_{3}<\mathrm{H}_{2} \mathrm{C}=\mathrm{CHCH}_{2}{ }^{+} \sim \mathrm{HC} \equiv \mathrm{CCH}_{2}{ }^{+}<\mathrm{C}_{6} \mathrm{H}_{5} \mathrm{CH}_{2}{ }^{+}
$$

A segmentação $\alpha$, é uma das segmentações mais comuns, iniciada no sítio radical, no qual a ligação que é fragmentada não é a estabelecida diretamente com o sítio radical e sim ao átomo vizinho, de posição $\alpha$. Ela pode ocorrer em ligações saturadas ou insaturadas e podem envolver ou não um heteroátomo. Este tipo de segmentação é limitada a cátions radicais $\left(\mathrm{OE}^{\cdot+}\right)$. $15 \mathrm{~b}, 16 \mathrm{a}, 20$

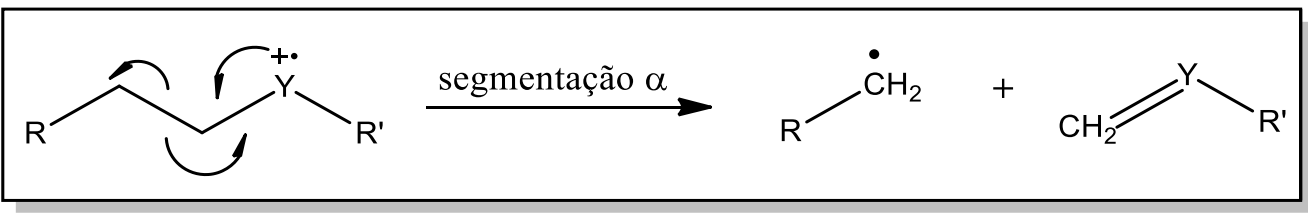

Figura 2. 1 Exemplo de Segmentação $\alpha$. Fonte: adaptado da ref.20.

A segmentação indutiva é iniciada no sítio carregado, baseada na atração entre um par de elétrons e um heteroátomo eletronegativo; esta segmentação forma um radical e uma molécula neutra. Esta segmentação, diferente da segmentação $\alpha$, não tem restrição podendo ser operada tanto em íons $\mathrm{OE}^{\cdot+}$ e cátions $\left(\mathrm{EE}^{+}\right) .{ }^{15 b, 16 a, 20}$

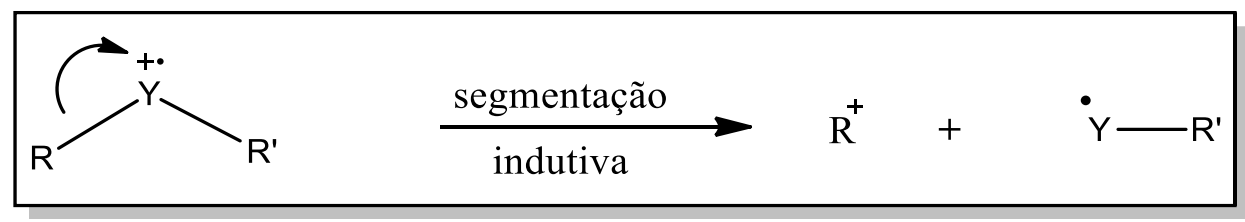

Figura 2. 2 Exemplo de Segmentação Indutiva. Fonte: adaptado da ref.20.

A segmentação de duas ligações é uma fragmentação que ocorre simultaneamente entre duas ligações; nela o íon molecular produz um $\mathrm{OE}^{+}$e um fragmento neutro com número par de elétrons. ${ }^{15 b, 16 a, 20}$ 


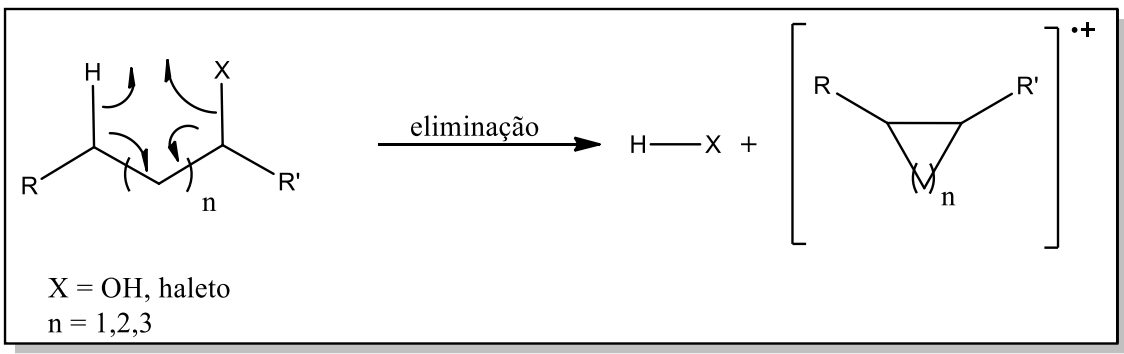

Figura 2. 3 Exemplo de Segmentação de duas Ligações. Fonte:adaptado da ref.20

Outro mecanismo de fragmentação comum é a segmentação retro Diels-Alder ${ }^{17}$, 25b , nela anéis de seis membros não saturados sofrem fragmentação formando um cátion radical de um dieno e um alceno neutro, derivados da cicloadição do dieno conjugado com 4 elétrons $\pi$ e do alceno com 2 elétrons $\pi$. De acordo com a regra de Stevenson, os elétrons desemparelhados e a carga estão com o fragmento dieno. ${ }^{15 b, 25 b, 25 c 16 a}$

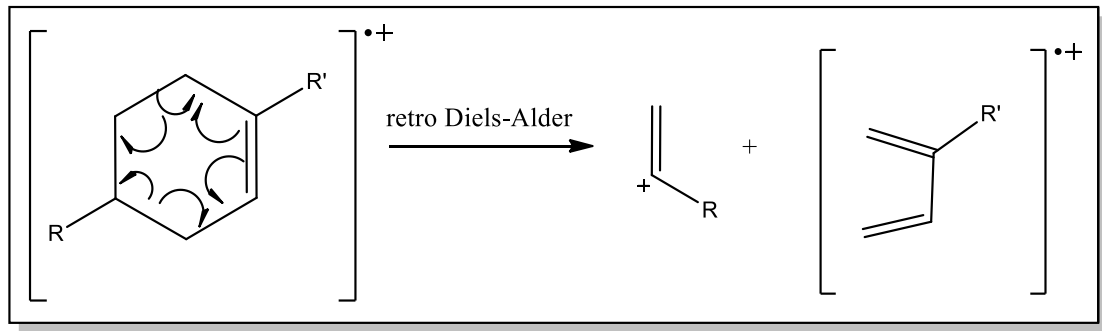

Figura 2. 4 Exemplo de Fragmentação Retro Diels-Alder. Fonte: adaptado da ref.20.

\subsubsection{Rearranjo do tipo McLafferty}

Em alguns espectros de massa existem algumas reações que produzem íons cujos os átomos não mantem uma relação de conectividade com a molécula original: parte do íon precursor reagiu antes ou durante a decomposição. Com isso, alguns rearranjos mais complexos produzem íons nos quais são considerados pouco expressivos para a elucidação de determinadas estruturas/composições. Porém, este tipo específico de rearranjo vem sendo estudado e melhor compreendido fazendo com que esses íons antes negligenciáveis tenham seu valor para a compreensão da estrutura analisada ${ }^{15 b, 25 b, 25 c}$.

Um dos mecanismos, antes não bem compreendidos, baseia-se no rearranjo do hidrogênio na posição- $\gamma$ a um grupo insaturado, proporcionando simultaneamente a $\beta$ - clivagem (cisão na ligação $\beta$ ). Assim, um elétron desemparelhado será doado para formar uma nova ligação com um átomo adjacente. Já o segundo no segundo passo será fornecido pela transferência de outra ligação para o átomo adjacente, resultando na $\beta$-clivagem. Este tipo de rearranjo veio a ser conhecido como rearranjo do tipo McLafferty ${ }^{16 a}$, 17, 20-21, 23a, 25b . 
Este fragmento foi proposto por Fred McLafferty em 1956 com o intuito inicial de propor um mecanismo visando aldeídos alifáticos. Ele representa rearranjos cujos compostos apresentam insaturação, como grupo carbonila, no qual o átomo de hidrogênio na posição- $\gamma$ é transferido para a área carregada, cátion radical, por meio de um estado de transição com um anel de seis membros. ${ }^{15 b, 17 b, 20}$

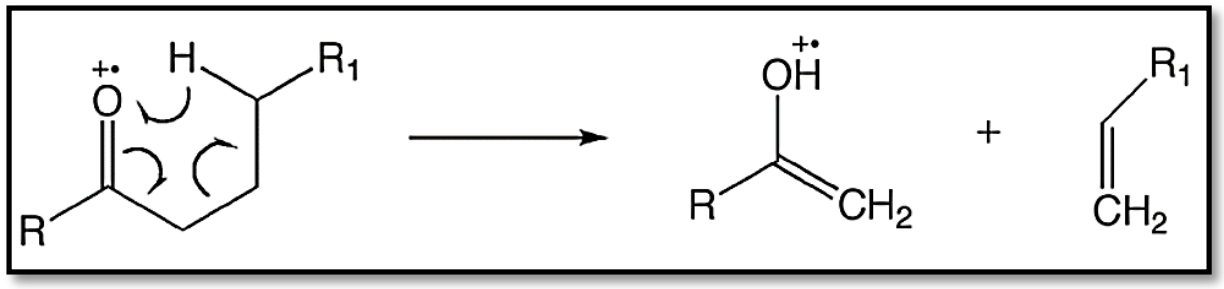

Figura 2. 5 Rearranjo do Tipo McLafferty. Fonte: adaptado da ref.20.

Visto os principais mecanismos de fragmentação e rearranjos associados à sistemas ionizados, pode-se avançar na descrição geral dos métodos de estrutura eletrônica aqui aplicados.

\section{Capítulo 3. Métodos de Estrutura Eletrônicas}

Em 1926, o físico Erwin Schrödinger ${ }^{10}$ postulou que a conexão entre a concepção da natureza dual (onda-partícula) da matéria proposta Louis de Broglie ${ }^{4}$ e o princípio da incerteza de Heisenberg poderia ser expressada através da Equação de Onda - uma expressão que expõe matematicamente o princípio de conservação de energia para um elétron sujeito à um potencial. Assim, pode-se imaginar que a aplicação da equação de Schrödinger para sistemas quaisquer poderia apresentar limitações consideráveis em função do número de elétrons do sistema atômico-molecular em análise, visto que, todo o modelo de Schrödinger tomou como base o o elétron sujeito a um potencial nuclear no átomo de hidrogênio. Sendo assim, para sistemas monoeletrônicos a equação de Schrödinger poderia ser relativamente bem sucedida na descrição do comportamento do elétron sujeito a um potencial nuclear. ${ }^{28}$

Por outro lado, o problema fundamental da química quântica é a resolução da equação de Schrödinger para $\mathrm{N}$ elétron e $\mathrm{M}$ núcleos. Esta equação é um problema de autofunçãoautovalor, dado na Eq. (1):

$$
\widehat{H} \Psi(\boldsymbol{r}, \boldsymbol{R})=E \Psi(\boldsymbol{r}, \boldsymbol{R})
$$

A equação de Schrödinger independente do tempo pode ser caracterizada como uma função de autovalor, em que $\Psi(\boldsymbol{r}, \boldsymbol{R})$ (autofunção) é a função de onda para o estado estacionário, $\widehat{H}$ é o operador Hamiltoniano e $E$ (autovalor) é a energia do sistema atômico ou molecular. $^{28}$ 
O operador hamiltoniano não relativístico pode ser descrito como,

$$
\widehat{\mathrm{H}}=-\frac{1}{2} \sum_{\mathrm{i}=1}^{\mathrm{N}} \nabla_{\mathrm{i}}^{2}-\sum_{\mathrm{A}=1}^{\mathrm{M}} \frac{1}{2 \mathrm{M}_{\mathrm{A}}} \nabla_{\mathrm{A}}^{2}-\sum_{\mathrm{A}=1}^{\mathrm{M}} \sum_{\mathrm{i}=1}^{\mathrm{N}} \frac{\mathrm{Z}_{\mathrm{A}}}{\mathrm{r}_{\mathrm{Ai}}}+\sum_{\mathrm{A}=1}^{\mathrm{M}-1} \sum_{\mathrm{B}>A}^{\mathrm{M}} \frac{\mathrm{Z}_{\mathrm{A}} \mathrm{Z}_{\mathrm{B}}}{\mathrm{R}_{\mathrm{AB}}}+\sum_{\mathrm{i}=1}^{\mathrm{N}-1} \sum_{\mathrm{j}>i}^{\mathrm{N}} \frac{1}{\mathrm{r}_{\mathrm{ij}}}
$$

onde o primeiro termo corresponde ao operador de energia cinética do elétron, operador de energia cinética dos núcleos, interação entre núcleo e elétron, interação entre os núcleos e interação entre os elétrons. ${ }^{28}$

Esta equação só possui solução analítica para sistemas ideais como: partícula na caixa, oscilador harmônico, rotor rígido e também solução para o átomo de hidrogênio. ${ }^{14}$ Para qualquer outro sistema, isto é, sistemas com mais de um elétron, são necessárias aproximações para resolver a equação de Schrödinger. Devido ao último termo do operador Hamiltoniano Eq. (2), interação elétron-elétron, esta equação não pode ser resolvida por métodos usuais, pois a equação está acoplada. Para contornar esta limitação, lança-se mão da Aproximação de BornOppenheimer (ABO), que é a abordagem mais utilizada em estudos quânticos de átomos e moléculas. Esta aproximação se embasa fisicamente, no fato dos núcleos serem muito mais massivos do que os elétrons e com isso, se movimentam mais lentamente em relação aos elétrons. Portanto, para o movimento eletrônico, os núcleos podem ser considerados fixos e como uma boa estimativa podemos considerar que o termo $-\sum_{A=1}^{M} \frac{1}{2 \mathrm{M}_{\mathrm{A}}} \nabla_{\mathrm{A}}{ }^{2} \approx 0$. Desta forma o termo que descreve a interação núcleo-núcleo passa a ser uma constante para o movimento eletrônico. De modo que o hamiltoniano eletrônico pode ser escrito como ${ }^{28}$ :

$$
\widehat{H}_{e l e}=-\frac{1}{2} \sum_{\mathrm{i}=1}^{\mathrm{N}} \nabla_{\mathrm{i}}^{2}-\sum_{\mathrm{A}=1}^{\mathrm{M}} \sum_{\mathrm{i}=1}^{\mathrm{N}} \frac{\mathrm{Z}_{\mathrm{A}}}{\mathrm{r}_{\mathrm{Ai}}}+\sum_{\mathrm{A}=1}^{\mathrm{M}-1} \sum_{\mathrm{B}>A}^{\mathrm{M}} \frac{\mathrm{Z}_{\mathrm{A}} \mathrm{Z}_{\mathrm{B}}}{\mathrm{R}_{\mathrm{AB}}}+\sum_{\mathrm{i}=1}^{\mathrm{N}-1} \sum_{\mathrm{j}>i}^{\mathrm{N}} \frac{1}{\mathrm{r}_{\mathrm{ij}}}
$$

Desta forma a ABO “desacopla" os movimentos eletrônico e nuclear, de modo a proporcionar a reescrita da função de onda molecular utilizando a conhecida aproximação adiabática $^{28}$ :

$$
\Psi(\boldsymbol{r}, \boldsymbol{R}) \approx \phi_{e l e}(\boldsymbol{r} ; \boldsymbol{R}) \chi_{n u c}(\boldsymbol{R})
$$

Em que $\phi_{\text {ele }}(\boldsymbol{r} ; \boldsymbol{R})$ indica que a função de onda depende explicitamente das coordenadas eletrônicas e parametricamente às coordenadas nucleares. Assim, obtemos a equação de Schrödinger eletrônica na equação eq. $5 .^{28}$ 


$$
\widehat{H}_{\text {ele }} \phi_{\text {ele }}(\boldsymbol{r} ; \boldsymbol{R})=\varepsilon_{\text {ele }} \phi_{\text {ele }}(\boldsymbol{r} ; \boldsymbol{R})
$$

Note que esta equação é energia única para uma dada geometria molecular considerada. ${ }^{13}$

A energia total obtida após a utilização da aproximação fornece o potencial a que os núcleos estão sujeitos ao se movimentarem, com isso, a função fornece a superfície de energia potencial. $^{13,14}$

Os métodos de estrutura eletrônica se dedicam na busca por solução acuradas da Eq. (5). Dentre estes métodos, se destacou a aproximação de Hartree-Fock (HF) ${ }^{29}$ para a função de onda. O método Hartree-Fock consiste em conciliar o método variacional, representando a função de onda como um determinante de Slater a partir da aproximação Born-Oppenheimer. ${ }^{28}$

Analisando a equação de Schrödinger eletrônica (Eq. (5)) nota-se que ela apresenta somente a parte das coordenadas espaciais, e para obter uma melhor descrição dos elétrons deve-se acrescentar as coordenadas de spin, são elas as funções de spin, $\alpha$, spin up e, spin down, $\beta$. Agora, considerando todas as coordenadas, espaciais (r) e spin $(w), x_{i}=\left\{r_{i}, w_{i}\right\}$, a função de onda para um sistema contendo $\mathrm{N}$ elétrons é dada por $\Phi=\Phi\left(x_{i}, x_{j}, \ldots, x_{k}\right){ }^{28}$

Em um sistema com mais de um elétron é necessário que a função de onda siga o princípio de exclusão de Pauli, com isso a função de onda que descreve esse sistema deve ser antissimétrica perante a troca das coordenadas de dois elétrons, princípio de antissimetria. ${ }^{28}$

$$
\Phi\left(x_{1}, x_{2}, \ldots, x_{i}, \ldots, x_{j}, \ldots, x_{n}\right)=-\Phi\left(x_{1}, x_{2}, \ldots, x_{j}, \ldots, x_{i}, \ldots, x_{n}\right)
$$

O operador Hamiltoniano que descreve a energia cinética e potencial de um elétron $i$ em um sistema multieletrônico, desconsiderando a interação elétron-elétron, pode ser descrito como na equação eq. $6 .^{28}$

$$
\widehat{H}=\sum_{i=1}^{N} h_{i} .
$$

Sendo que as soluções do operador $h_{i}$ podem ser escritas como um conjunto de spinorbitais:

$$
h_{j} x_{j}=\varepsilon x_{j}
$$

Partindo da ideia de que o operador Hamiltoniano representa uma soma de outros operadores envolvidos, surge então o conceito de Produto de Hartree, $\psi^{H P}$, no qual a função de 
onda do sistema será descrita como um produto de funções de spin-orbitais, temos a equação eq. $8 . \cdot^{13,15,16}$

$$
\psi^{H P}\left(x_{1}, x_{2}, \ldots, x_{n}\right)=\chi_{i}\left(x_{1}\right) \chi_{j}\left(x_{2}\right) \ldots \chi_{N}\left(x_{N}\right)
$$

Porém o produto de Hartree não leva em consideração a correlação eletrônica entre os elétrons, não respeitando com isso o princípio da antissimetria. Portanto, ao introduzir o conceito de determinante de Slater ${ }^{30}$, faz-se uma combinação linear destes produtos devido à indistinguibilidade dos elétrons, respeitando o princípio de exclusão de Pauli.

Para um sistema com $\mathrm{N}$ elétrons, temos o seguinte determinante de Slater na equação eq. $9 .{ }^{30}$

$$
\psi\left(x_{1}, x_{2}, \ldots, x_{N}\right)=\frac{1}{\sqrt{N !}}\left[\begin{array}{cccc}
\chi_{i}\left(x_{1}\right) & \chi_{j}\left(x_{1}\right) & \cdots & \chi_{N}\left(x_{1}\right) \\
\chi_{i}\left(x_{2}\right) & \chi_{j}\left(x_{2}\right) & \cdots & \chi_{N}\left(x_{2}\right) \\
\vdots & \vdots & \ddots & \vdots \\
\chi_{i}\left(x_{N}\right) & \chi_{j}\left(x_{N}\right) & \cdots & \chi_{N}\left(x_{N}\right)
\end{array}\right]
$$

Neste determinante os termos estão representando os spins-orbitais moleculares de cada elétron; por admitir que eles são ortogonais e normalizados, o termo $\frac{1}{\sqrt{N !}}$ representa uma constante de normalização da função de onda ${ }^{31}$.

De acordo com o método variacional, é escolhido o melhor conjunto de spin-orbital, no qual a $E_{o} \leq\left\langle E_{\psi}\right\rangle$. Um estratégia de minimização deste tipo função determinantal é através dos multiplicadores de Lagrange, que conduz à equação canônica de HF. Nesta representação, $\hat{f}$ é o operador de Fock aplicado sobre o spin-orbital com o qual se obtém o autovalor de energia, como exposto na equação eq. $10 .^{28 b}$

$$
\hat{f} \chi\left(x_{i}\right)=\varepsilon \chi\left(x_{i}\right)
$$

Roothaan $^{32}$ em 1951, propôs a expansão da função de onda como uma combinação linear de funções de base que transformam a equação integro-diferencial de HF em um problema algébrico, muito mais vantajoso para implementação computacional. Esta equação ficou conhecida como Equação de Hartree-Fock-Roothaan (HFR). Para a resolução desta equação utiliza-se no método do campo autoconsistente (SCF-Self Consistent Field). ${ }^{28 \mathrm{~b}}$

Apesar do método HF apresentar bons resultados, surgiu outro importante método para o estudo da estrutura eletrônica, conhecido como Teoria do Funcional da Densidade (DFT). Este método propõem um tratamento estatístico de átomos com populações eletrônicas intermediárias, e para espécies moleculares também de tamanho intermediário (sistema com 
mais de 20 átomos), através da utilização de funcionais de densidade. Nesta perspectiva, a densidade eletrônica $\rho(\boldsymbol{r})$ assume o caráter de observável mecânico-quântico que permite uma formulação conceitual mais fácil de se compreender um sistema molecular, por depender apenas de três coordenadas, ao contrário do tratamento ondulatório do formalismo HF, que necessita de coordenadas próprias para cada elétron para a construção da função de onda. Dessa forma a DFT tornou-se um dos métodos mais utilizados devido aos resultados com boa acurácia química e um baixo custo computacional relativamente baixo quando comparado com os métodos ab initio. A proposta da DFT é obter propriedades no estado fundamental sem, a priori, precisar utilizar as funções de onda multieletrônicas. ${ }^{28 a}$

Este método está fundamentado nos teoremas propostos por Hohenberg e $\mathrm{Kohn}^{33}$, garantindo que podemos escrever a energia como um funcional da densidade eletrônica, permitindo correlacionar estes conceitos, de forma unívoca. No primeiro teorema afirma-se que o potencial externo, $v(r)$, ao qual os elétrons são submetidos, é funcional único da densidade. Estes teoremas provam que não se pode ter dois potenciais externos diferentes para uma mesma densidade, de modo que para uma dada densidade eletrônica tem-se um único potencial externo, com população eletrônica definida, cujas propriedades estão associadas à uma descrição préconcebida no modelo HF. ${ }^{28 b}$

$$
\rho(r) \stackrel{H K}{\rightarrow}\left(\begin{array}{c}
N \\
v(r)
\end{array}\right) \rightarrow \hat{\mathrm{H}} \rightarrow \psi \rightarrow \text { todos os observáveis }
$$

Como cada configuração de densidade tem um potencial associado, analogamente, pode-se estabelecer também uma relação entre a energia, o potencial externo e o funcional da densidade, como exposto na equação eq. 12.

$$
E_{o}=E_{v}[\rho(r)]
$$

No segundo teorema aplica-se o princípio variacional ao funcional da energia para encontrar a densidade que está ligada ao estado fundamental de energia. Definindo, então, através da densidade tentativa, o potencial externo, o hamiltoniano, a função de onda e a energia. A energia total do sistema será maior ou igual a energia exata.

$$
E_{o}[\rho] \leq E_{t}[\rho]
$$

Com isso, podemos descrever, a partir da $\mathrm{ABO}$, o funcional eletrônico de energia expresso pela teoria de funcional de densidade $e^{16}$ :

$$
E_{t}[\rho]=T[\rho]+V_{e e}[\rho]+V_{e N}[\rho]
$$




$$
\begin{aligned}
& E_{t}[\rho]=T[\rho]+V_{e e}[\rho]+\int \rho(r) v(r) d r \\
& E_{t}[\rho]=\hat{F}_{H K}+\int \rho(r) v(r) d r .
\end{aligned}
$$

A energia cinética e o efeito de interação elétron-elétron representam o funcional Hohenberg-Kohn $\left(\widehat{F}_{H K}\right)$, funcional universal que se aplica em qualquer sistema eletrônico, já o último termo apresenta restrições para alguns sistemas eletrônicos, ele representa a energia gerada pelos núcleos devido ao potencial externo. A partir desses teoremas foi possível demonstrar a relação entre a densidade eletrônica e a energia do estado fundamental.

A relação do funcional $G[\rho]$ com a minimização da energia pode ser vista na equação a seguir, no qual a densidade respeita o princípio estacionário, $\delta E_{t}[\rho(\boldsymbol{r})]=0$, sujeita também a restrição da $N$-represenabilidade $\int \rho_{t}(r) d_{r}-N=0$.

$$
G[\rho]=E_{v}[\rho]-\varsigma\left(\int \rho_{t}(r) d r-N\right)
$$

Onde $\varsigma$ é denominado como sendo a variação funcional em relação à densidade $\rho$.

$$
\varsigma=v(r)+\frac{\delta \hat{F}_{H K}[\rho]}{\delta \rho}
$$

Em seguida, Kohn e Sham ${ }^{33 b}$ apresentaram uma nova forma de representar a densidade com relação a energia total do estado fundamental, considerando sistemas que não interagem entre si, sem interação elétron-elétron, sendo representada pelo seguinte Hamiltoniano:

$$
\widehat{H}_{n i} \Psi_{i}=\left[\sum_{i}^{N}\left(-\frac{1}{2} \nabla_{i}^{2}\right)+\sum_{i}^{N} v_{n i}\right] \Psi_{i}=\varepsilon \Psi_{i} .
$$

Neste tipo de sistema, a energia cinética e a densidade podem ser calculadas de uma única forma, sendo descrito pela equação eq. 18.

$$
\begin{gathered}
T_{s}[\rho]=\left\langle\psi_{s}\left|\sum_{i}^{N}\left(-\frac{1}{2} \nabla_{i}^{2}\right)\right| \psi_{s}\right\rangle=\sum_{i}^{N}\left\langle\psi_{s}\left|-\frac{1}{2} \nabla_{i}^{2}\right| \psi_{s}\right\rangle \\
\rho_{s}(r)=\sum_{i}^{N}\left|\psi_{i}\right|^{2}
\end{gathered}
$$

Afirmam que devido ao sistema não interagir entre si, é gerado um potencial fictício, consequentemente, uma densidade fictícia também, porém igual a densidade eletrônica real. 
Reescrevendo, com isso, o funcional universal decompondo a energia cinética em parte energia das partículas não interagentes, $T_{S}[\rho]$, e a outra representando a interação de Coulomb, $J[\rho]$.

Reorganizando temos que:

$$
\begin{gathered}
\hat{F}_{H K}[\rho]=T[\rho]+V_{e e}[\rho] \\
\widehat{F}_{H K}[\rho]=T_{s}[\rho]+J[\rho]+T[\rho]-T_{s}[\rho]+V_{e e}[\rho]-J[\rho] \\
\hat{F}_{H K}[\rho]=T_{s}[\rho]+J[\rho]+E_{x c}[\rho] .
\end{gathered}
$$

Com

$$
E_{x c}[\rho]=T[\rho]-T_{s}[\rho]+V_{e e}[\rho]-J[\rho] .
$$

Sendo $E_{x c}[\rho]$ a energia de troca e correlação levando então ao novo funcional: ${ }^{16}$

$$
\varsigma=\frac{\delta T_{S}[\rho]}{\delta \rho(r)}+v_{e f f}(r)
$$

No qual $v_{e f f}(r)$ representa o potencial efetivo :

$$
v_{e f f}(r)=v(r)+\int \frac{\rho\left(r^{\prime}\right)}{\left|r-r^{\prime}\right|} d r^{\prime}+v_{x c}(r)
$$

Após igualarem os potenciais efetivo e fictício, Kohn e Sham obtiveram as equações monoeletrônicas autoconsistentes:

$$
\begin{gathered}
{\left[-\frac{1}{2} \nabla^{2}+v_{e f f}\right] \psi_{i}=E_{i} \psi_{i},} \\
v_{e f f}(r)=v(r)+\int \frac{\rho\left(r^{\prime}\right)}{\left|r-r^{\prime}\right|} d r^{\prime}+v_{x c}(r) e \\
\rho_{s}(r)=\sum_{i}^{N}\left|\psi_{i}\right|^{2} .
\end{gathered}
$$

Com isso o funcional da energia total pode ser descrito das seguintes formas:

$$
E[\rho]=T_{s}[\rho]+J[\rho]+E_{x c}[\rho]+\int v(r) \rho(r) d r
$$

$\mathrm{Ou}$

$$
E[\rho]=\sum_{i}^{N} \int \psi_{i}^{*}\left(-\frac{1}{2} \nabla^{2}\right) \psi_{i} d r+J[\rho]+E_{x c}[\rho]+\int v(r) \rho(r) d r
$$


Um problema em utilizar o método DFT deve-se ao fato de que não consegue obter uma descrição adequada a energia de troca-correlação, dificultando a resolução dessas equações descritas acima. Com isso, utiliza-se também aproximações para facilitar as resoluções destas equações e assim são constantemente desenvolvidos novos funcionais que contornem os problemas de troca-correlação e dispersão. São eles LDA - Local Density Approximation, GGA - Generalized Gradient Approximation e os funcionais híbridos ${ }^{28 b}, 34$.

Apoiado na ideia de que a densidade eletrônica $\rho(r)$ é a observável fundamental para a descrição de reatividade química, Richard W. Bader desenvolveu uma das mais complexas e, ao mesmo tempo, didáticas ferramentas da mecânica quântica: a Teoria Quântica de Átomos em Moléculas (QTAIM). ${ }^{6}$ Este método é considerado inovador no estudo de ligações químicas e considerado eficiente para a descrição de interações intra e/ou intermoleculares.

Na QTAIM, assim como na DFT, a densidade eletrônica é a observável quantummecânica fundamental, da qual as outras propriedades gerais podem ser extraídas, inclusive a descrição da reatividade química. Na QTAIM, os átomos são definidos a partir da topologia fornecida por $\rho(r)$ e são chamados de atratores. A densidade que irá descrever como a carga eletrônica estará disposta em volta do núcleo, fornecendo a probabilidade de encontrar o elétron.

A densidade eletrônica, que é uma grandeza escalar e, por meio da QTAIM, pode ser observada através de grafos, tais como contornos, nos quais demonstram a distribuição da densidade eletrônica podendo concluir que as linhas mais próximas do núcleo possuem densidade máxima e, à medida que se afastam, ocorre um decaimento populacional. Essas linhas de contorno são medidas através do gradiente de densidade, $\nabla \rho(r)$, tal que como condição de contorno, pode-se dizer que o gradiente será perpendicular a um vetor unitário $(\nabla \rho(\mathrm{r}) \bullet \mathrm{n}(r)=0)$; a partir de uma sequência formada por estes vetores é definido as linhas de contorno. A trajetória dos gradientes é definida a partir dos atratores, tal que os gradientes são ligados diretamente em função dos atratores.

Como a descrição da densidade eletrônica é puramente topológica, pode-se fazer uso de regras de diferenciação, de modo que a depender de como $\rho(r)$ de distribui no espaço, serão gerados pontos de máximo e mínimo. Dessa forma, quando o rotacional do gradiente de $\rho(r)$, ou seja, a laplaciana de $\rho(r)\left[\nabla^{2} \rho(\mathrm{r})\right]$ for obtido, haverá um descritor escalar do comportamento de $\rho(r)$ neste ponto, tal que este ponto poderá ser um ponto de máximo, mínimo ou de sela. Para a descrição de ligações químicas, o significado de $\left[\nabla^{2} \rho(r), 0\right.$ ganha importância porque 
indica topologicamente que ligações químicas de natureza covalente apresentam características de ponto de sela; o que espacialmente reflete na exposição gráfica de um ponto crítico, agora chamado de ponto crítico de ligação (BCP - Bond Critical Point), a partir do qual se manifesta a mudança abrupta de população eletrônica. O BCP interliga atratores através do caminho de ligação. Sendo assim, a caracterização da natureza da ligação pode ser feita através de $\nabla^{2} \rho(r)$, cuja obtenção é possível pela diagonalização da Hessiana de densidade eq. 27, cuja forma diagonalizada é expressa em eq. 28.

$$
\begin{aligned}
& A=\left[\begin{array}{ccc}
\frac{\partial^{2} \rho}{\partial^{2} x^{2}} & \frac{\partial^{2} \rho}{\partial x \partial y} & \frac{\partial^{2} \rho}{\partial x \partial z} \\
\frac{\partial^{2} \rho}{\partial y \partial x} & \frac{\partial^{2} \rho}{\partial^{2} y^{2}} & \frac{\partial^{2} \rho}{\partial y \partial z} \\
\frac{\partial^{2} \rho}{\partial z \partial x} & \frac{\partial^{2} \rho}{\partial z \partial y} & \frac{\partial^{2} \rho}{\partial^{2} z^{2}}
\end{array}\right] \\
& \Lambda=\left[\begin{array}{ccc}
\frac{\partial^{2} \rho}{\partial^{2} x^{2}} & 0 & 0 \\
0 & \frac{\partial^{2} \rho}{\partial^{2} y^{2}} & 0 \\
0 & 0 & \frac{\partial^{2} \rho}{\partial^{2} z^{2}}
\end{array}\right]
\end{aligned}
$$

Assim a soma dos elementos da diagonal principal fornece a grandeza escalar $\nabla^{2} \rho(r)$, eq. 29 .

$$
\nabla^{2} \rho(r)=\frac{\partial^{2} \rho}{\partial^{2} x^{2}}+\frac{\partial^{2} \rho}{\partial^{2} y^{2}}+\frac{\partial^{2} \rho}{\partial^{2} z^{2}}
$$

A partir da análise da matriz Hessiana podemos dizer, que para $\nabla^{2} \rho(r)<0$ temos uma ligação de caráter covalente, já quando temos $\nabla^{2} \rho(r)>0$ identifica-se uma ligação de caráter iônico ou uma força intermolecular que envolve espécies de camada fechada ${ }^{35}$.

Visto os aspectos fundamentais dos modelos teóricos para a descrição de estrutura eletrônica, seguiremos com a apresentação dos métodos computacionais usados na exploração do processo de fragmentação molecular, e consequente rearranjo do tipo McLafferty, exposto nesta dissertação.

\subsection{Detalhes Computacionais}

Para a realização do estudo dos três sistemas analisados neste trabalho (1-Nitropropano, 2-Pentanona e Butirofenona) foram realizados cálculos de otimização com a metodologia 
$\mathrm{UHF}^{29}$ e base atômica LanL2MB ${ }^{36}$. Para a descrição acurada da termoquímica do processo de fragmentação foi aplicado o método de estrutura eletrônica baseado na DFT, através do funcional $\mathrm{M}^{3} 6^{37}$, e base atômica 6-311+G(d,p $)^{38}$. Simultaneamente, foram realizados cálculos de cinética do rearranjo McLafferty para os três sistemas estudados. Para tal estudo, foi aplicado o modelo baseado na Teoria de Eyring ${ }^{39}$ e Evans-Polanyi ${ }^{39 b}$, explorado por Mulyava ${ }^{40}$ para combustão de parafinas, com d-correção, como aplicado por Morais ${ }^{41}$ e colaboradores na análise de exclusão de efeito túnel em reações envolvendo carbeno substituído. Esta correção leva em consideração uma possível generalização da Termodinâmica de Gibbs-Boltzmann proposta por Tsallis ${ }^{42}$.

Para o tratamento de informações sobre a formação de complexos do tipo van der Waals $^{43}$, foram realizados dois tipos de cálculos; a dinâmica molecular semi-clássica de BornOppenheimer (1-Nitropropano) e o cálculo de coordenada intrínseca de reação (IRC) com a combinação $\omega \mathrm{B} 97 \times \mathrm{x} / 6-31+\mathrm{G}(\mathrm{d}, \mathrm{p})^{44}$ (para todos dos sistemas).

As análises de estrutura eletrônica foram realizadas utilizando três técnicas: QTAIM, NBO, Densidade de Spin e Índices Multicêntricos. Através destas técnicas, foi possível avaliar o nível de influência de grupos sobre a cadeia carbônica em fragmentação.

Todos os cálculos de optimização de geometria para a obtenção de dados energéticos e de estrutura eletrônica foram realizados através do pacote Gaussian $09^{45}$, enquanto que o tratamento topológico de todos os sistemas aqui apresentados foi desenvolvido com o pacote AIMAll $^{46}$. Todas as exposições gráficas de orbitais naturais e de densidade de spin foram realizadas através do programa ChemCraft ${ }^{47}$. 


\section{Capítulo 4. Resultados e Discussão}

\subsection{Análise Cinética e Termodinâmica do Rearranjo do tipo McLafferty}

Neste capítulo, serão expostos alguns resultados que sustentam, do ponto de vista químico-quântico, o mecanismo do tipo McLafferty. Serão apresentados dados sobre a cinética de fragmentação molecular do sistema do 1-Nitropropano (sistema a), 2- Pentanona (sistema b) e da Butirofenona (sistema c).

Para todos os sistemas analisados $(\mathbf{a} / \mathbf{b} / \mathbf{c})$, mesmo apresentando estruturas e composição diferentes, após serem expostos ao processo de ionização, é identificado que as substâncias, antes de seguirem com o procedimento da fragmentação, passam por um rearranjo similar - o rearranjo do tipo McLafferty. De forma generalizada, podemos expor o mecanismo de fragmentação molecular, incluindo o rearranjo do tipo McLafferty, como descrito na Figura 4.1 .

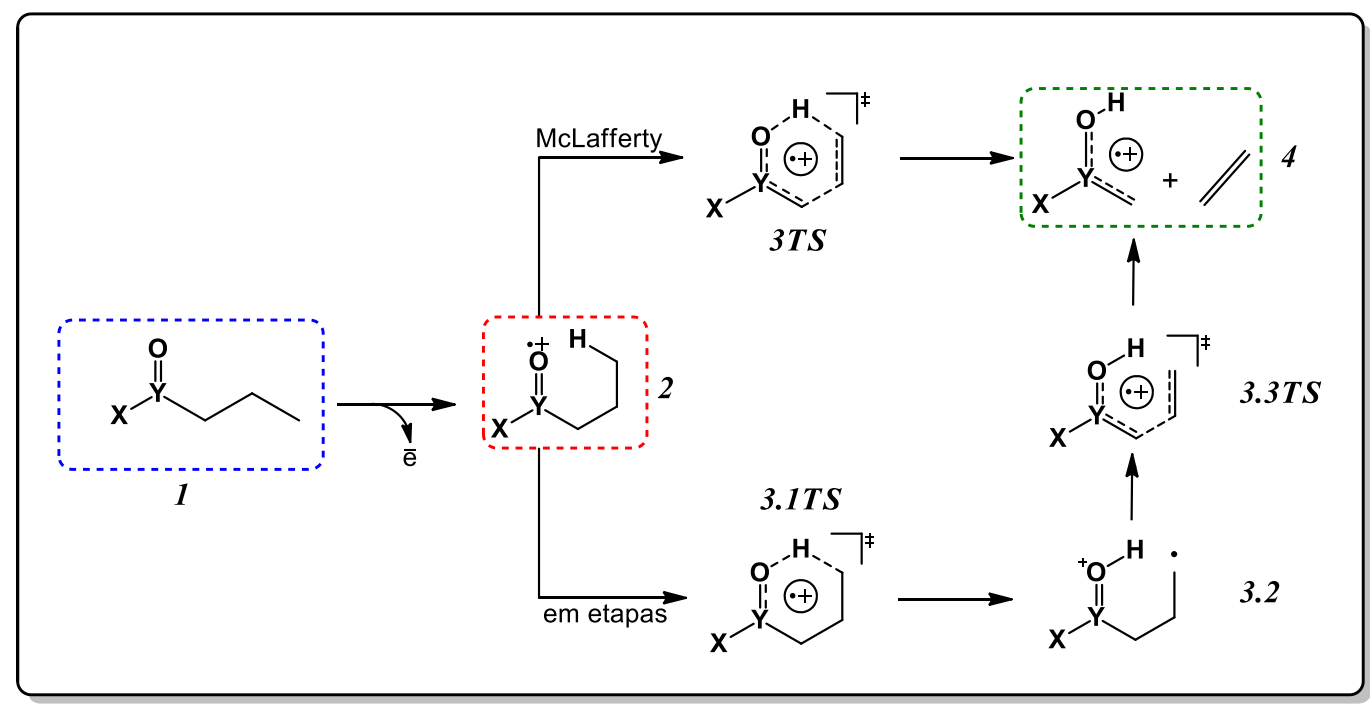

Figura 4. 1. Mecanismo geral para fragmentação do 1-Nitropropano, 2-Penanona e Butirofenona

Seguindo o mecanismo geral, descrito na Figura 4.1, é possível observar que as três substâncias estudadas se diferenciam apenas pelos substituintes X e Y, que são apresentados na Tabela 4.1.

Tabela 4. 1 Descrição dos substituintes X e Y para os sistemas estudados.

\begin{tabular}{ccc}
\hline Sistema & $\mathbf{X}$ & $\mathbf{Y}$ \\
\hline 1-Nitropropano (a) & $\mathrm{O}$ & $\mathrm{N}$ \\
\hline 2- Pentanona (b) & $\mathrm{CH}_{3}$ & $\mathrm{C}$ \\
\hline Butirofenona (c) & $\mathrm{C}_{6} \mathrm{H}_{5}$ & $\mathrm{C}$ \\
\hline
\end{tabular}


O processo de fragmentação para estes sistemas obedece, de forma generalizada, o seguinte perfil: ocorre a abstração de um elétron do sistema molecular 1, dando origem ao cátion radical 2; esta espécie pode sofrer fragmentação via rearranjo do tipo McLafferty concertado ou o em etapas, conduzindo aos mesmos produtos de fragmentação, 4. Seguindo o mecanismo concertado, a estrutura 2 passa pelo rearranjo no qual o hidrogênio, que se encontra na posição$\gamma$, é transferido para o oxigênio, ocorrendo simultaneamente a $\beta$ - clivagem - através do estado de transição 3.TS - conduzindo ao produto 4 .

Diferente do mecanismo McLafferty clássico, o processo em etapas não sofre a $\beta$ clivagem simultaneamente com a transferência de hidrogênio. Neste mecanismo, assim que o sistema passa pelo processo de ionização e forma a estrutura $\mathbf{2}$, ela irá sofrer um rearranjo onde é transferindo o hidrogênio- $\gamma$ - através do estado de transição 3.1.TS - gerando um grupo $[\mathrm{Y}=\mathrm{OH}]^{+}$, tornando o carbono- $\gamma$ o novo sítio radical (3.2). O sistema 3.2 segue com uma nova fragmentação - através do estado de transição 3.3.TS - conduzindo aos mesmos produtos descritos em 4.

Partindo desses três sistemas (a, b e c), será analisado, através de estudo energético e eletrônico, a preferência entre as duas possibilidades de mecanismos do tipo McLafferty (concertado e passo a passo) e como o efeito do substituinte irá influenciar no procedimento do rearranjo.

Iniciando a discussão deste trabalho, será tomado como ponto de partida o mecanismo de fragmentação (Figura 4.1), via rearranjo de McLafferty do sistema a [o 1-nitropropano $\left(\mathrm{PrNO}_{2}\right)$, sistema estudado por Nibbering $\left.{ }^{23 \mathrm{a}}\right]$, com as estruturas representadas na Figura 4.2.

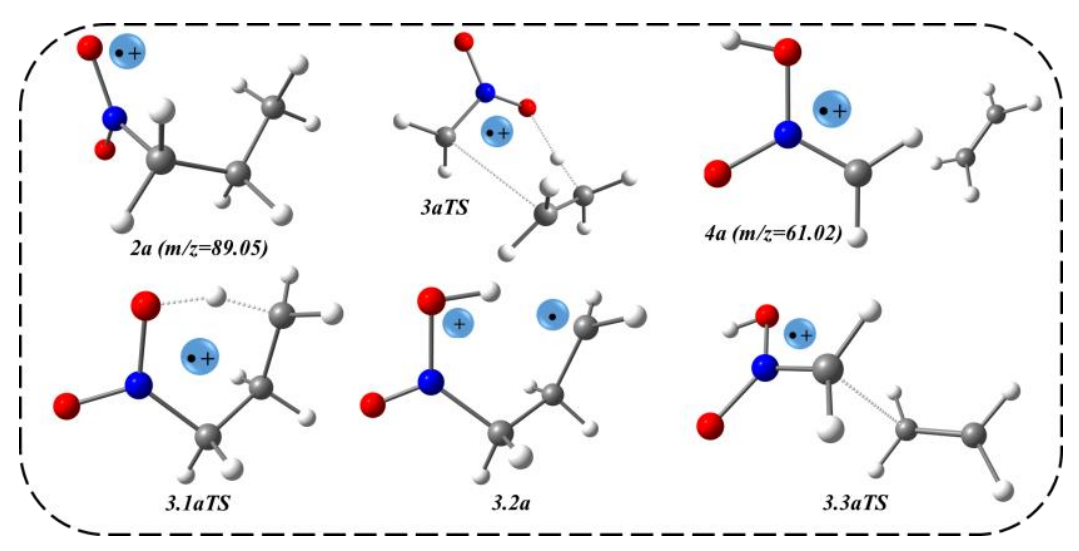

Figura 4. 2. Representação das estruturas do $\mathrm{PrNO}_{2}$ com suas respectivas relações massa/carga Fonte: autor. 
Através dos modelos teóricos, descritos na seção Detalhes Computacionais, foi possível obter a coordenada de fragmentação para o mecanismo concertado e em etapas. A energética da fragmentação do composto a se encontra na Figura 4.3.

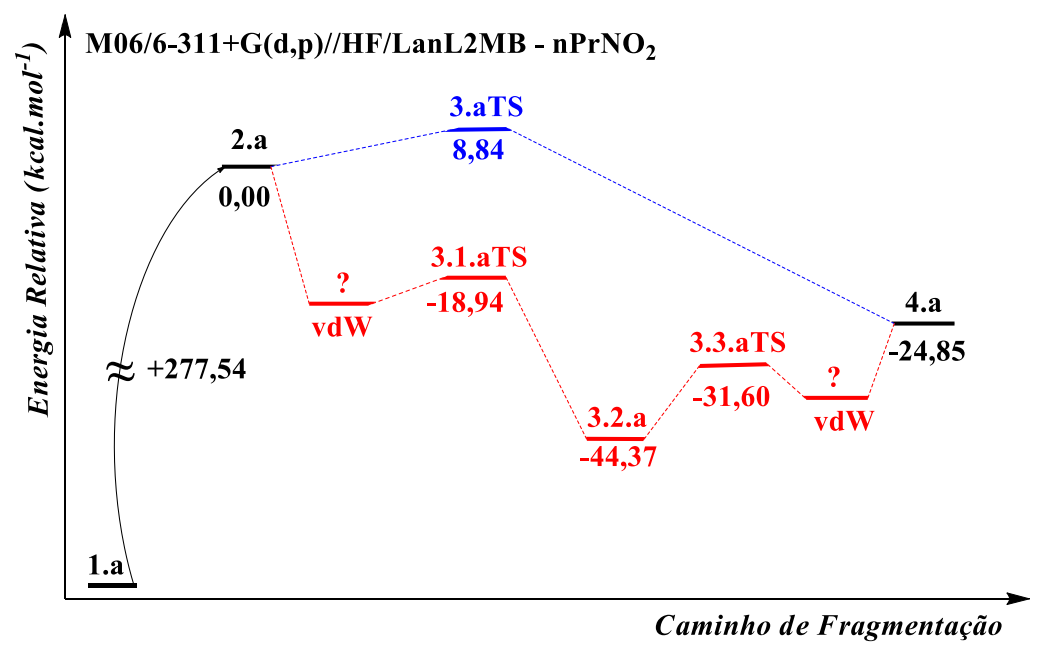

Figura 4. 3. Coordenada de reação para a fragmentação do sistema a (1-nitropropano). Fonte: autor.

A coordenada de fragmentação da Figura 4.3 corresponde ao caminho de fragmentação do sistema a (1-nitropropano) o qual resulta na formação do produto 4.a a partir de dois possíveis caminhos de fragmentação: concertado (azul) ou em etapas (vermelho). Nota-se que a abstração do elétron demanda uma energia de $+277,54 \mathrm{kcal} \mathrm{mol}^{-1}$; ou seja, verificando-se que este é um processo extremamente endotérmico. Uma vez gerada a espécie 2.a, é possível perceber que o rearranjo, através de 3.1.aTS, para a espécie 3.2.a passa por uma redução abrupta de energia (-18,94 kcal.mol $\left.{ }^{-1}\right)$. Essa discrepância de comportamento, pelo surgimento de uma barreira de ativação aparente de natureza negativa indica a possível existência de um complexo de van der Waals (vdW) que antecede o estado de transição.

Para a verificação da ocorrência do complexo vdW que antecede o 3.1.aTS, foi realizado um cálculo de coordenada intrínseca de reação (IRC) utilizando o método DFT com funcional híbrido $\omega B 97 x D$ e função de base 6-31+G(d,p), partindo-se de um estado de transição previamente optimizado com este mesmo método, 3.1.aTS. A partir do IRC foi verificado que de fato existe um complexo vdW, resultante da estabilização do cátion radical 2.a, que antecede o 3.1.aTS, e que apresenta energia relativa menor que o TS correspondente, levando agora a uma barreira de ativação relativa real de $+2,56 \mathrm{kcal} \mathrm{mol}^{-1}$.

Uma vez que o produto 3.2.a é formado, ele pode sofrer uma nova fragmentação através de 3.3.aTS - que representa uma barreira de $+12,77 \mathrm{kcal} \mathrm{mol}^{-1}-$ levando a formação de uma 
molécula neutra de etileno e o respectivo fragmento cátion radicalar associado, produto 4.a. Surpreendentemente, o sistema 4a apresenta energia superior a do estado de transição que o antecedeu. Para explicar este fato foram realizados cálculos de dinâmica semi-clássica do tipo Born-Oppenheimer, utilizando a combinação HF e base atômica 3-21G, gerando a coordenada exposta na Figura 4.5.

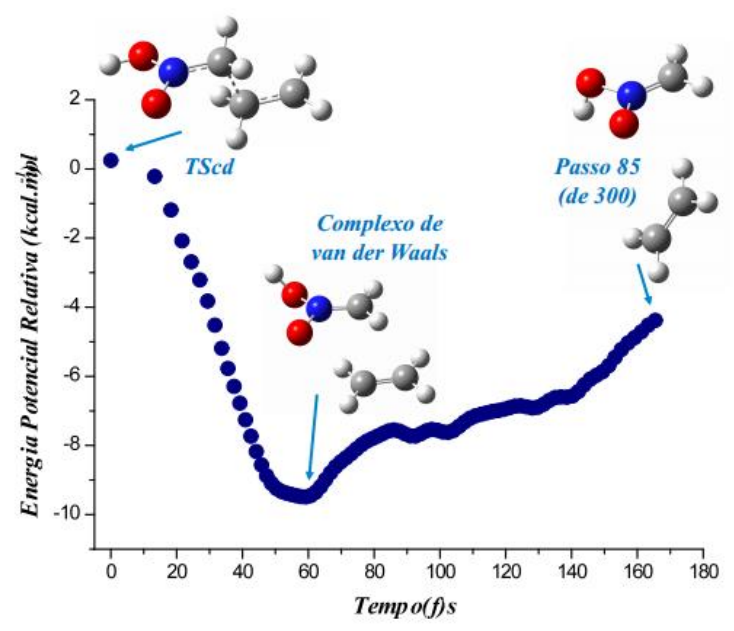

Figura 4. 4. Energia Potencial Relativa da formação de complexo do tipo van der Waals. Fonte: autor

Dessa forma, observa-se que a partir do estado de transição o sistema sofreu fragmentação e rapidamente atinge um estado energético mais baixo do que o estado de transição; na sequencia este complexo formado se instabiliza e passa a apresentar um aumento de energia em relação ao estado de transição, possivelmente pelo aumento de repulsão entre os fragmentos formados. Esse comportamento indica que o estado de transição não apresenta maior energia que o produto formado, pois o mesmo pode se estabilizar através da formação de um complexo do tipo van der Waals, de menor estado energético que, neste caso, sucede o estado de transição.

Analisando o mecanismo concertado do tipo McLafferty clássico (em azul), verificouse que o cátion radical 2.a sofre rearranjo passando pelo estado de transição concertado 3.aTS, com barreira energética de aproximadamente $+8,84 \mathrm{kcal} \mathrm{mol}^{-1}$, levando a formação do produto 4.a, com estabilização de 16,01 kcal.mol ${ }^{-1}$. As características estruturais do estado de transição gerado já deixam claras que a barreira associada não possibilita a geração de complexos antes ou depois do estabelecimento deste. De acordo com este perfil, admitindo o modo vibracional do estado de transição como sendo $v_{i}=140,28 i \mathrm{~cm}^{-1}$, a taxa de fragmentação envolvendo o rearranjo direto é $k=2,07 \times 10^{6} \mathrm{~s}^{-1}$. A magnitude desta taxa indica um rearranjo bastante rápido, cujas causas serão revisitadas posteriormente neste trabalho. 
Por fim, analisando o perfil termodinâmico das duas coordenadas referentes ao sistema a, verificou-se que para o mecanismo concertado, embora haja uma grande estabilização após a formação do produto 4.a através do 3.aTS, o mesmo apresenta energia maior que o cátion radical 2.a de partida. Em contrapartida, o mecanismo de fragmentação em etapas apresentou uma estabilização do cátion radical 2.a levando a uma complexo vdW, induzindo as etapas subsequentes à também apresentarem energias mais baixas que 2.a; embora a barreira energética para a formação do intermediário 3.2.a passando pelo 3.2.aTS ser maior em relação ao concertado, o mecanismo em etapas apresentou energias relativas de todos os passos inferior ao cátion radical de partida 2.a. Dessa forma, podemos notar que fragmentação que conduz o mecanismo em etapas se mostrou cineticamente mais favorável do que o mecanismo concertado. (Figura 4.3)

Seguindo a análise energética, a segunda substância a ser explorada corresponde ao sistema b (2-Pentanona, sistema estudado por Kercher ${ }^{23 c}$ ). Usando argumentos anteriores, descreveremos na Figura 4.5 as geometrias moleculares associadas aos passos representativos do mecanismo de fragmentação do sistema b, descritos na Figura 4.6.

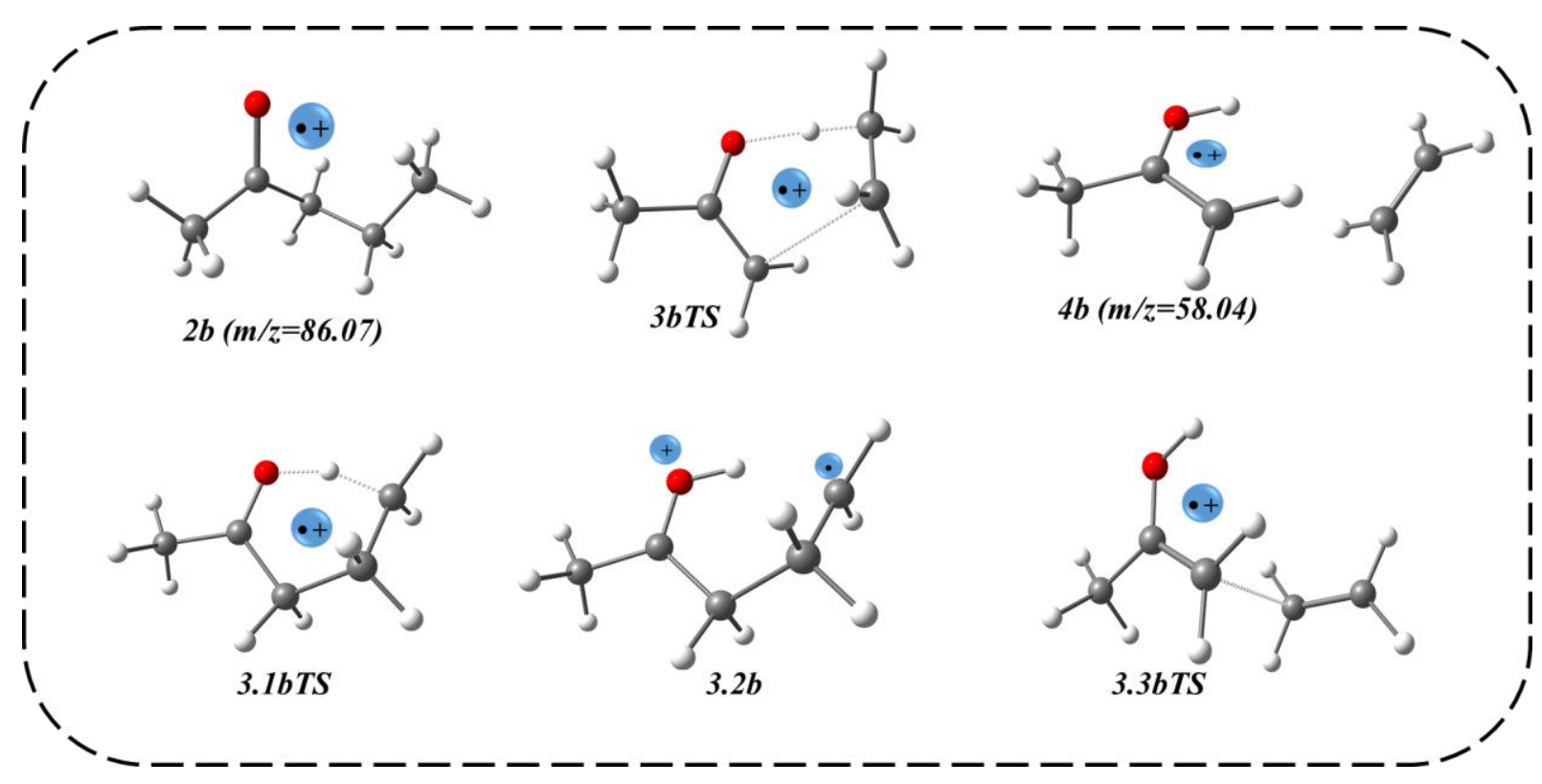

Figura 4. 5. Representação das estruturas da 2-Pentanona com suas respectivas relações massa/carga Fonte: autor.

A análise químico-quântica deste rearranjo (2-Pentanona), também foi aplicada a metodologia M06/6-311+G(d,p)//UHF/LanL2MB com o qual foi possível obter as coordenadas de fragmentação para o mecanismo concertado e em etapas explícitas na Figura 4.7. 


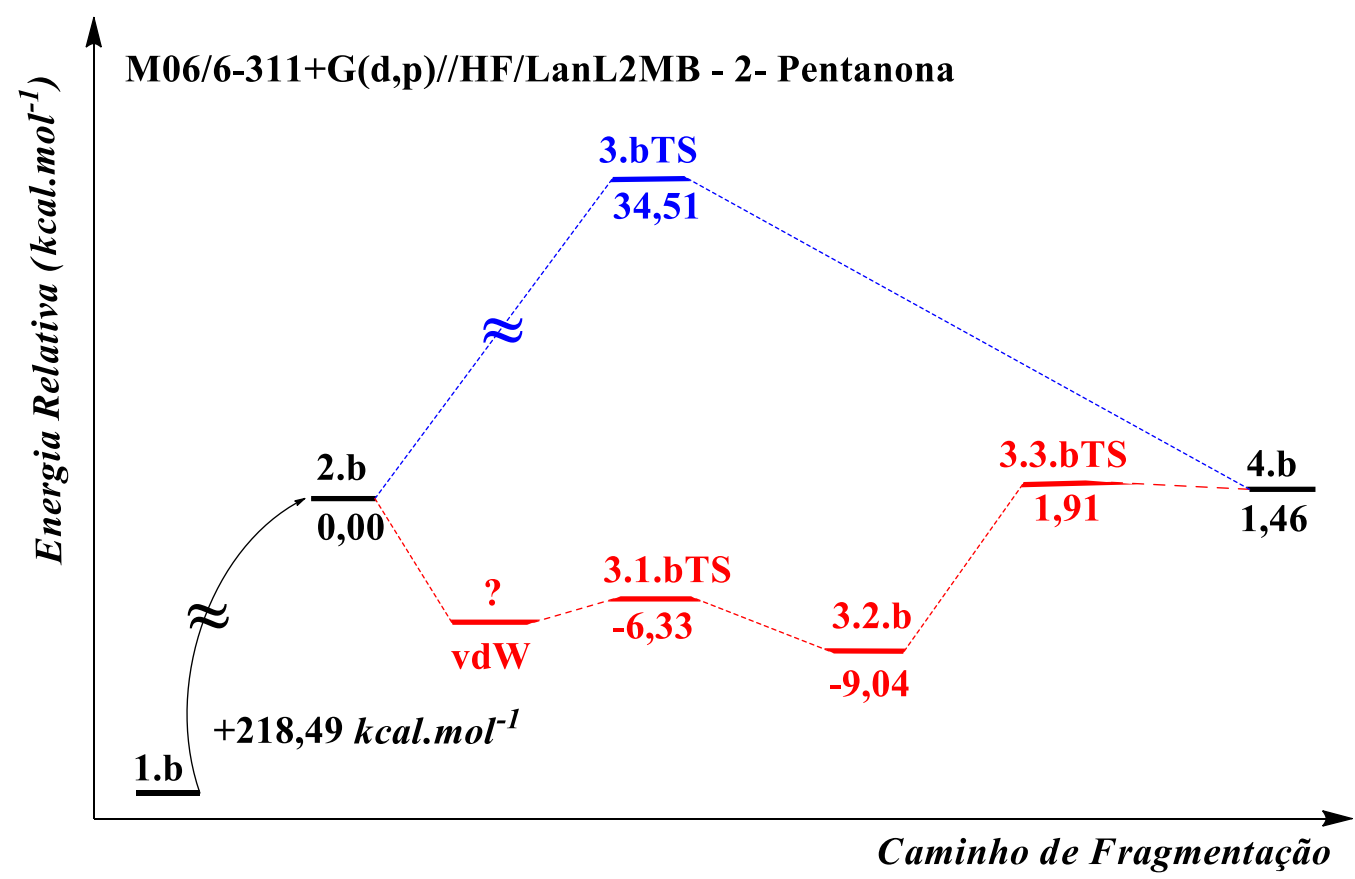

Figura 4. 6. Coordenada de reação para a fragmentação do sistema b (2-pentanona). Fonte: autor.

Analisando a coordenada de fragmentação da 2-pentanona descrita na Figura 4.6 se observa a formação do produto 4.b por duas rotas mecanísticas distintas; em azul, temos o mecanismo concertado para o rearranjo do tipo McLafferty e em vermelho o mecanismo em etapas. Ambos os mecanismo partem do mesmo substrato reagente, a 2-pentanona. Inicialmente pode ser percebido que a abstração do elétron em b demanda $+218,49 \mathrm{kcal}^{\mathrm{mol}} \mathrm{m}^{-1}$, evidenciando novamente que a ionização do substrato reagente é um processo extremamente endotérmico, como observado para o sistema 1-nitropropano. Comparado com o composto $\mathbf{a}$, o composto b não apresenta em sua região ionizada um grupo retirador, daí a diferença energética entre a ionização de a e de b. Após a ionização o sistema molecular catiônico 2.b é formado, e este pode se rearranjar através de dois possíveis caminhos de fragmentação (concertado ou em etapas) para a formação do produto observado $\mathbf{4 . b}$.

Verifica-se que seguindo o mecanismo em etapas, a estrutura 2.b sofre um rearranjo e converter-se na estrutura 3.2b, passando por uma geometria de estado de transição (3.1.bTS) com uma barreira energética negativa aparente de aproximadamente $-6,33 \mathrm{kcal}^{\mathrm{mol}}{ }^{-1}$, indicando a possibilidade de existência de um complexo de van der Waals que antecede o estado de transição (com menor energia que o TS correspondente).

Para a elucidação do mecanismo acerca da possibilidade de estabelecimento do complexo vdW que antecede o 3.1.bTS para formação da estrutura 3.2.b foi realizado um cálculo de coordenada intrínseca de reação (IRC) utilizando o método DFT com funcional 
híbrido $\omega \mathrm{B} 97 \mathrm{xD}$ e função de base $6-31+\mathrm{G}(\mathrm{d}, \mathrm{p})$, partindo-se de um estado de transição previamente optimizado com este mesmo método, 3.1.bTS. A partir do IRC foi verificado que de fato existe um complexo vdW, resultante da estabilização do cátion radical 2.b, que antecede o 3.1.bTS, e que apresenta energia relativa menor que o TS correspondente, levando agora a uma barreira de ativação relativa real de $2,13 \mathrm{kcal} . \mathrm{mol}^{-1}$.

Retomando o mecanismo a partir da formação do intermediário 3.2b formado, este sofre uma nova fragmentação, passando pela geometria de estado de transição 3.3.bTS com barreira energética de aproximadamente $+10,95 \mathrm{kcal} \mathrm{mol}^{-1}$, levando a formação de uma molécula de etileno neutra e um fragmento cátion radicalar correspondente, produto 4.b com estabilização de 0,45 kcal.mol ${ }^{-1}$.

Analisando o mecanismo concertado (Figura 4.6) é observado que após a formação do cátion radical 2.b o mesmo sofre o rearranjo do tipo McLafferty clássico, passando por uma geometria de estado de transição 3.bTS com barreira energética de aproximadamente $+34,51$ kcal.mol ${ }^{-1}$, levando a formação do produto 4.b; neste caso com estabilização relativa ao estado de transição concertado de $33,05 \mathrm{kcal} \mathrm{mol}^{-1}$, evidenciando que o estado de transição apresenta energia relativa muito elevada. Para 3.bTS o modo vibracional associado ao estado de transição é $v_{i}=321,11 i \mathrm{~cm}^{-1}$, de modo que a taxa de fragmentação de b via rearranjo clássico é $k=3,34 \times 10^{-}$ ${ }^{13} s^{-1}$.

Comparando a análise cinética para os dois mecanismos propostos, fica evidente o favorecimento do mecanismo em etapas em relação ao concertado, devido à relativa facilidade de transferir hidrogênio através o estado de transição em etapas - três vezes menor do que a energia apresentada pelo estado de transição concertado. Analisando o mecanismo em etapas, verifica-se que o 3.1.bTS, passa pela formação de um anel de seis membros que possibilita a transferência do $\mathrm{H}-\gamma$, sem a ocorrência da $\beta$-clivagem, levando a formação do intermediário 3.2b, mais estável, a qual possibilita um rearranjo estrutural (3.3.bTS) que leva a formação do produto 4.b com menor consumo energético em relação ao 3.bTS do mecanismo concertado o qual apresenta a formação de um anel de seis membros com maior deformação angular e consequente maior energia.

Por fim, analisando o sistema c (Butirofenona, sistema estudado por Osterheld e Brauman $^{23 b}$ ), observa-se a formação do produto 4.c através de duas possibilidades de mecanismos distintas, cujas estruturas dos passos representativos estão expostas na Figura 4.7, associadas à coordenada de fragmentação da Figura 4.8. 


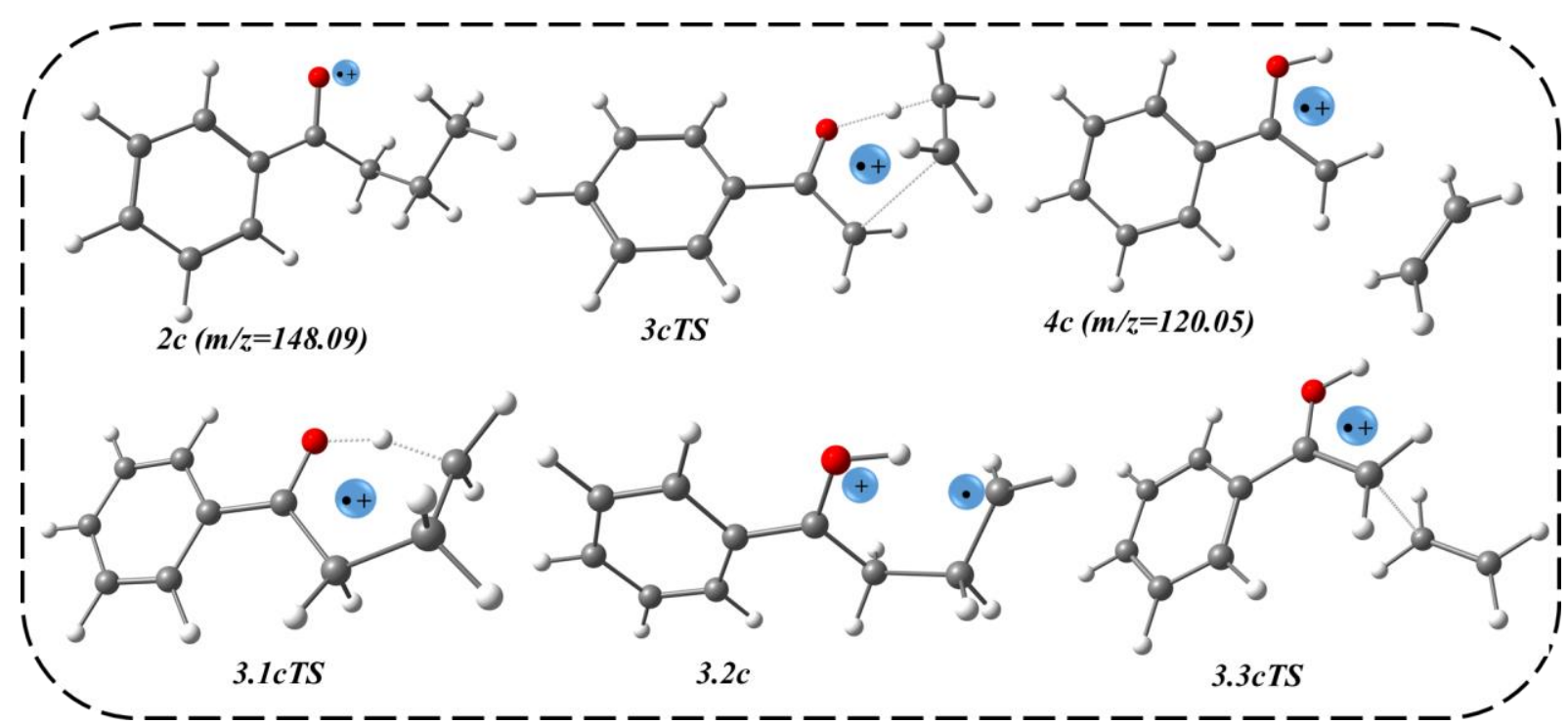

Figura 4. 7. Representação das estruturas da Butirofenona com suas respectivas relações massa/carga Fonte: autor.

A partir do estudo termodinâmico desse sistema foi possível construir a coordenada de reação para a formação do produto 4.c a partir das duas rotas propostas, a qual está exposta na Figura 4.10, onde se verifica que em azul, temos o mecanismo concertado para o rearranjo do tipo McLafferty e em vermelho o mecanismo em etapas, como nas análises anteriores.

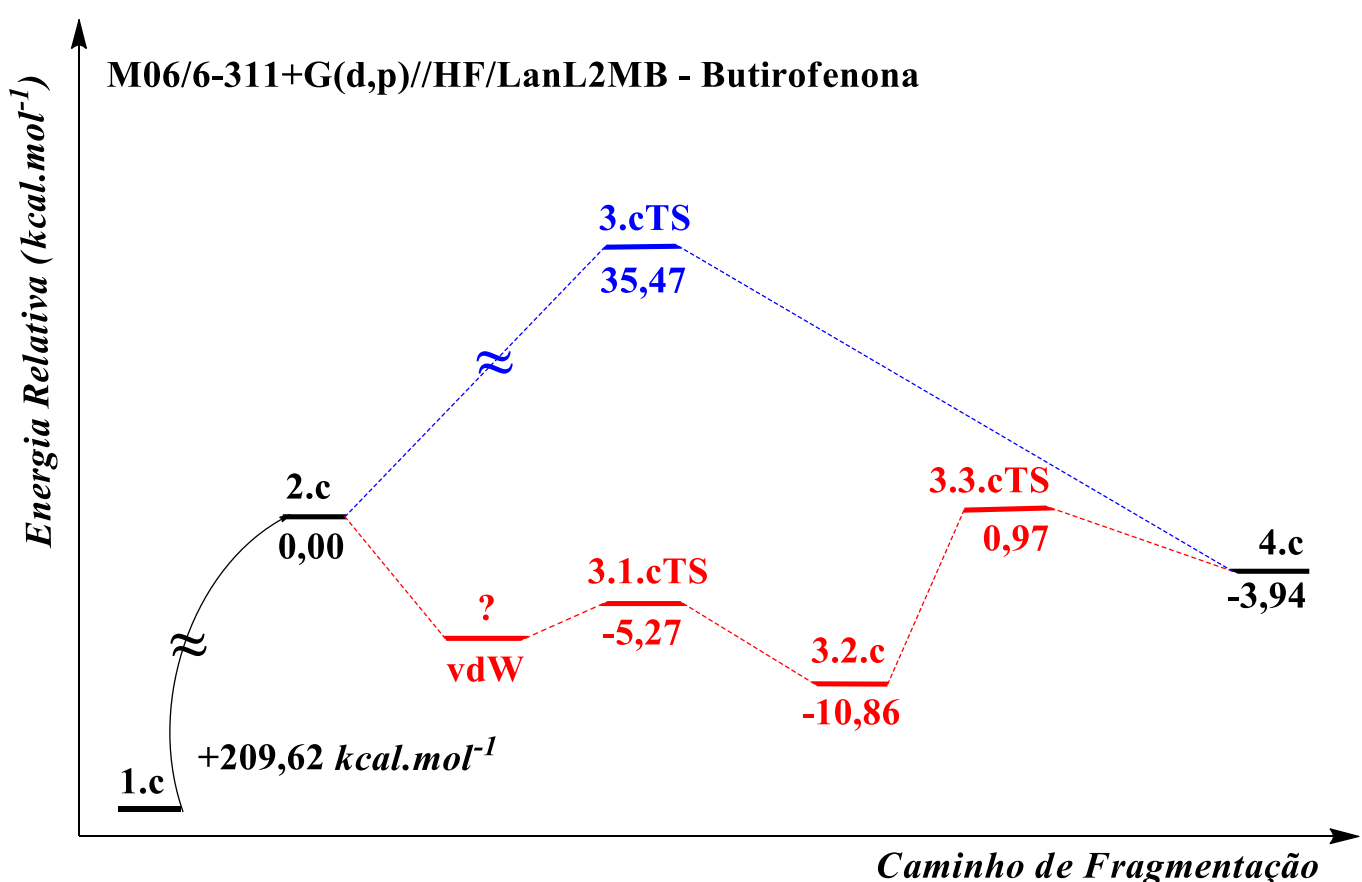

Figura 4. 8. Coordenada de reação para a fragmentação do sistema c (Butirofenona). Fonte: autor.

O substrato reagente de partida é o mesmo para os dois modelos mecanísticos, a Butirofenona (1.c). Inicialmente é possível notar que a demanda energética para a abstração de 
um elétron em c é de $+209,62$ kcal.mol ${ }^{-1}$, revelando que o grupo aromático exerce redução da energia necessária para ionizar a carbonila.

Após a ionização o sistema molecular catiônico 2.c formado pode se rearranjar através de dois possíveis caminhos de fragmentação (concertado ou em etapas) para a formação do produto observado 4.c. Verificou-se que para o mecanismo em etapas, a estrutura 2.c sofre um rearranjo e converter-se na estrutura 3.2c, sucedido por uma geometria de estado de transição (3.1.cTS) de transferência do $\mathrm{H}-\gamma$ para o oxigênio do grupo carbonila, com uma barreira energética negativa de aproximadamente $-5,27 \mathrm{kcal} \mathrm{mol}^{-1}$, indicando novamente a possibilidade de existência de um complexo de van der Waals que antecede o estado de transição (com menor energia que o TS correspondente).

Novamente, para identificação do complexo vdW que antecede o 3.1.cTS foram realizados cálculos de coordenada intrínseca de reação (IRC) com a mesma metodologia utilizada para os cálculos de IRC anteriores, partindo da geometria do 3.1.cTS previamente optimizado com este método. A partir desta análise foi novamente observado que há formação de um complexo vdW, resultante da estabilização do cátion radical 2.c, que antecede o 3.1.cTS, e que apresenta energia relativa menor que o TS correspondente; levando agora a uma barreira de ativação relativa real da ordem de $+2,2 \mathrm{kcal} \mathrm{mol}^{-1}$ (Figura 4.9).

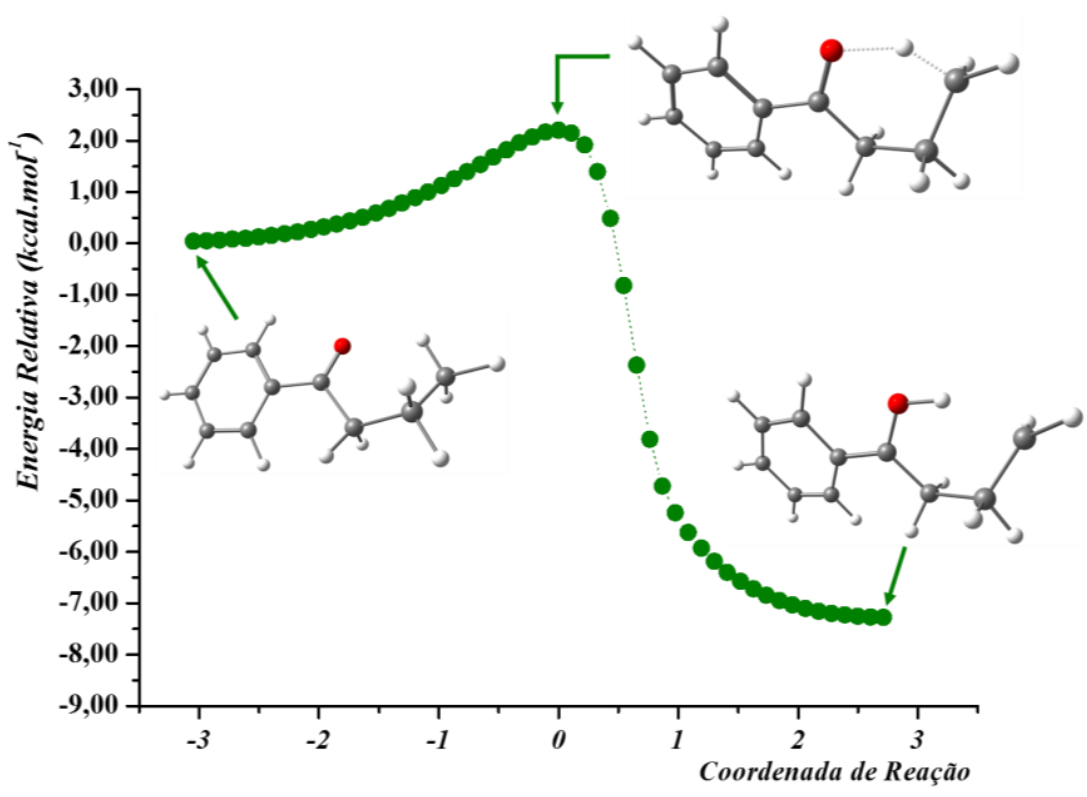

Figura 4. 9. Coordenada Intrínseca de Reação (IRC) para a transferência de hidrogênio radicalar no sistema c (Butirofenona) a partir do 3.1.cTS.

Retomando a coordenada de reação, após a formação do intermediário 3.2c, este sofre uma nova fragmentação, passando pela geometria de estado de transição 3.3.cTS com barreira 
energética de aproximadamente $+11,83 \mathrm{kcal} \mathrm{mol}^{-1}$, levando a formação de uma molécula de etileno neutra e um fragmento cátion radicalar correspondente, produto 4.c com estabilização de 4,91 kcal.mol ${ }^{-1}$.

Considerando o mecanismo concertado (Figura 4.8) observou-se que após a formação do cátion radical 2.c, este sofre um rearranjo do tipo McLafferty clássico passando por uma geometria de estado de transição concertado 3.cTS com barreira energética de aproximadamente $+35,47 \mathrm{kcal} \mathrm{mol}^{-1}$, levando a formação do produto 4.c, com estabilização relativa de 39,41 kcal.mol ${ }^{-1}$, evidenciando que o estado de transição apresenta energia relativa muito elevada, embora leve a formação de um produto com expressiva estabilização relativa.

Fazendo a mesma análise cinética realizada para a e b, se admitirmos para o 3.cTS o modo vibracional associado ao estado de transição é $v_{i}=468,36 i \mathrm{~cm}^{-1}$, a taxa de fragmentação de c via rearranjo clássico é $\mathrm{k}=8,74 \times 10^{-14} \mathrm{~s}^{-1}$. Verifica-se, de maneira geral, que o mecanismo direto é dificultado para sistemas que melhor estabilizam o cátion radical formado.

Baseado na análise cinética para os dois mecanismos propostos, torna-se evidente o favorecimento do mecanismo em etapas em relação ao concertado. Nota-se que o perfil reacional para o sistema $\mathbf{c}$ é muito semelhante ao sistema $\mathbf{b}$, inclusive em relação a conformação apresentada pelas estruturas equivalente no mecanismo; dessa forma é justificável o perfil energético do sistema c ser idêntico ao de b.

\subsection{Análise de estrutura eletrônica do Rearranjo do Tipo McLafferty}

Com o objetivo de compreender o mecanismo do tipo McLafferty, do ponto de vista eletrônico, foram realizadas análises de Orbitais Naturais de Ligação (NBO), análise topológica baseada na Teoria Quântica de Átomos em Moléculas (QTAIM), cálculos de índices multicêntricos e análise da densidade de spin.

\subsubsection{Análises NBO, QTAIM, densidade de spin e índices multicêntricos do Rearranjo do Tipo McLafferty}

Para compreender o mecanismo do tipo McLafferty, do ponto de vista eletrônico, foram realizados cálculos NBO, QTAIM, densidade de spin e índices multicêntricos no qual foram explorados os estados de transição 3.1TS, 3.3TS. Essas análises foram realizadas apenas para 
os sistemas a (1-nitropropano) e c (butirofenona). Uma vez que o mecanismo para a 2pentanona é muito semelhante a butirofenona, inclusive a conformação adotada pela estrutura na parte da molécula onde ocorre o rearranjo, foi admitido, para fins práticos, que os contornos de orbitais naturais de ligação são equivalentes para os sistemas b e c.

O primeiro sistema estudado foi o a (1-nitropropano), para o qual foi verificado inicialmente, que para o 3.1.aTS - estado de transição que caracteriza o rearranjo do tipo McLafferty em etapas (transferência do H- $\gamma$ ) - apresenta um comportamento bastante peculiar do ponto de vista eletrônico; primeiro, pela natureza multicêntrica do processo de transferência protônica e, depois pelo envolvimento direto do orbital $\sigma \mathrm{C}-\mathrm{H}$ em uma deslocalização com o orbital semi ocupado do oxigênio radicalar primário, descrito na Figura 4.6.

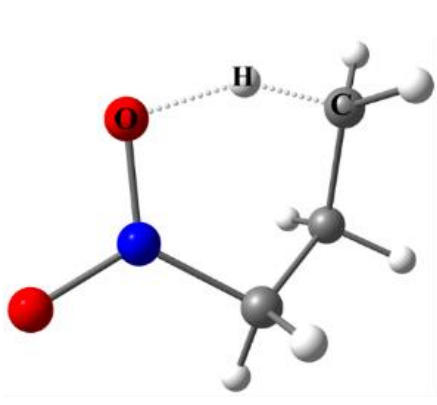

a

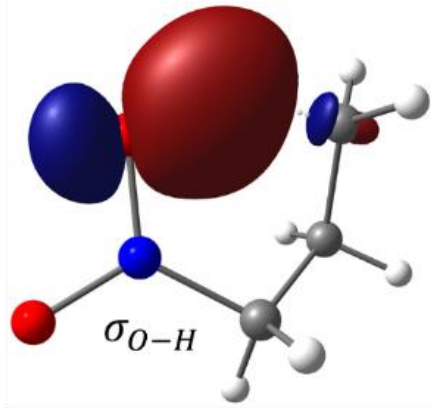

b

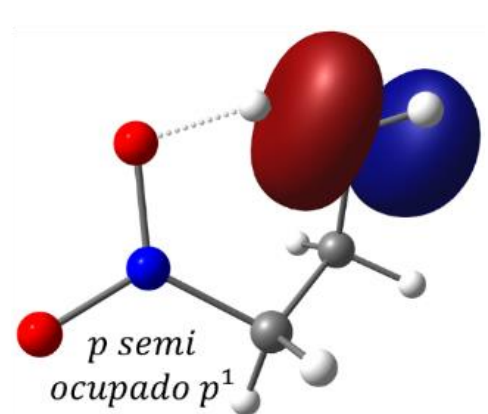

c

$$
\begin{gathered}
\sigma_{O-H} \rightarrow p^{1}=135,27{\mathrm{kcal} . \mathrm{mol}^{-1}} \\
I_{O H C}=0,021
\end{gathered}
$$

Figura 4. 10. Representação geral da geometria de estado de transição do rearranjo do tipo McLafferty (a), do orbital ligante (b) e do orbital $p$ semi preenchido (c) do átomo de carbono- $\gamma$ (isocontorno $=0.062208)$. Fonte: autor

Como pode ser verificado na Figura 4.10.a, a combinação das simetrias da ligação dos fragmento O-H e do orbital semi preenchido do carbono- $\gamma$ proporciona uma transferência-H radicalar facilitada, tendo em vista a própria energia de deslocalização apresentada nesta mesma figura. A deslocalização, admitindo o fragmento ligante $\mathrm{C}-\mathrm{H}_{\gamma}$ e o orbital semi preenchido do oxigênio (do grupo nitro), apresenta uma magnitude inferior à da descrita na Figura 4.10.a $\left(\sigma_{C-H} \rightarrow p^{1}=48,46 \mathrm{kcal} \mathrm{mol}^{-1}\right)$, indicando que o rearranjo do tipo McLafferty, na concepção do modelo NBO, é eletronicamente favorecida.

Visto o rearranjo principal, segue-se agora com o segundo estado de transição da fragmentação do 1-nitropropano. Para o estado de transição 3.3aTS, foram realizados cálculos 
de densidade de spin, para verificar a provável concentração de elétron desemparelhados no sistema transiente em fragmentação (Figura 4.11).

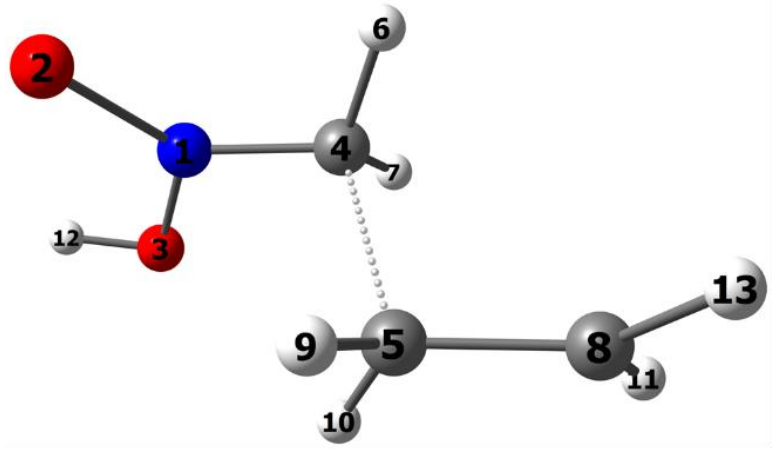

$\mathbf{a}$

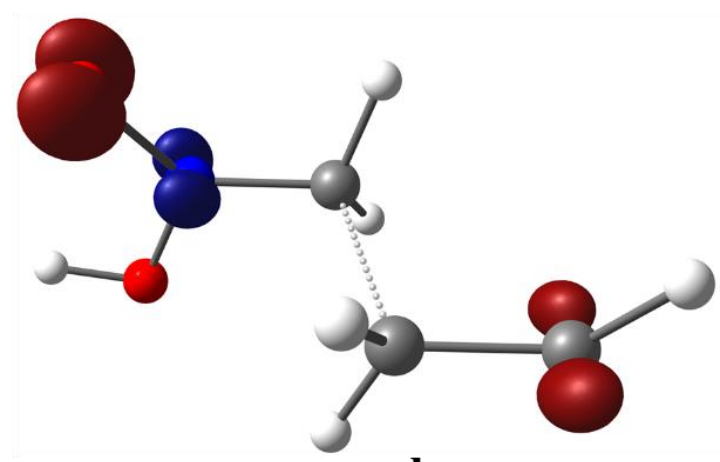

b

Figura 4. 11. Representação estrutural do estado de transição 3.3aTS (a) e da densidade de spin do sistema (região em vermelho representa probabilidade de se encontrar elétron desemparelhado; isocontorno $=0.069442$ ). Fonte: autor.

Verificou que neste estado de transição, o caráter radicalar se manifesta principalmente nas regiões extremas do complexo. Assim, para verificar a preferência de fragmentação, foram realizados cálculos NBO, onde foi possível observar a deslocalização eletrônica envolvendo os fragmentos, de natureza olefínica, N1-C4 e C5-C8 $\left(\pi_{N 1-C 4} \rightarrow p_{C 5}^{1}=94,98 \mathrm{kcal}_{\text {. } \mathrm{mol}^{-1} \mathrm{e}}\right.$ $p_{C 5}^{1} \rightarrow \pi_{N 1-C 4}^{*}=324,02$ kcal. $\mathrm{mol}^{-1}$ ). Como pode-se observar via NBO, a transferência do comportamento radicalar é quase completamente transferido para o fragmento nitrogenado, devido a energia de deslocalização entre os orbitais envolvendo a transferência do elétron desemparelhado ser maior na direção do fragmento nitrogenado.

Para entender o mecanismo estudado, do ponto de vista eletrônico, foram realizados cálculos de NBO referente ao estado de transição, 3.1.cTS, do rearranjo do tipo McLafferty envolvido no sistema 2.Butirofenona.

Verifica-se que no 3.1.cTS, estado de transição correspondente ao rearranjo do tipo McLafferty, há duas deslocalizações eletrônicas importantes: uma envolvendo deslocalização eletrônica entre o orbital $\sigma_{\mathrm{C}-\mathrm{H}}$ e orbital semi-preenchido $\mathrm{p}^{1}$ do oxigênio radicalar $(\mathbf{2 c})$ com energia de deslocalização $\sigma_{\mathrm{C}-\mathrm{H}} \rightarrow p^{1}=34,08 \mathrm{kcal}$. $\mathrm{mol}^{-1}$ e a deslocalização entre o orbital $\sigma_{\mathrm{O}-\mathrm{H}}$ e orbital semi-preenchido $\mathrm{p}^{1}$ do carbono radicalar (produto da transferência de H- $\alpha, \mathbf{3 . 2 c}$ ) com energia de deslocalização $\sigma_{\mathrm{O}-\mathrm{H}} \rightarrow p^{1}=50,51 \mathrm{kcal} \mathrm{mol}^{-1}$. Esta segunda é uma interação de maior energia estabilizadora, devido a melhor combinação entre as simetrias dos 
orbitais naturais envolvidos na transferência do $\mathrm{H}$ radicalar $\left(\sigma_{\mathrm{O}-\mathrm{H}}\right.$ e $\left.\mathrm{p}^{1}\right)$, demonstrada pelas ilustrações dos orbitais através da análise NBO, descrito na Figura 4.12 a seguir, proporcionando uma transferência de hidrogênio facilitada, indicando que o rearranjo do tipo McLafferty para esta estrutura é eletronicamente favorecido.

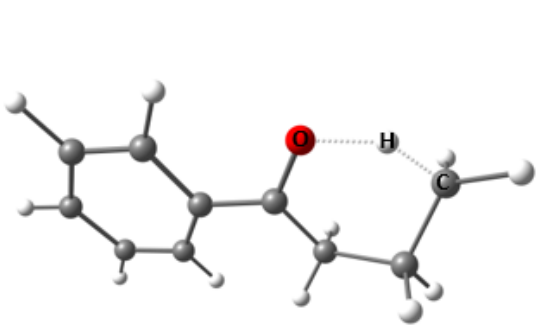

a

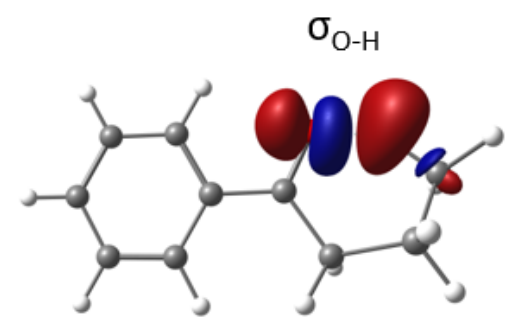

b

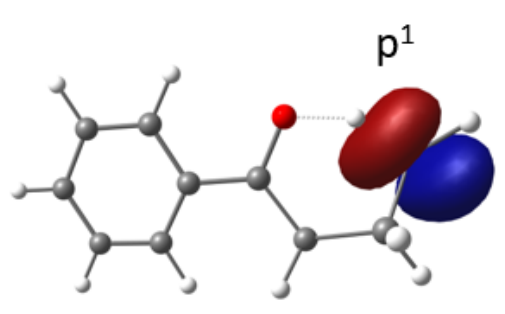

C

$$
\sigma_{O-H} \rightarrow p^{1}=50,51 \mathrm{kcal} / \mathrm{mol}
$$

Figura 4. 12. Representação geral da geometria de estado de transição do rearranjo do tipo McLafferty (a), do orbital ligante (b) e do orbital p semi preenchido (c) do átomo de carbono- $\gamma$ (isocontorno $=$ 0.062208). Fonte: autor.

$\mathrm{Na}$ Figura 4.13, analisando a densidade de spin referente ao estado de transição 3.cTS, verifica-se um maior valor de densidade de spin no átomo de carbono, mas com um pouco de participação do átomo de oxigênio, evidenciando a localização do elétron desemparelhado devido à deslocalização n-SOMO $\left(\mathrm{p}^{1} \mathrm{Ca}-\pi^{*}{ }_{\mathrm{C}-\mathrm{O}}\right)$ mais estabilizadora.

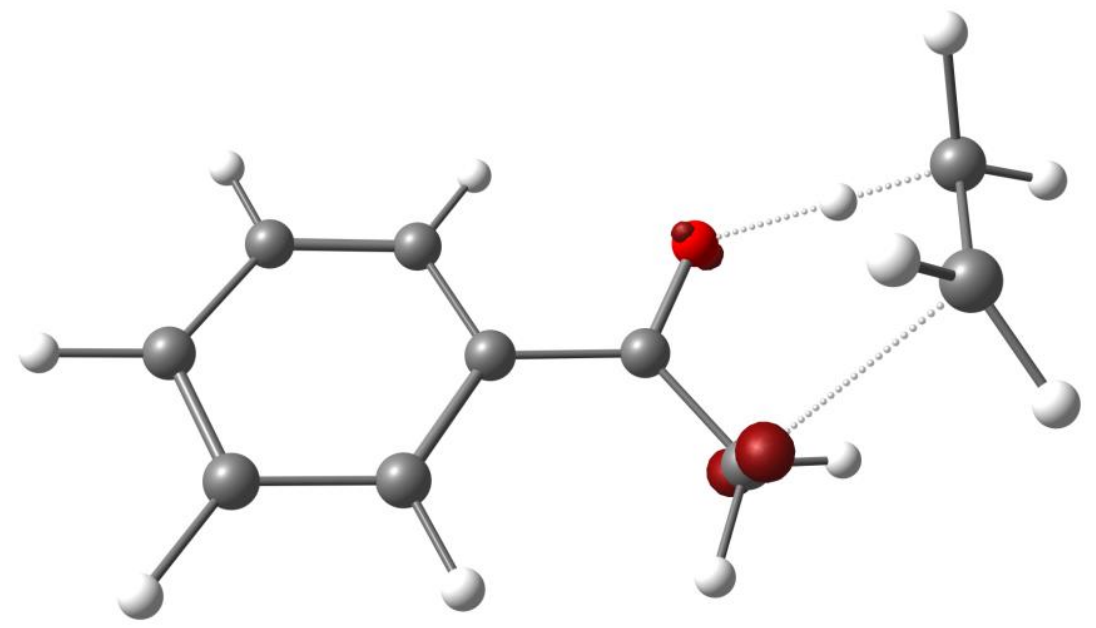

Figura 4. 13. Representação estrutural do estado de transição 3.cTS e da densidade de spin do sistema (região em vermelho representa probabilidade de se encontrar elétron desemparelhado; isocontorno $=0.069442$ ). Fonte: autor

A partir da Figura 4.14, podemos observar através da densidade de spin que neste estado de transição há uma equivalência entre os átomos de oxigênio e $\mathrm{C}_{\alpha}$, levando uma espécie de equilíbrio dinâmico da transferência do hidrogênio radicalar, levando a permanência da 
estrutura na conformação em forma de pseudo-anel de seis membros, corroborando o favorecimento do rearranjo do tipo McLafferty.

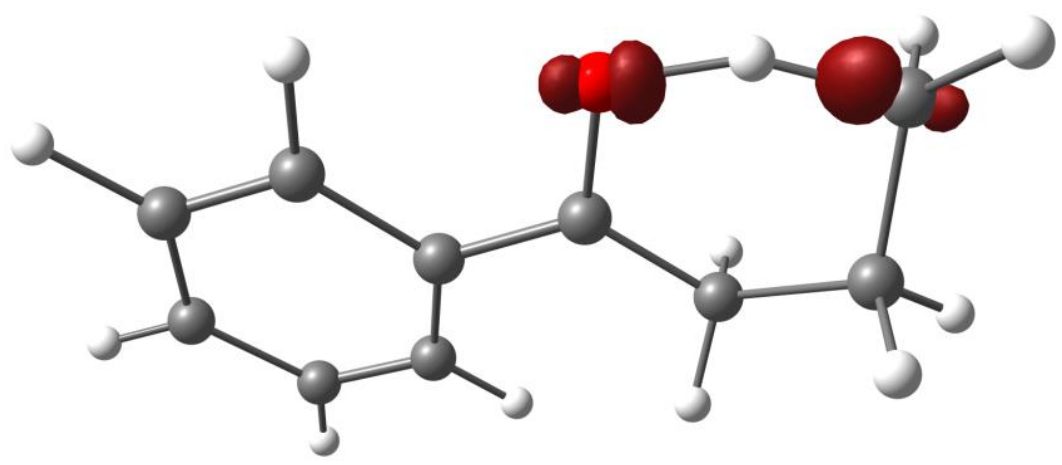

Figura 4. 14. Representação estrutural do estado de transição 3.1cTS e da densidade de spin do sistema (região em vermelho representa probabilidade de se encontrar elétron desemparelhado; isocontorno $=0.069442$ ). Fonte: autor

Na Figura 4.15 podemos verificar a distribuição de densidade de spin para o estado de transição 3.3cTS.

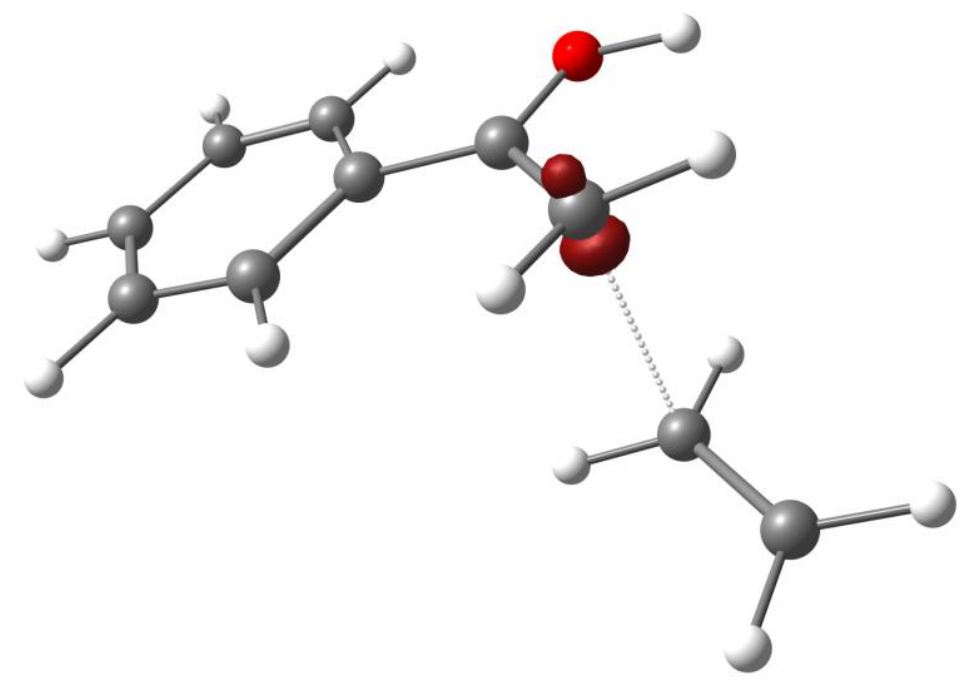

Figura 4. 15. Representação estrutural do estado de transição 3.3cTS e da densidade de spin do sistema (região em vermelho representa probabilidade de se encontrar elétron desemparelhado; isocontorno $=0.069442$ ). Fonte: autor

\subsubsection{Análise Topológica QTAIM do efeito do substituinte nos sistemas estudados}

Seguindo com as análises, nas Figuras (4.16, 4.17 e 4.18) estão representados os dados topológicos fornecidos pela análise de QTAIM para todos os sistemas $(\mathbf{a} / \mathbf{b} / \mathbf{c})$ respectivamente. 


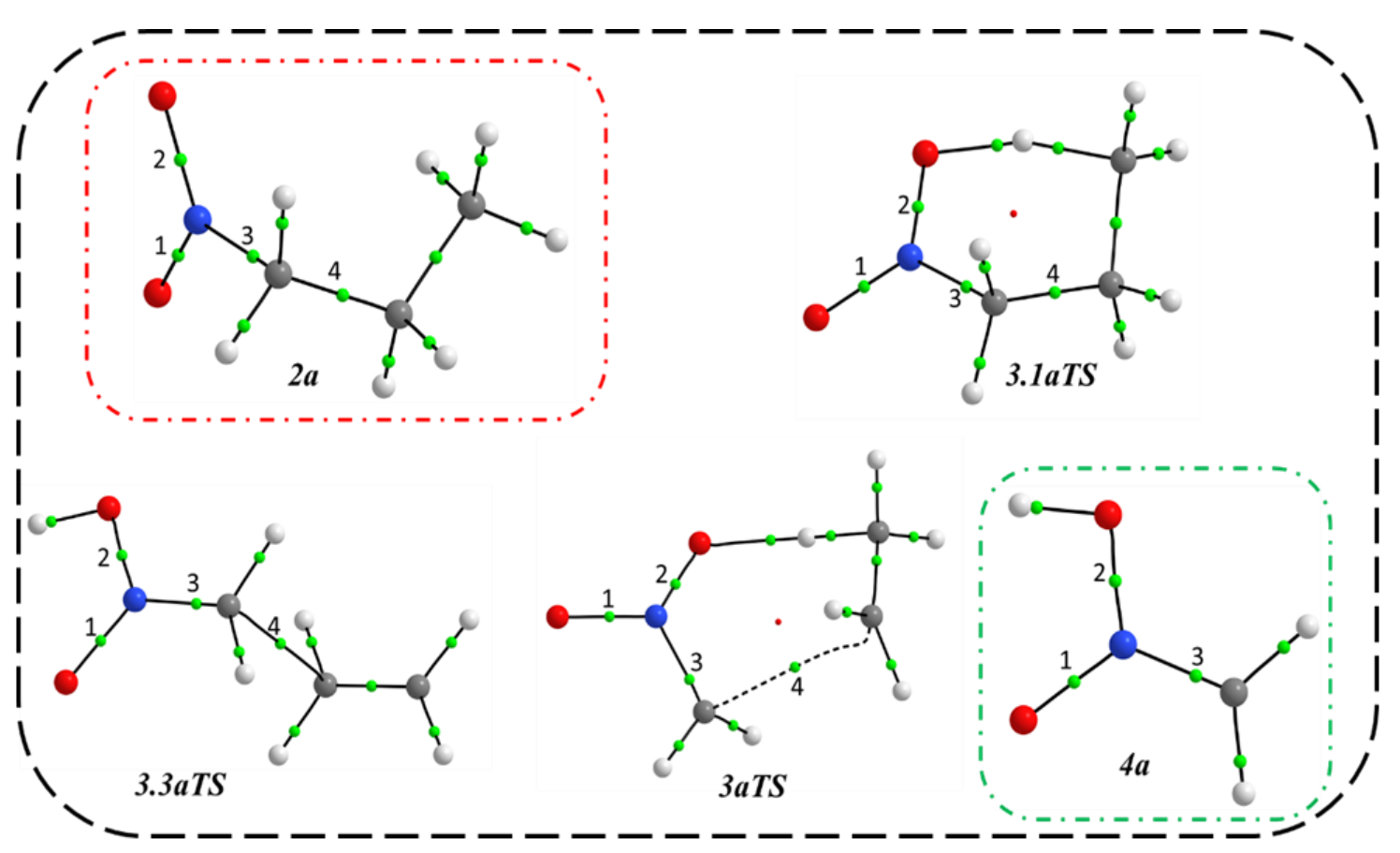

\begin{tabular}{|c|c|c|c|c|c|}
\hline Sistema & $\mathbf{B C P}$ & $\boldsymbol{\rho}$ & $\boldsymbol{\nabla}^{\mathbf{2}} \boldsymbol{\rho}$ & $\mathbf{\varepsilon}$ & $\mathbf{V}$ \\
\hline \multirow{3}{*}{$\mathbf{2 a}$} & 1 & 0.339378 & -0.555800 & 0.006335 & -0.450514 \\
\cline { 2 - 6 } & 2 & 0.339664 & -0.550279 & 0.003320 & -0.451479 \\
\cline { 2 - 6 } & 3 & 0.170896 & -0.105426 & 0.074343 & -0.364511 \\
\cline { 2 - 6 } & 4 & 0.230173 & -0.517176 & 0.009862 & -0.224586 \\
\hline \multirow{3}{3.1aTS}{} & 1 & 0.347591 & -0.365086 & 0.235330 & -0.512469 \\
\cline { 2 - 6 } & 2 & 0.339326 & -0.581597 & 0.015534 & -0.445809 \\
\cline { 2 - 6 } & 3 & 0.189173 & -0.255829 & 0.075938 & -0.373129 \\
\cline { 2 - 6 } & 4 & 0.234186 & -0.528477 & 0.018473 & -0.221159 \\
\hline 3.3aTS & 1 & 0.334969 & -0.370944 & 0.118124 & -0.464918 \\
\cline { 2 - 6 } & 2 & 0.315129 & -0.468167 & 0.081391 & -0.390500 \\
\cline { 2 - 6 } & 3 & 0.299015 & -0.592076 & 0.072899 & -0.707951 \\
\cline { 2 - 6 } & 4 & 0.025084 & +0.050651 & 0.041473 & -0.015513 \\
\hline 3aTS & 1 & 0.326917 & -0.490103 & 0.110811 & -0.551086 \\
\cline { 2 - 6 } & 2 & 0.344846 & -0.528119 & 0.278716 & -0.621144 \\
\cline { 2 - 6 } & 3 & 0.231742 & +0.019569 & 0.473137 & -0.562625 \\
\cline { 2 - 6 } & 4 & 0.007213 & +0.031767 & 0.185455 & -0.003880 \\
\hline 4a & 1 & 0.332634 & -0.425260 & 0.061071 & -0.447541 \\
\cline { 2 - 6 } & 2 & 0.317145 & -0.459943 & 0.075608 & -0.393040 \\
\cline { 2 - 6 } & 3 & 0.300943 & -0.536991 & 0.075987 & -0.730127 \\
\hline
\end{tabular}

Figura 4. 16. Representação das estruturas do 1- Nitropropano com seus pontos críticos de ligação (BCP) e tabela com os respectivos valores; densidade $(\rho)$, laplaciana de densidade $\left(\nabla^{2} \rho\right)$, eliplicidade $(\varepsilon)$ e potencial químico $(\mathrm{V})$. 


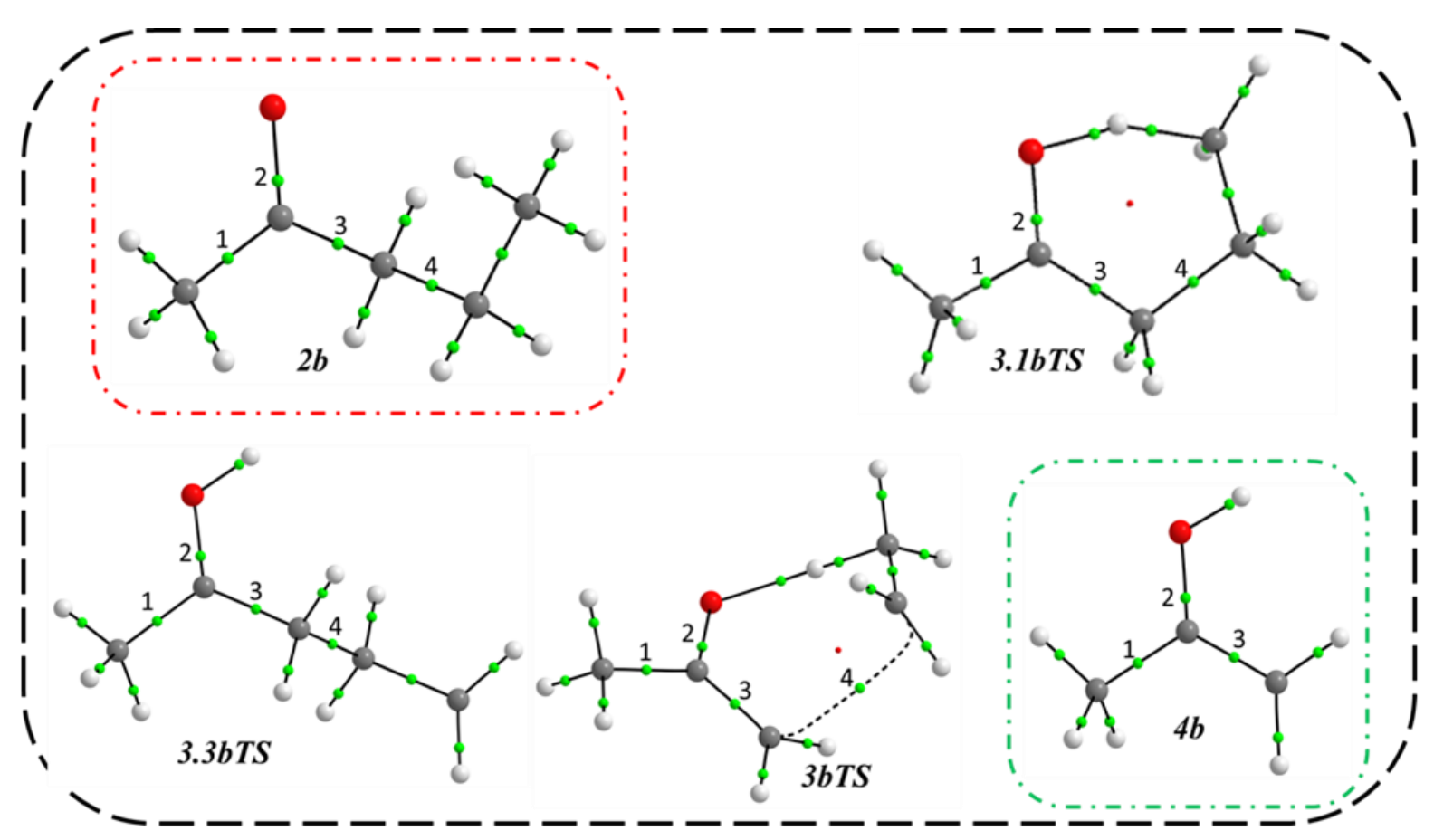

\begin{tabular}{|c|c|c|c|c|c|}
\hline Sistema & $\mathbf{B C P}$ & $\boldsymbol{\rho}$ & $\boldsymbol{\nabla}^{\mathbf{}} \boldsymbol{\rho}$ & $\boldsymbol{\varepsilon}$ & $\mathbf{V}$ \\
\hline \multirow{3}{*}{$\mathbf{2 b}$} & 1 & 0.238944 & -0.577972 & 0.001360 & -0.255498 \\
\cline { 2 - 6 } & 2 & 0.328635 & -0.288671 & 0.090322 & -0.925607 \\
\cline { 2 - 6 } & 3 & 0.235454 & -0.552103 & 0.007093 & -0.250267 \\
\cline { 2 - 6 } & 4 & 0.225537 & -0.475418 & 0.007830 & -0.211997 \\
\hline \multirow{3}{3.1bTS}{} & 1 & 0.242043 & -0.590029 & 0.005523 & -0.248458 \\
\cline { 2 - 6 } & 2 & 0.338750 & -0.232588 & 0.020779 & -0.979041 \\
\cline { 2 - 6 } & 3 & 0.237084 & -0.555002 & 0.011533 & -0.233914 \\
\cline { 2 - 6 } & 4 & 0.233038 & -0.508800 & 0.015243 & -0.218808 \\
\hline 3.3bTS & 1 & 0.245712 & -0.610616 & 0.005007 & -0.254391 \\
\cline { 2 - 6 } & 2 & 0.324201 & -0.205957 & 0.100221 & -0.920673 \\
\cline { 2 - 6 } & 3 & 0.243274 & -0.593538 & 0.003285 & -0.248831 \\
\cline { 2 - 6 } & 4 & 0.222740 & -0.456547 & 0.019849 & -0.203481 \\
\hline \multirow{3}{3}{ 3bTS } & 1 & 0.240522 & -0.573676 & 0.018651 & -0.242150 \\
\cline { 2 - 6 } & 2 & 0.295552 & -0.676263 & 0.138112 & -0.669764 \\
\cline { 2 - 6 } & 3 & 0.303301 & -0.874640 & 0.161206 & -0.380248 \\
\cline { 2 - 6 } & 4 & 0.010300 & +0.048486 & 0.642447 & -0.008864 \\
\hline \multirow{4}{*}{ 4b } & 1 & 0.242556 & -0.588779 & 0.008986 & -0.251379 \\
\cline { 2 - 6 } & 2 & 0.321305 & -0.381231 & 0.120922 & -0.869530 \\
\cline { 2 - 6 } & 3 & 0.278499 & -0.726752 & 0.118605 & -0.318855 \\
\hline
\end{tabular}

Figura 4. 17. Representação das estruturas do 2- Pentanona com seus pontos críticos de ligação (BCP) e tabela com os respectivos valores; densidade $(\rho)$, laplaciana de densidade $\left(\nabla^{2} \rho\right)$, eliplicidade $(\varepsilon)$ e potencial químico $(\mathrm{V})$. 


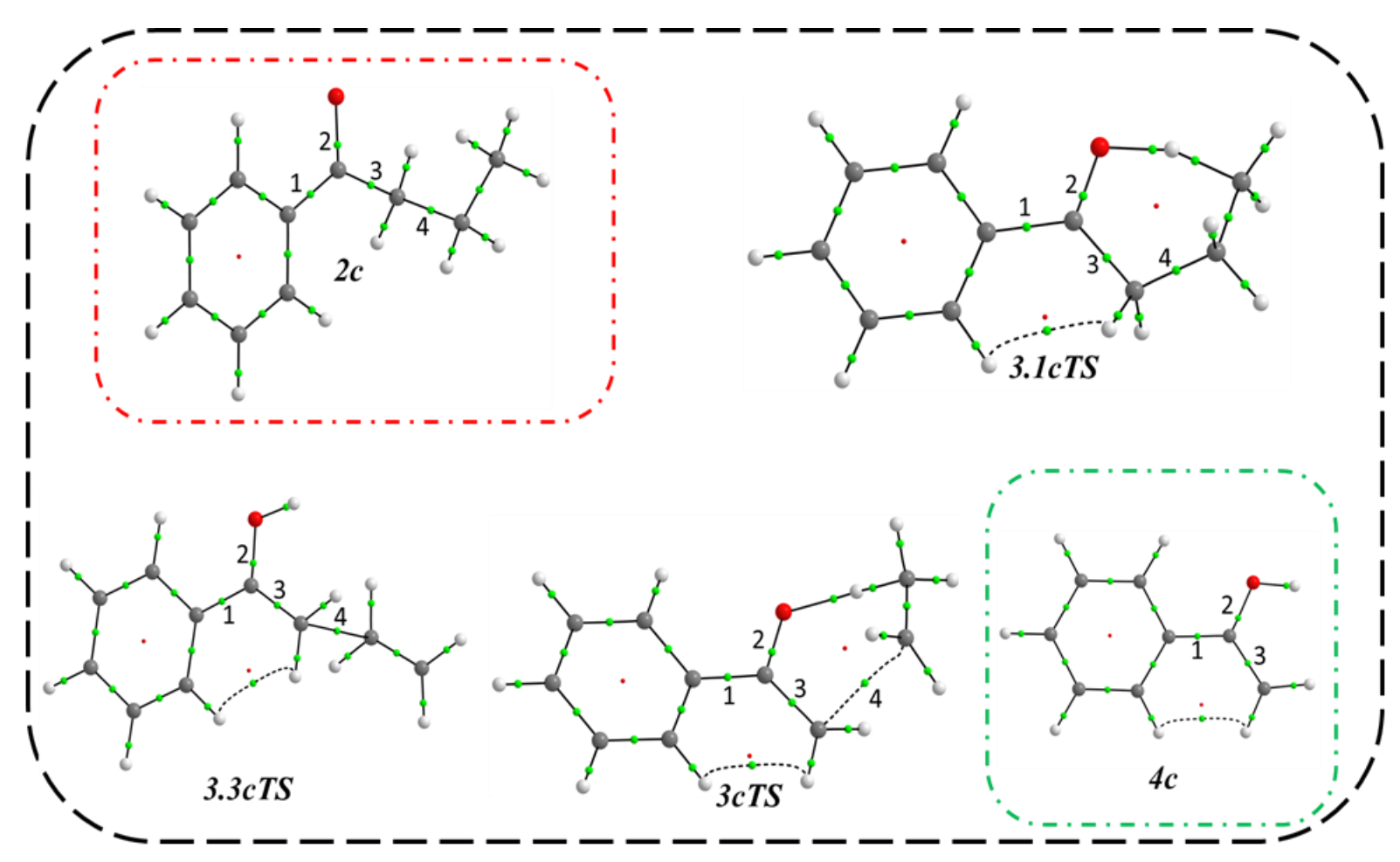

\begin{tabular}{|c|c|c|c|c|c|}
\hline Sistema & $\mathbf{B C P}$ & $\boldsymbol{\rho}$ & $\boldsymbol{\nabla}^{\mathbf{}} \boldsymbol{\rho}$ & $\boldsymbol{\varepsilon}$ & $\mathbf{V}$ \\
\hline \multirow{3}{*}{$\mathbf{c}$} & 1 & 0.277785 & -0.715088 & 0.174302 & -0.362938 \\
\cline { 2 - 6 } & 2 & 0.313890 & -0.402938 & 0.141982 & -0.834591 \\
\cline { 2 - 6 } & 3 & 0.227093 & -0.481124 & 0.025856 & -0.255396 \\
\cline { 2 - 6 } & 4 & 0.219818 & -0.441167 & 0.009193 & -0.221117 \\
\hline \multirow{3}{3.1cTS}{} & 1 & 0.274510 & -0.701775 & 0.158909 & -0.337707 \\
\cline { 2 - 6 } & 2 & 0.328890 & -0.365425 & 0.099281 & -0.909848 \\
\cline { 2 - 6 } & 3 & 0.235287 & -0.518375 & 0.043290 & -0.247595 \\
\cline { 2 - 6 } & 4 & 0.229622 & -0.485395 & 0.016958 & -0.229542 \\
\hline \multirow{3}{3.3cTS}{} & 1 & 0.281385 & -0.745374 & 0.154148 & -0.344211 \\
\cline { 2 - 6 } & 2 & 0.308401 & -0.328768 & 0.054930 & -0.829015 \\
\cline { 2 - 6 } & 3 & 0.271651 & -0.651337 & 0.157741 & -0.320692 \\
\cline { 2 - 6 } & 4 & 0.025538 & +0.049370 & 0.099810 & -0.013364 \\
\hline \multirow{3}{3}{ CTS } & 1 & 0.270285 & -0.687199 & 0.125523 & -0.309702 \\
\cline { 2 - 6 } & 2 & 0.296488 & -0.688333 & 0.032522 & -0.637222 \\
\cline { 2 - 6 } & 3 & 0.296280 & -0.809081 & 0.124074 & -0.373479 \\
\cline { 2 - 6 } & 4 & 0.020654 & +0.044435 & 0.332780 & -0.010337 \\
\hline \multirow{4}{4c}{} & 1 & 0.281916 & -0.744429 & 0.156149 & -0.341444 \\
\cline { 2 - 6 } & 2 & 0.307603 & -0.372626 & 0.043914 & -0.813896 \\
\cline { 2 - 6 } & 3 & 0.277219 & -0.684979 & 0.146982 & -0.331907 \\
\hline
\end{tabular}

Figura 4. 18. Representação das estruturas da Butirofenona com seus pontos críticos de ligação (BCP) e tabela com os respectivos valores; densidade $(\rho)$, laplaciana de densidade $\left(\nabla^{2} \rho\right)$, eliplicidade $(\varepsilon)$ e potencial químico $(\mathrm{V})$. 
Relativo ao processo de estabilização de radical no passo 2 , verifica-se que o passo $2 \mathbf{c}$ é o que apresenta maior estabilidade eletrônica relativa. Esta observação pode ser feita pela análise dos pontos críticos 1,2 e 3 . No sistema $2 \mathbf{c}$, observa-se que $\nabla^{2} \rho<0$, indicando uma ligação de natureza covalente, cuja a magnitude é superior quando comparando com os sistemas $2 \mathbf{a}$ e $2 \mathbf{b}$ sobre o mesmo BCP. Este efeito evidencia o papel deslocalizador do fragmento fenil, presente na butirofenona. Ainda sobre este mesmo passo, pode-se verificar o aumento relativo da elipticidade e densidade de energia potencial, o que corrobora as observações anteriores.

Ainda no passo 2, verificamos que o BCP3 para 2a apresenta características de interação covalente fraca $\left(\nabla^{2} \rho \sim 0,1\right)$ relativo ao mesmo ponto crítico em $2 \mathbf{b}$ e $2 \mathbf{c}$. Nota-se a diferença devido à natureza do grupo $-\mathrm{NO}_{2}$ presente em $2 \mathbf{a}$, que proporciona forte polarização da ligação $\mathrm{N}-\mathrm{C}$.

$\mathrm{Na}$ descrição topológica do rearranjo concertado, os BCP's 2 e 3 são os principais índices de facilitação da fragmentação; partindo desta ideia central, verifica-se que para os sistemas $\mathbf{2 b}$ e $\mathbf{2 c}$, que apresentam maiores energias de ativação para o rearranjo concertado. Os pontos 2 e 3 apresentam características topológicas de ligações covalentes mais fortes do que as apresentadas para estes mesmos pontos no sistema 2a.

$\mathrm{Na}$ descrição do mecanismo de fragmentação em etapas, é necessário considerar dois estados de transição: os passos 3.1TS e 3.3TS. Nota-se que para o BCP2, as propriedades topológicas indicam força da interação covalente na ordem 3.1aTS > 3.1cTS > 3.1bTS; esta ordem descreve a natureza da covalência nas ligações representadas pelo BCP2, ou seja, está relacionada com a densidade de energia potencial (V) e da laplaciana $\left(\nabla^{2} \rho\right)$.

Neste estudo topológico, são expostas informações que evidenciam a deslocalização eletrônica envolvendo o fragmento $\mathrm{C}=\mathrm{O}$ e fenil do composto $\mathbf{b}$ através do sistema 3.1bTS. $\mathrm{O}$ passo 3.3TS pode ser, por sua vez acompanhado pelos pontos 3 e 4, cuja tendência geral de distribuição de densidade eletrônica indica a medida que 3 aumenta, 4 diminui. Analisando o ponto crítico 3, para o passo 3.3TS, a ordem decrescente de $\nabla^{2} \rho$ é 3.3cTS $>3.3 \mathrm{bTS}>3.3 \mathrm{aTS}$. Neste estado de transição, a presença do gripo fenil é o responsável pela deslocalização eletrônica; tal deslocalização promove o aumento do caráter covalente da região descrita pelo BCP3.

Aqui os sistemas 4b, 4c e 4a servirão apenas como critério relativo. 
Para a descrição multicêntrica do rearranjo, em última análise, foram determinados os índices tricêntricos e dicêntricos para os estados de transição do mecanismo direto (3TS) e em etapas de (primeiro passo, 3.1TS). Os dados foram compilados na Tabela 4.2.

Tabela 4. 2. Índices multicêntricos relativos aos estados de transição dos sistemas 1-nitropropano (a), 2-pentanona (b) e butirofenona (c).

\begin{tabular}{|c|c|c|c|}
\hline TS & $\mathrm{I}_{\mathrm{CHO}}$ & $\mathrm{I}_{\mathrm{CH}}$ & $\mathrm{I}_{\mathrm{HO}}$ \\
\hline 3aTS & $-0,008$ & 0,311 & 0,090 \\
\hline 3.1aTS & 0,009 & 0,209 & 0,263 \\
\hline 3bTS & $-0,005$ & 0,285 & 0,133 \\
\hline 3.1bTS & 0,004 & 0,208 & 0,252 \\
\hline 3cTS & $-0,005$ & 0,311 & 0,105 \\
\hline 3.1cTS & 0,004 & 0,208 & 0,252 \\
\hline
\end{tabular}

De acordo com o formalismo dos índices multicêntricos, o sinal negativo designa interação entre grupos não ligados. Dessa forma, podemos interpretar o rearranjo por via direta, McLafferty clássico, com como eletronicamente inviável, visto que para todos os rearranjos clássicos os índices são negativos.

Outra forma de corroborar esta conclusão é fazendo a análise dos índices dicêntricos, C-H e O-H dos estados de transição 3.1aTS ,3.1bTS, 3.1cTS. Nesta análise dicêntrica, verificamos que o comportamento eletrônico destas ligações para os sistemas b e c apresentam semelhanças extremas, em ambos os sistemas as ligações $\mathrm{O}-\mathrm{H}$ são fortes quando comparados com as ligações C-H. Quando comparamos este comportamento para os estados de transição 3aTS, 3bTS e 3cTS, a ordem apresentada de força de ligação dicêntrica é inversa. Como visto anteriormente, a análise do mecanismo de fragmentação indica favorecimento cinético, eletrônico e termodinâmico do rearranjo passo a passo, assim podemos concluir que através da análise dicêntrica e tricêntrica o mecanismo clássico do tipo McLafferty é pouco provável. 


\section{Capítulo 5. Conclusões}

Neste trabalho foi verificado que o rearranjo do tipo McLafferty em etapas se mostrou um rearranjo, cinética, eletrônica e termodinamicamente favorecido eletronicamente para todos os sistemas estudados, independentemente da natureza do grupo químico associado. Esta observação pode ser comprovada por análises QTAIM, NBO, por índices multicêntricos e análise de densidade de spin. Ao mesmo tempo, verifica-se que o referido rearranjo é cinética e termodinamicamente favorecido. Com isso, foi possível obter uma descrição teórica dos possíveis caminhos de fragmentação (concertado ou em etapas) referente ao rearranjo do tipo McLafferty e identificar os mais favoráveis.

Do ponto de vista cinético e termodinâmico, foi verificado que a ordem crescente de favorecimento de rearranjo McLafferty clássico é $c<b<a$, a ordem crescente de velocidade para o rearranjo em etapas é $\mathrm{a}<\mathrm{c} \approx \mathrm{b}$

Topologicamente o sistema $2 \mathbf{c}$ apresenta maior estabilidade eletrônica relativa, devido ao papel de deslocalizador do fragmento fenil, seguido do sistema b e do sistema a. Esta estabilidade se reflete na própria energia demandada para a ionização dos sistemas analisados neste trabalho. Dessa forma, a análise topológica mostra que os íons eletronicamente mais estáveis são aqueles cujas gerações necessitam de menos energia para a sua geração .

Através do formalismo dos índices multicêntricos, também foi comprovado que o rearranjo por via direta é pouco provável, visto que durante o estabelecimento dos respectivos estados de transição para rearranjo direto, os índices tricêntricos envolvendo os principais fragmentos é de natureza negativa, indicando que estes fragmentos são não ligados no estado de transição. 


\section{ANEXO}

\section{A.1 - Proposta de Mecanismo Completo de Fragmentação da Butirofenona}

No estudo de Osterheld e Brauman ${ }^{23 b}$ acerca da fragmentação da butirofenona foi identificado experimentalmente a formação dos intermediários descritos na Figura A.1. Neste estudo os autores propõem três caminhos de reação para obtenção destes produtos, entretanto esses mecanismos estão incompletos e não descrevem em totalidade a formação dos produtos. Neste trabalho foi explorado o rearranjo do tipo McLafferty para três sistemas distintos a, b, c como descrito, toda via como foi identificado que o mecanismo de fragmentação da butirofenona apresenta produtos diferentes daqueles produzidos pela rota mecanística que passa pelo rearranjo do tipo McLafferty (caminho 3), realizamos um estudo completo dos três mecanismos possíveis para a fragmentação da butirofenona (caminho 1, 2 e 3) levando a uma proposta mecanística completa justificada teoricamente.

O mecanismo de fragmentação da Butirofenona foi estudado usando duas estratégias; na primeira delas, foi aplicado a metodologia CBS-4M (Complete Basis Set), do qual, foram obtidas as optimizações das geometrias de estados de transição e repouso descritos pela fragmentação. E para a segunda, foram realizados cálculos de otimização com a metodologia UHF e base atômica LanL2MB e, em seguida, correção termoquímica com o método baseado na DFT, através do funcional híbrido M06 e com base atômica 6-311+G(d,p). Para a descrição do complexo de van der Walls foi realizado um cálculo de coordenada intrínseca de reação (IRC) com a combinação $\omega B 97 \times D / 6-31+G(d, p)$. Todos os cálculos de optimização de geometria para a obtenção de dados energéticos e de estrutura eletrônica foram realizados através do pacote Gaussian $09^{45}$. A exposição gráfica do IRC foi realizada através do programa ChemCraft ${ }^{47}$.

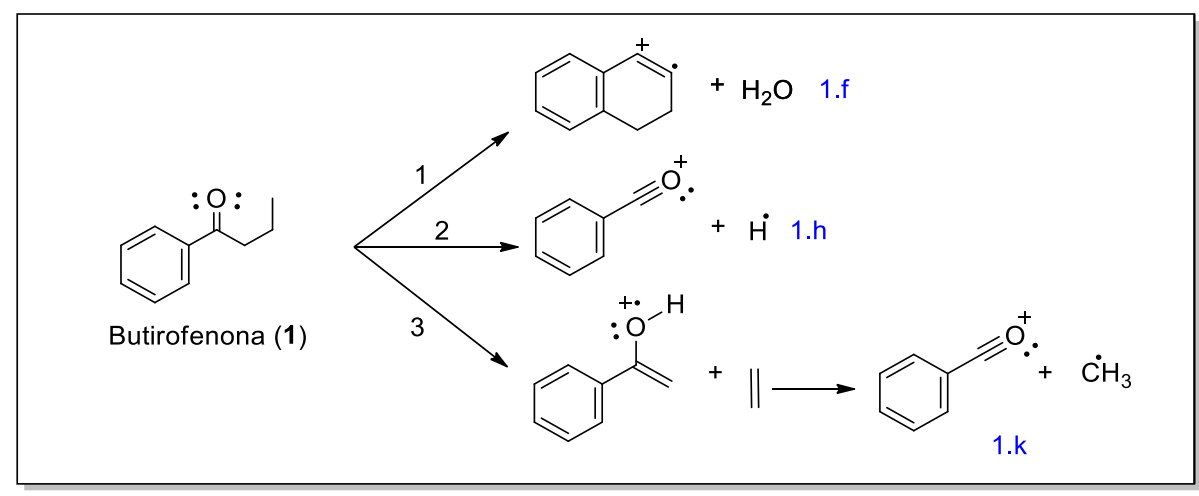

Figura A. 1. Representação do sistema butirofenona com seus respectivos produtos de fragmentação. (Fonte: Adaptado da ref. 44) 
O primeiro caminho de fragmentação a ser analisado será o caminho 1 de fragmentação da butirofenona, como mostra a Figura A.2, baseado em um sistema "em etapas" que ocorre da seguinte forma: inicialmente ocorre a ionização da butirofenona (1) levando a formação do cátion radical 1.RAD.a, esta nova estrutura sofre um rearranjo transferindo o hidrogênio- $\gamma$ para o átomo de oxigênio do grupo carbonila através do estado de transição TS.1.a-b, que resulta na geração do grupo $\mathrm{OH}$ e da localização do radical sobre o carbono- $\gamma$, como descrito pela estrutura 1.b; este sistema é um rotâmero de 1.c; este último possibilita a interação entre o radical e o par de elétrons existentes no anel, passando então por um novo estado de transição TS.1.c-d, conduzindo ao sistema 1.d; a estrutura 1.d rearranja-se através do estado de transição TS.1.de, localizando o radical sobre o grupo $\mathrm{OH}$ que, ao se rearranjar (via TS.1.e-f) chegando na sua forma mais estável 1.f.

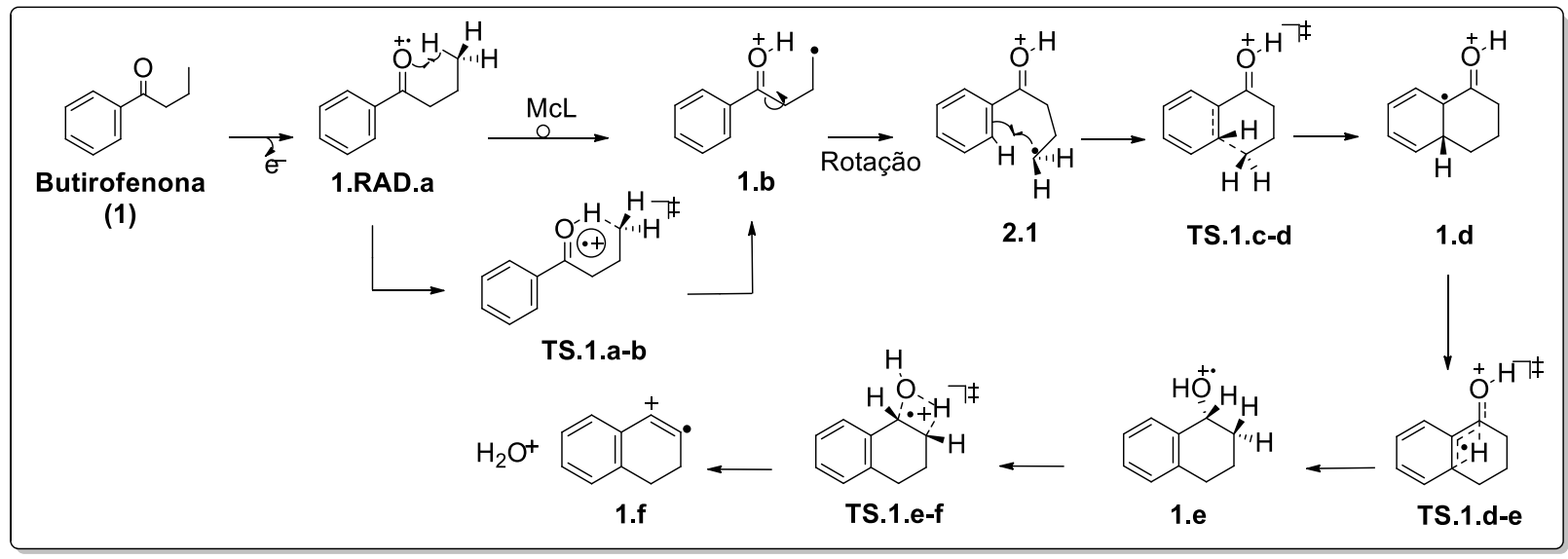

Figura A. 2. Coordenada de fragmentação caminho 1.

Já no caminho 2, temos outra proposta de mecanismo de fragmentação descrita na Figura A.3.

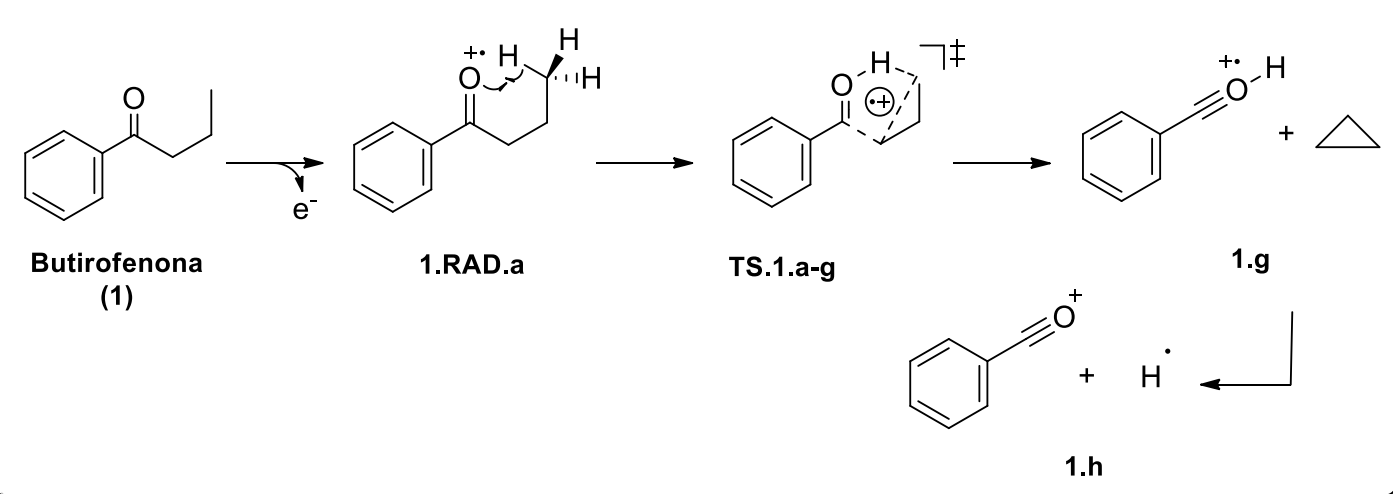

Figura A. 3. Coordenada de fragmentação caminho 2. 
Para justificar a formação do produto 1.h, apresentamos o seguinte mecanismo, onde os primeiros passos ocorrem da mesma forma que no caminho 1, diferenciando-se a partir do estado de transição observado, TS.1.a-g, que ocorre logo em seguida a estrutura 1.RAD.a. Neste passo, o hidrogênio- $\gamma$ é transferido para o grupo do oxigênio da carbonila, formando a ligação do grupo $\mathrm{OH}$; porém o estado de transição indica também uma quebra de ligação, liberando um ciclopropano e um novo cátion radical, 1.g, e por fim, formando a estrutura 1.h, no qual observa-se a liberação do hidrogênio radical do composto, deixando a estrutura no estado mais estável. Nota-se que para o mecanismo percorrer este caminho, ele deverá ocorrer de forma concertada.

No caminho 3, já temos uma nova proposta de mecanismos de fragmentação conforme a Figura A.4.

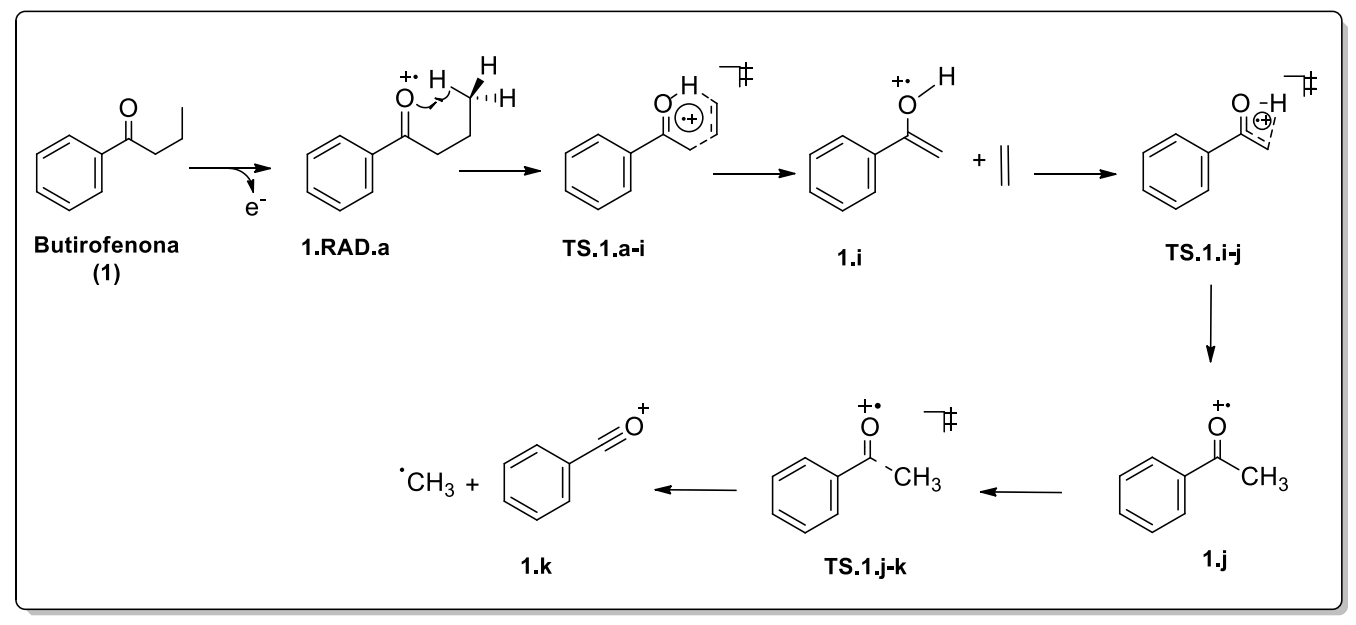

Figura A. 4. Coordenada de fragmentação caminho 3.

Nesta proposta de mecanismo concertado, Figura A.4, temos o primeiro passo iniciando pela abstração do elétron, seguido de um estado de transição concertado (TS.1.a-i), em que ocorre, simultaneamente, a transferência de hidrogênio- $\gamma$ para o sitio radical e a geração de uma olefina neutra (1.i). Após este passo, outro estado de transição é estabelecido (TS.1.i-j), dando origem ao cátion radical 1.j. Em seguida, devido a estrutura $\mathbf{1 . j}$ não se encontrar na forma mais estável, há a liberação de um hidrogênio, passando pelo estado de transição TS.1.j-k. Por fim, ocorre a quebra da ligação entre o carbono da carbonila e o carbono da metila, formando o produto mais estável deste possível mecanismo, 1.k.

Para a descrição cinética e termodinâmica deste sistema, foi aplicado outra metodologia, CBS-4M, no qual foi possível obter duas coordenadas de fragmentação, descritas a seguir nas figuras abaixo. 
A coordenada de reação da Figura A.5 corresponde a formação do mecanismo de fragmentação do caminho 1. Para abstração inicial do elétron da butirofenona foi constatada uma barreira energética de aproximadamente 215,63 kcal/mol. Ou seja, pode-se observar novamente, como no sistema 1, que este processo também demanda muita energia. A partir da formação do sistema catiônico, 1.RAD.a, este sofre um rearranjo do tipo McLafferty e será convertido na estrutura 1.b, passando por estado de transição TS.1.a-b de barreira energética negativa de $-5,83 \mathrm{kcal} / \mathrm{mol}$, indicando a possível existência de um complexo de van der Waals que antecede o estado de transição, com mais baixa energia. Em seguida, o sistema passou por uma barreira energética de rotação de aproximadamente $2,13 \mathrm{kcal} / \mathrm{mol}$, possibilitando passar por um novo rearranjo, no qual tem-se outro estado de transição TS.1.c-d de barreira energética de 3,42 kcal/mol formando a estrutura 1.d. A partir desta estrutura, o sistema passa por um novo estado de transição TS.1.d-e, com barreira energética de 48,76 kcal/mol, levando a formação da estrutura 1.e, no qual o radical está localizado na hidroxila. Nota-se, que esta parte do processo exige uma alta barreira energética de ativação, que se deve a dificuldade proporcionada pela angulação da estrutura. Continuando o processo, a estrutura passa por um novo estado de transição TS.1.e-f, de barreira energética de aproximadamente 16,62kcal/mol, a segunda maior barreira do processo devido angulação do sistema, formando o produto final mais estável, em relação ao cátion radical inicial, com estabilização de $-44,75 \mathrm{kcal} / \mathrm{mol}$.

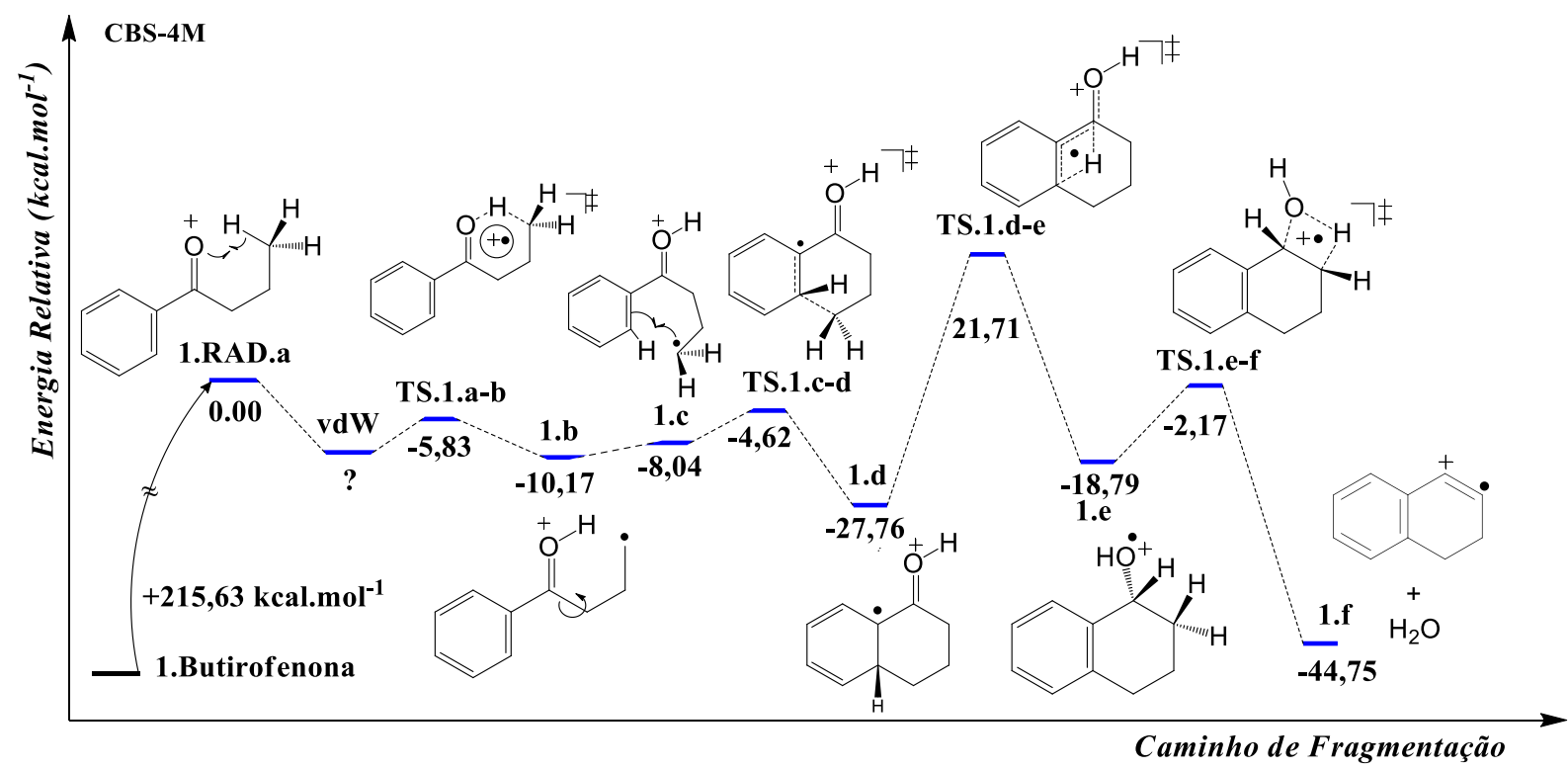

Figura A. 5. Coordenada de fragmentação caminho 1

Para a verificação da magnitude da barreira de ativação relativa ao rearranjo anteriormente descrito, foi realizado um cálculo de coordenada intrínseca de reação (IRC) com a combinação $\omega B 97 \times \mathrm{x} / 6-31+\mathrm{G}(\mathrm{d}, \mathrm{p})$, partindo-se de um estado de transição previamente 
optimizado com este mesmo método. Com isso, foi observado que o rearranjo ocorre através de uma barreira da ordem de $+2,2 \mathrm{kcal} \mathrm{mol}^{-1}$, como descrito na Figura A.6. Dessa forma verifica-se que a barreira energética do referido rearranjo apresenta magnitude maior que zero, indicando que esse rearranjo é antecedido por um complexo do tipo van der Waals.

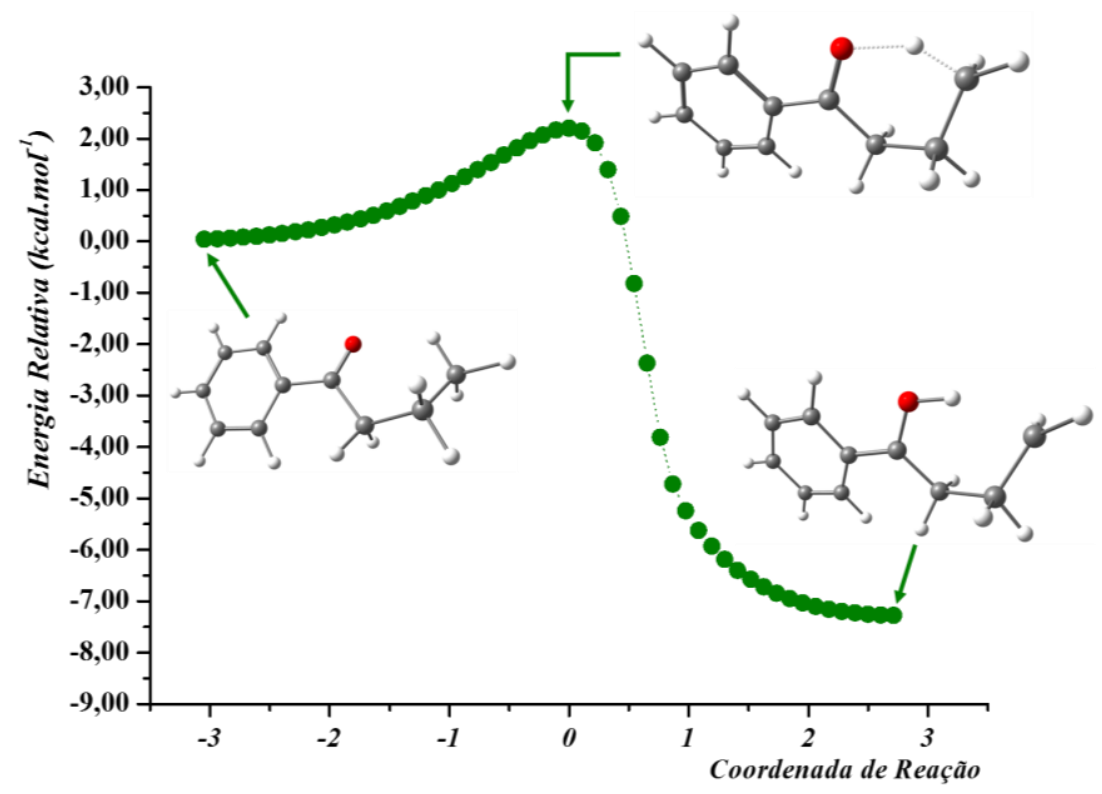

Figura A. 6. Coordenada Intrínseca de Reação (IRC) para a transferência de hidrogênio radicalar no caminho 1 a partir do TS.1.a-b.

Ao realizar a mesma análise para o caminho 2 de fragmentação da butirofenona, mecanismo concertado, que passa por um respectivo estado de transição TS.1.a-g, verificou-se que a metodologia utilizada não conseguiu descrever a energética do sistema, devido à não convergência da estrutura TS.1.a-g. Numa tentativa de encontrar a geometria de equilíbrio para o estado de transição, outras métodos computacionais foram aplicados (tal como o CBS-Lq), não houve convergência para a estrutura TS.1.a-g. Ao mesmo tempo, observa-se que para os passos 1.h e 1.k conduzem ao mesmo cátion, diferenciando-se apenas pela presença dos radicais $\mathrm{H}^{*}$ ou $\mathrm{CH}_{3}{ }^{\circ}$, respectivamente. Com isso, podemos justificar a formação desta estrutura 1.h, no caminho 2 através do mecanismo proposto no caminho 3.

Finalmente, analisando, o caminho 3 de fragmentação da butirofenona (Figura A.7), o mecanismo parte do mesmo cátion radical 1.RAD.a. Em seguida, o sistema passa por outro estado de transição TS.1.a-i, no qual, converte-se na estrutura 1.i. Porém, como este passo também corresponde a um mecanismo concertado, o método não conseguiu descrever a barreira 
energética envolvida, devido a não convergência da estrutura TS.1.a-i, assim como para o caminho 2. Como os passos seguintes foram identificados experimentalmente, considera-se que a estrutura 1.i passa por outro rearranjo, de barreira extremamente energética, de valor aproximadamente 42,37 kcal/mol, convertendo-se na estrutura TS.1.i-j, formando o novo cátion radical 1.j. Em seguida, o sistema passa por um estado de transição TS.1.j-k, onde ocorre o novo posicionamento do cátion radical e em seguida a quebra da ligação entre o carbono da carbonila e o carbono da metila, com uma barreira energética de aproximadamente 9,29 $\mathrm{kcal} / \mathrm{mol}$, proporcionando, com isso, o produto final desta fragmentação, 1.k.

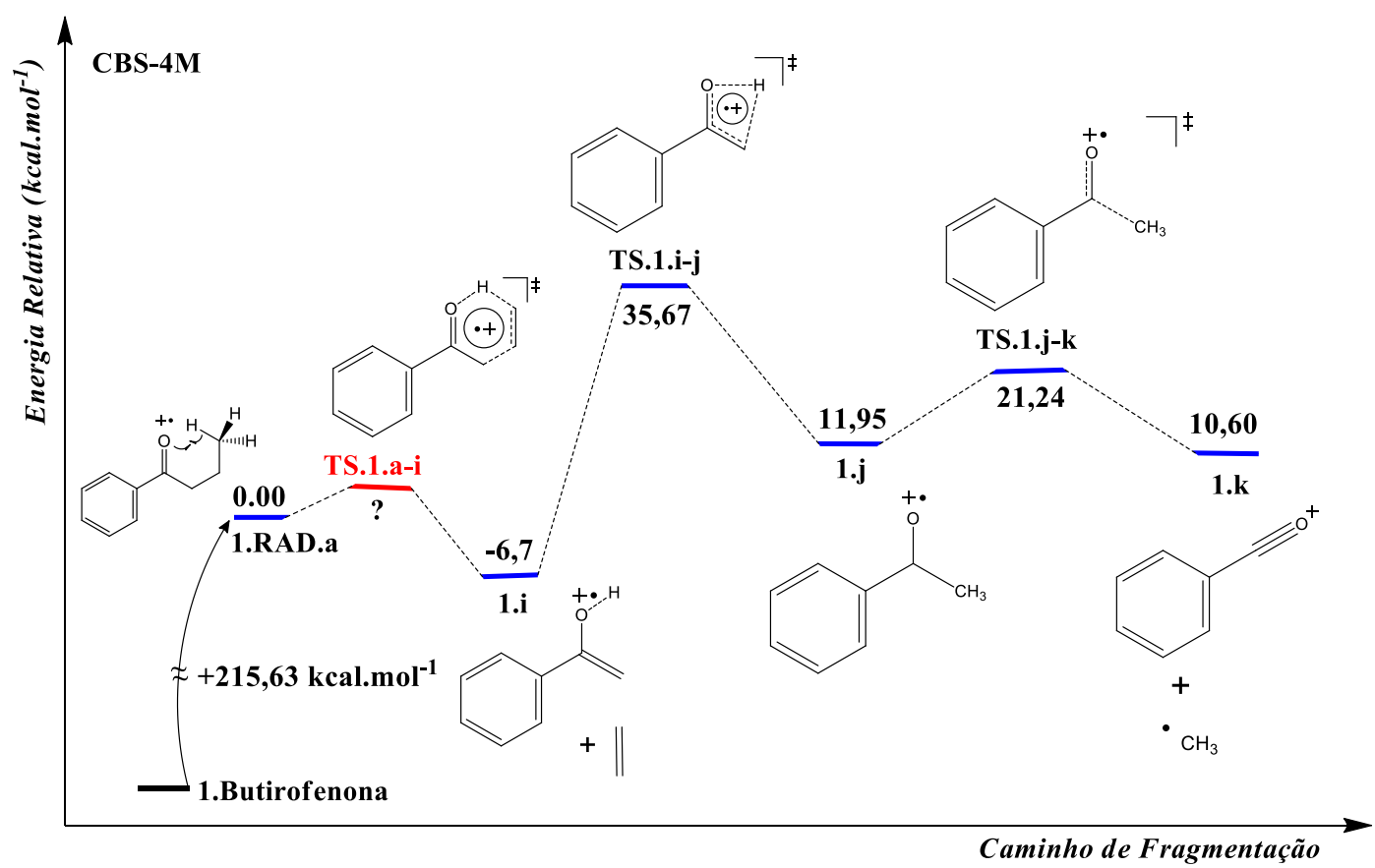

Figura A. 7. Coordenada de fragmentação caminho 3.

Fazendo uma comparação entre os perfis termodinâmicos das três possibilidades de sistemas propostas, pode-se dizer que o caminho 1 é mais favorável termodinamicamente do que o caminho 3, devido a energia do produto 1.g ser menor do que a energia do produto $\mathbf{1 . k}$ em relação ao mesmo ponto de partida, 1.RAD.a. Porém, a análise cinética dos caminhos 1 e 3 mostra que o perfil cinético do caminho 3 é mais favorável de ocorrer devido a maior barreira energética do caminho de fragmentação 3 (TS.1.i-j) ser menor em relação a maior barreira energética (TS.1.d-e) do caminho de fragmentação 1.

Como foi observado no caminho 3, o estado de transição TS.1.a-i, correspondente ao mecanismo concertado, não foi possível ser descrito com a metodologia CBS-4M. De forma que para explicação da formação do produto 1.i, foi realizada uma nova proposta de mecanismo de em etapas descrito na Figura A.8: 


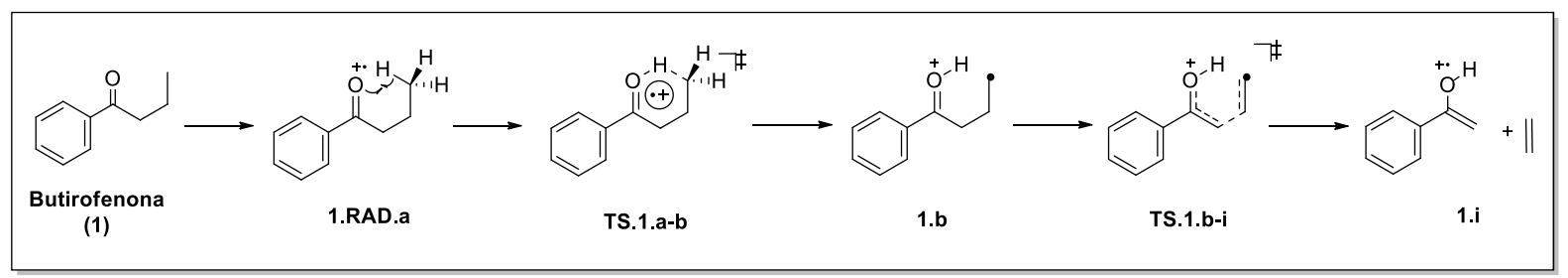

Figura A. 8. Proposta alternativa de coordenada de reação

Neste mecanismo partirmos da estrutura do cátion radical, 1.RAD.a, o sistema passa pelo estado de transição TS.1.a-b convertendo-se na estrutura 1.b, conforme ocorre no caminho 1. Porém, em seguida, passa por outro estado de transição TS.1.b-i , formando na estrutura 1.i.

Objetivando uma análise cinética e termodinâmica para uma possível comparação entre as barreiras energéticas envolvidas no caminho 3 e o novo mecanismo proposto, foram realizados cálculos de otimização com a metodologia UHF e base atômica LanL2MB e, em seguida, correção termoquímica com o método baseado na DFT, através do funcional híbrido M06 e com base atômica 6-311+G(d,p).

Como resultado temos que para o mecanismo concertado, este método conseguiu descrever a barreira energética envolvida durante o rearranjo do tipo McLafferty, pois ele conseguiu convergir a estrutura para a geometria requerida. Com ambos os caminhos de fragmentações determinados, podemos agora fazer uma comparação (Figura A.9) onde mostramos que a energética envolvida no sistema em etapas é bem mais favorável de ocorrer do que o processo concertado.

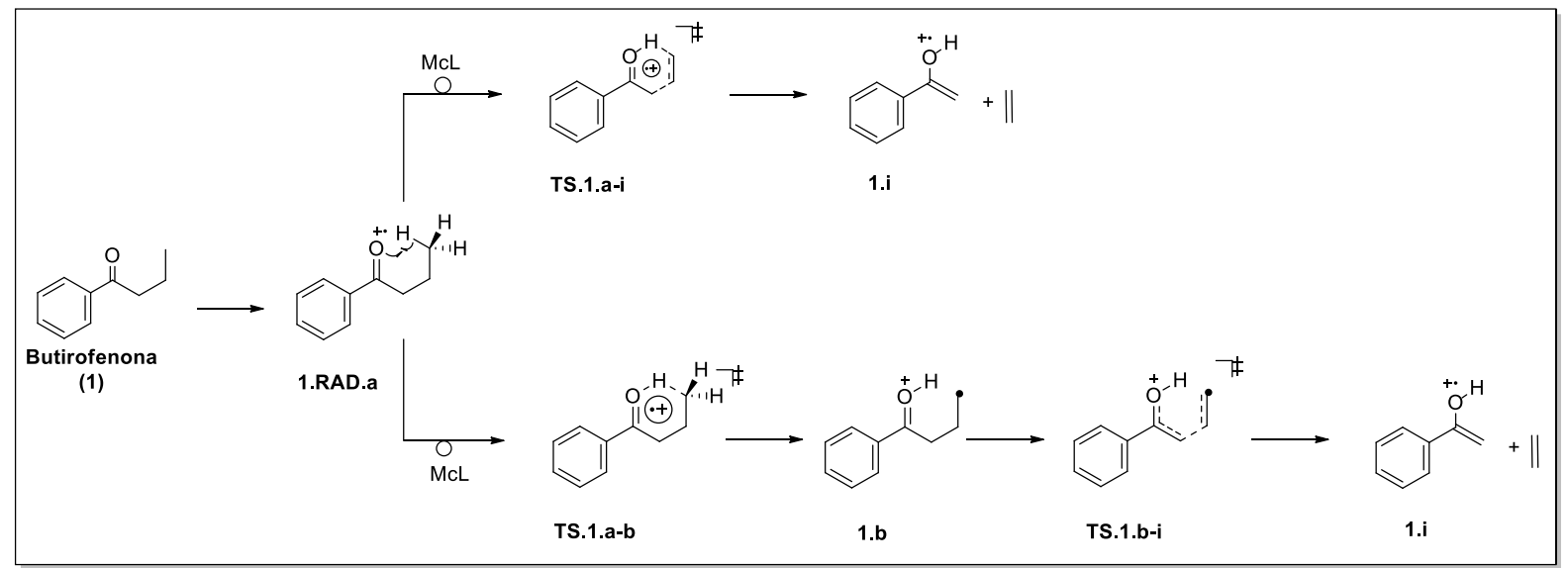

Figura A. 9. Proposta alternativa de coordenada de fragmentação - Caminho de fragmentação concertado e "em etapas".

Pode-se observar que no sistema concertado, a barreira energética envolvida é de aproximadamente $35,47 \mathrm{kcal} / \mathrm{mol}$ para converter o 1.RAD.a na estrutura 1.i. Já analisando o 
mecanismo em etapas, a maior barreira energética do sistema é menor que $10 \mathrm{kcal} / \mathrm{mol}$, como pode ser observado na Figura A.10.

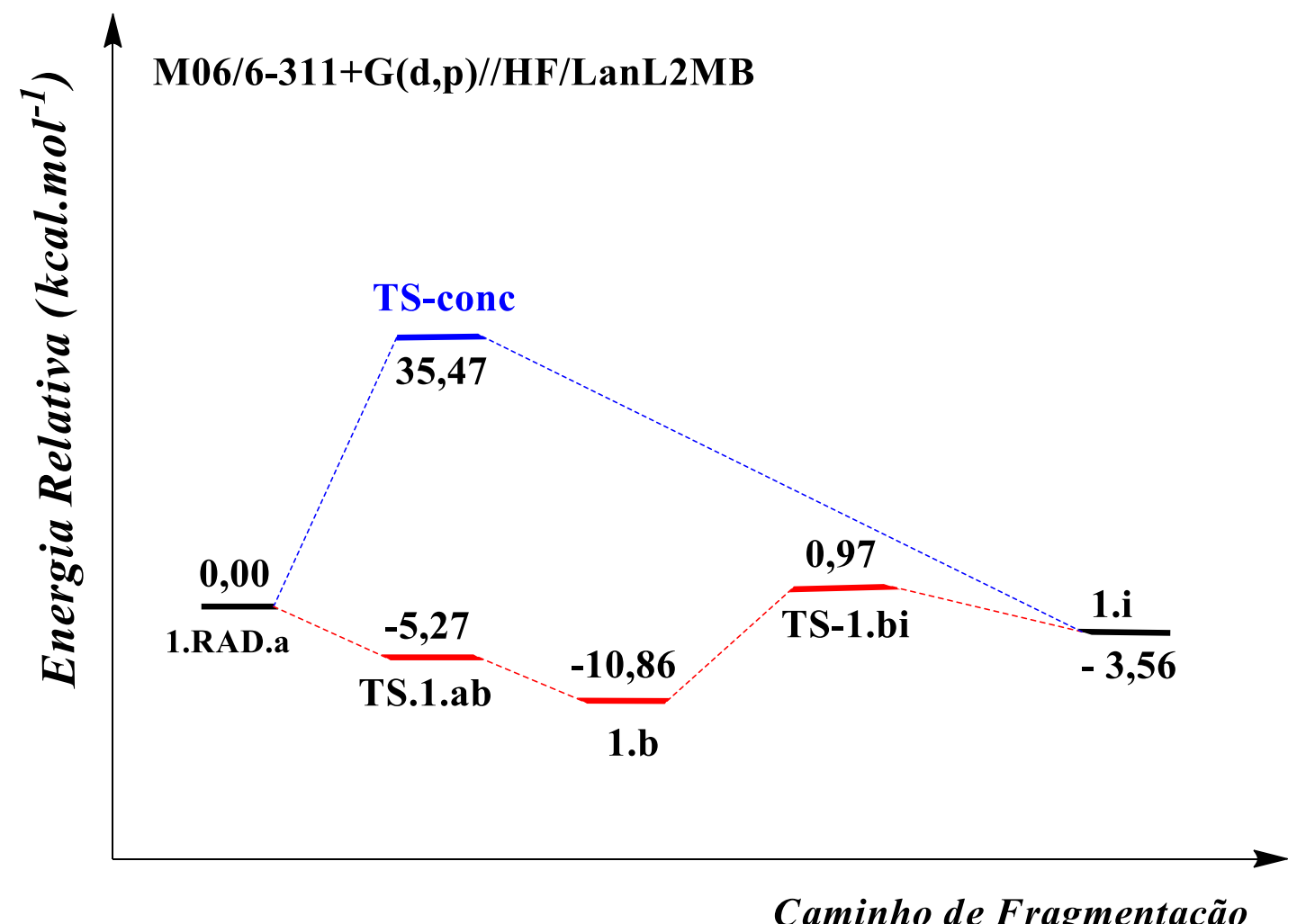

Figura A. 10. Coordenada de fragmentação - Proposta alternativa de coordenada de fragmentação Caminho de fragmentação concertado e "em etapas".

Através da análise da coordenada de reação da Figura A.10 fica claro que o mecanismo em etapas é expressivamente favorecido em relação ao concertado assim como constatado anteriormente. Evidenciando que embora necessite passar por mais etapas o rearranjo deverá ocorrer através de um mecanismo que demande menor energia e apresente estruturas que com possibilidades de estabilização dos intermediários formados ao longo do caminho de fragmentação. Contudo o mecanismo concertado não pode ser negligenciado pois em condições extremas e em temperaturas elevadas o estado de transição concertado pode ser acessado. Porém nas condições normais de análise, o rearranjo deverá ocorrer pelo mecanismo em etapas.

\section{A.2 - Proposta de Mecanismo Completo de Fragmentação do 1-Nitropropano}

O mecanismo de fragmentação do 1-nitropropano também apresenta mais de um caminho de fragmentação, o qual foi proposto experimentalmente por Nibbering e colaboradores $^{23 a}$. Neste trabalho foi descrito o mecanismo teórico do rearranjo de McLafferty 
para a fragmentação do 1-nitropropano corroborando as observações experimentais, entretanto um segundo caminho possível de fragmentação descrito experimentalmente não foi exposto ao longo do trabalho, de modo que neste anexo será exposta a proposta mecanística teórica completa para a fragmentação do 1-nitropropano para corroborar os resultados experimentais observados por Nibbering. Aqui, será tomado como ponto de partida o mecanismo de fragmentação, via rearranjo de McLafferty (de b para c) do 1-nitropropano $\left(\mathrm{PrNO}_{2}\right)$, descrito na Figura A.11.

Para a realização do estudo de fragmentação do1-nitropropano foi aplicado o método CBS-LQ (Complete Basis Set $)^{48}$, do qual foram obtidas as optimizações das geometrias de estados de repouso e de transição. Para o tratamento de informações sobre a forma de complexos do tipo van der Waals ${ }^{43}$, foram realizados cálculos de dinâmica molecular semiclássica de Born-Oppenheimer.

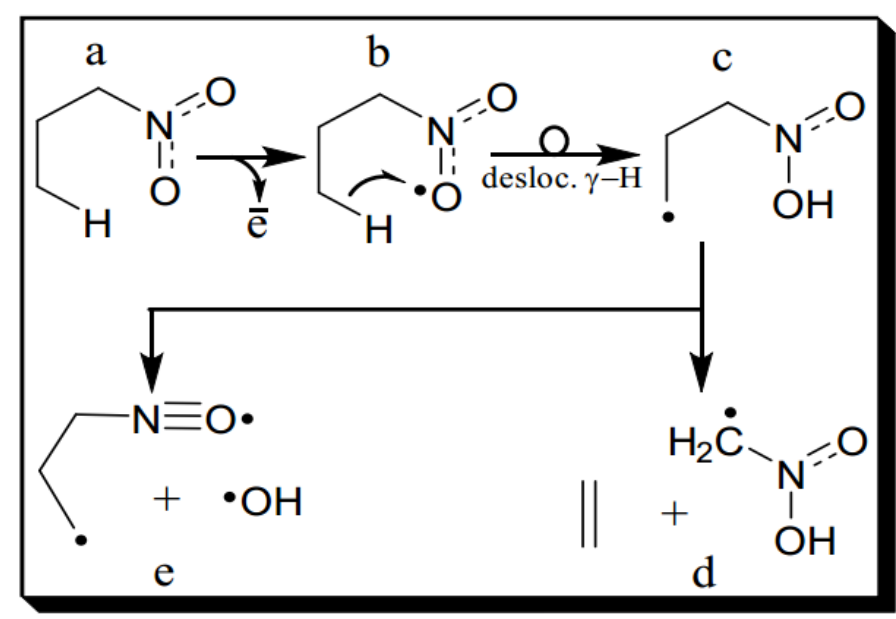

Figura A. 11. Mecanísmo de Fragmentação do $\mathrm{PrNO}_{2}$. Fonte: autor.

O processo de fragmentação para este sistema segue da seguinte forma; o primeiro passo ocorre através da fonte de ionização, a extração de 1 elétron do sistema molecular formando uma nova estrutura $\mathbf{b}$ do tipo cátion radical. Esse sistema sofre um rearranjo, transferindo o hidrogênio que se encontra na posição- $\gamma$ para o grupo nitro. Então, este $H-\gamma$, sofre um deslocamento no sentido do grupo nitro, fazendo com que ele estabeleça uma ligação com o oxigênio, gerando um grupo $\mathrm{OH}$ e tornando o carbono- $\gamma$ agora o cátion radical, estrutura c.

A nova estrutura c pode dar origem a dois tipos de fragmentações, um que produz a substância d apresentando como produtos uma molécula neutra de etileno e um fragmento nítrico. E a outra fragmentação conduz ao produto e que é acompanhado da saída do grupo $\mathrm{OH}$ 
na forma de radical e a formação de um grupo nitroso com duas regiões radicalares, ou seja, possivelmente este tipo de produto não possui grandes populações no espectro.

Para uma explicação químico-quântica deste rearranjo (1-Nitropropano), foi aplicada a metodologia CBS-LQ com o qual foi possível obter duas coordenadas de fragmentação explícitas na Figura A.12 e Figura A.14.

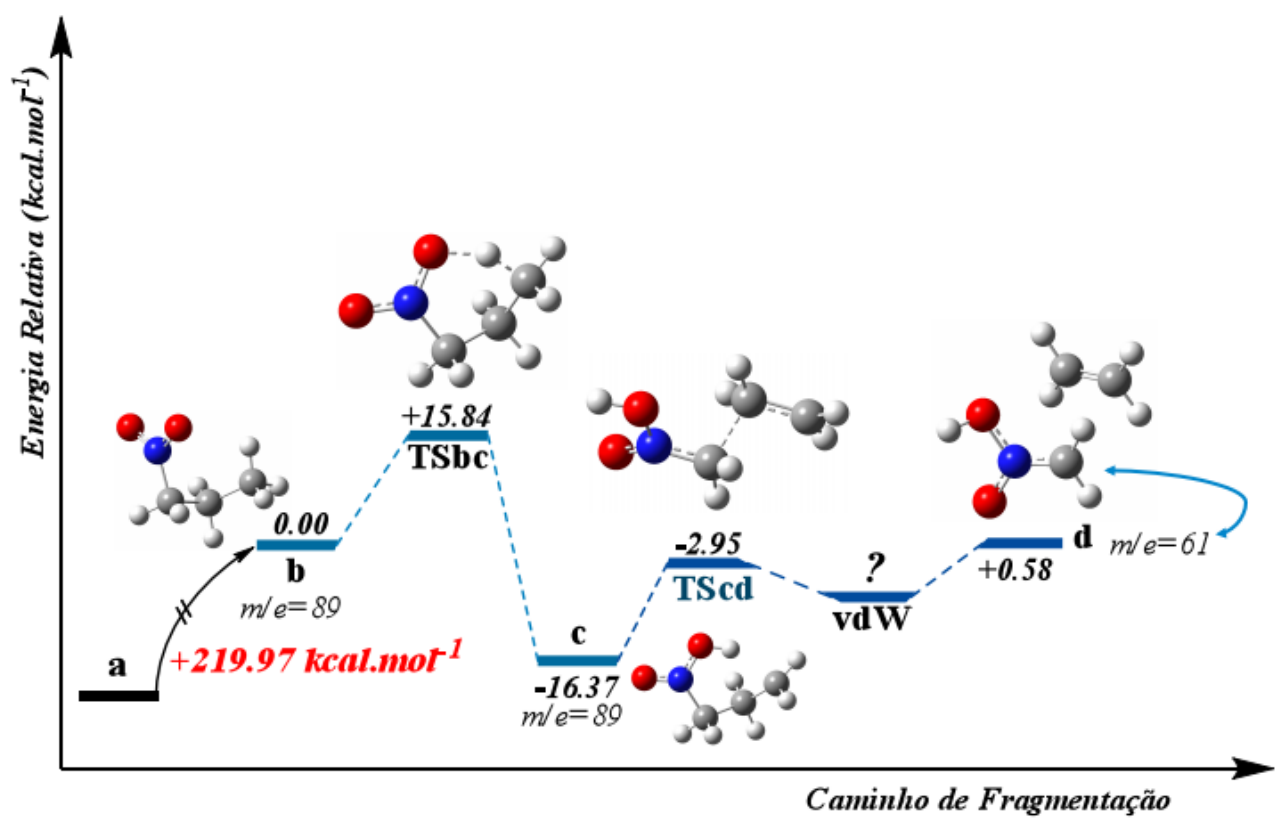

Figura A. 12. Caminho de reação produto (d). Fonte: autor

A coordenada de fragmentação da Figura A.12 corresponde a formação do produto d, no qual foi observado a retirada de 1 elétron do sistema molecular do 1-nitropropano, tornandoo um cátion radical. Para a saída deste elétron foi constatada uma barreira energética de aproximadamente $219,97 \mathrm{kcal} . \mathrm{mol}^{-1}$, ou seja, pode-se dizer que é um processo extremamente energético; e assim que o sistema molecular catiônico b é formado, ele pode sofrer um rearranjo e converter-se em c, a partir de uma barreira energética da ordem de 15,84 kcal.mol ${ }^{-1}$. Essa é a geometria de estado de transição associada a transferência do hidrogênio radical no primeiro passo do rearranjo McLafferty. Com isso, uma vez que o produto c é formado, ele pode sofrer uma nova fragmentação liberando da sua estrutura o etileno, fragmento neutro, e formando o grupo nítrico, fragmento cátion radicalar.

Verificou-se que o estado de transição TSed (Figura A.12) apresentou uma barreira energética da ordem de $14 \mathrm{kcal} . \mathrm{mol}^{-1}$ aproximadamente, com isso notou-se uma situação não esperada na coordenada de reação, uma vez que o produto do rearranjo final demonstrou um 
estado energético superior ao estado de transição, induzindo a conclusão de que é uma barreira de ativação negativa. Para explicar este fato foram realizados cálculos de dinâmica semiclássica do tipo Born-Oppenheimer, utilizando a combinação HF e base atômica 3-21G, gerando a coordenada exposta na Figura A.13.

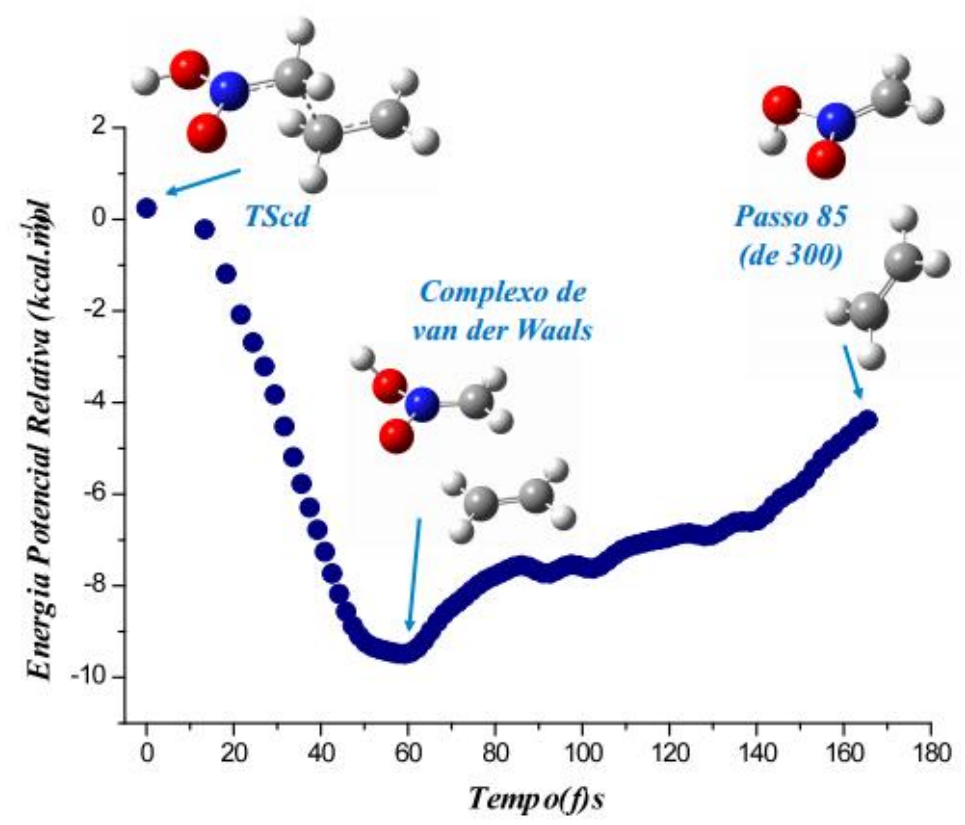

Figura A. 13. Energia Potencial Relativa da formação de complexo do tipo van der Waals. Fonte: autor

Foi observado nesta dinâmica que a partir do estado de transição o sistema sofreu fragmentação rapidamente atingindo um estado energético muito mais baixo do que o estado de transição, indicando que a barreira energética não é negativa e sim, associada à formação do complexo do tipo van der Waals, de menor estado de energia que, neste caso, sucede o estado de transição. E à medida que aumenta a repulsão entre os fragmentos observa-se um comportamento crescente em relação ao valor apresentado de energia.

A coordenada explícita na Figura A.14 corresponde a formação do produto e. Nesta coordenada, observa-se a formação de dois radicais no mesmo fragmento (grupo nitroso) e a saída do grupo $\mathrm{OH}$. Para chegar nesta alternativa, pode-se dizer que o fragmento c sofre um rearranjo passando por um estado de transição do tipo TSce, cuja barreira é da ordem de 35,71 kcal.mol ${ }^{-1}$, onde tem a saída do grupo $\mathrm{OH}$ gerando o produto hipotético de fragmentação, grupo nitroso com duas regiões radicalares, um sobre o grupo do átomo de nitrogênio e o outro sobre o átomo de carbono. Esta situação não é energeticamente favorável para o processo de 
fragmentação, pois os fragmentos sempre tendem a estruturas mais estáveis. Sendo que este produto apresenta dois fragmentos, e um deles é duplamente desestabilizado, com duas regiões radicalares. Concluindo, então, que a formação deste sistema não é energeticamente favorecida.

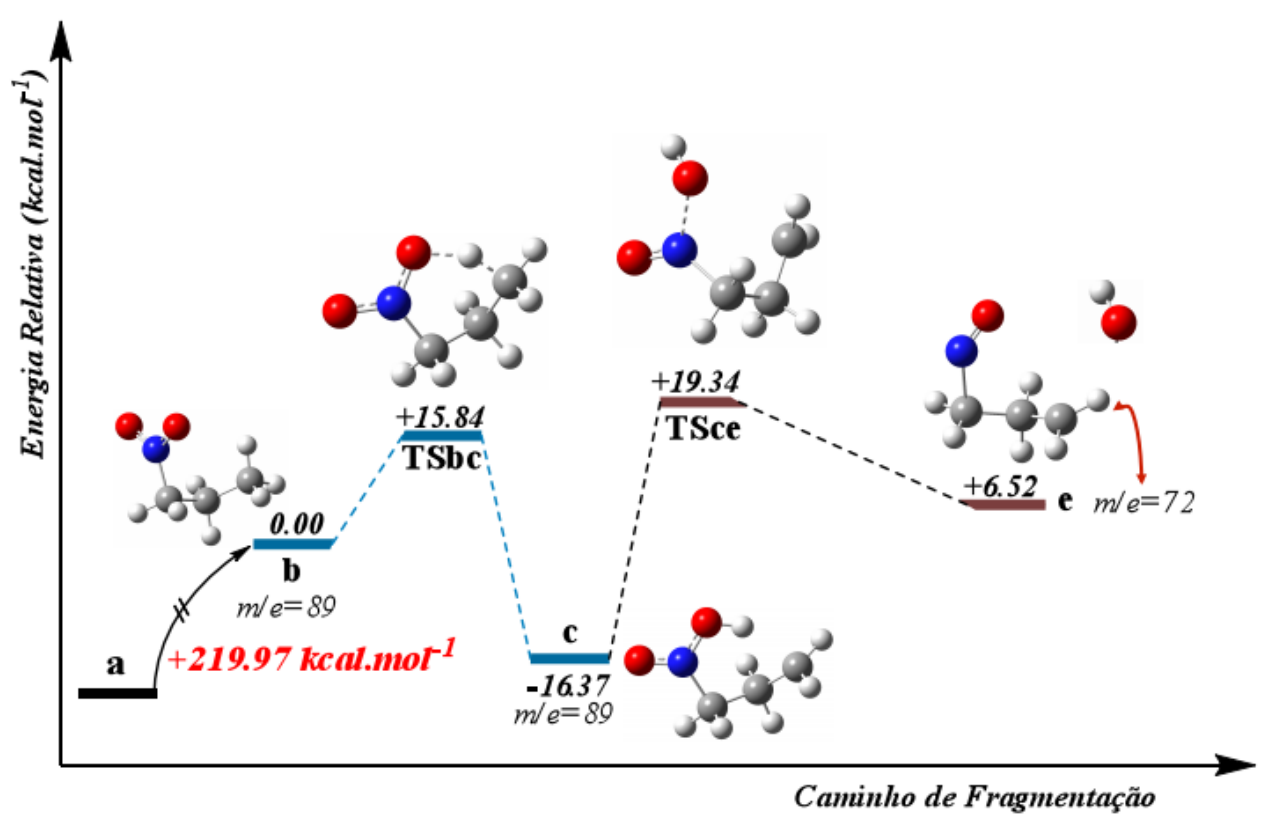

Figura A. 14. Caminho de Reação Produto (e). Fonte: autor

Por fim, analisando o perfil termodinâmico das duas coordenadas, verificou-se que a fragmentação que conduz aos fragmentos d é cinética e termodinamicamente favorável. (Figura A.15)

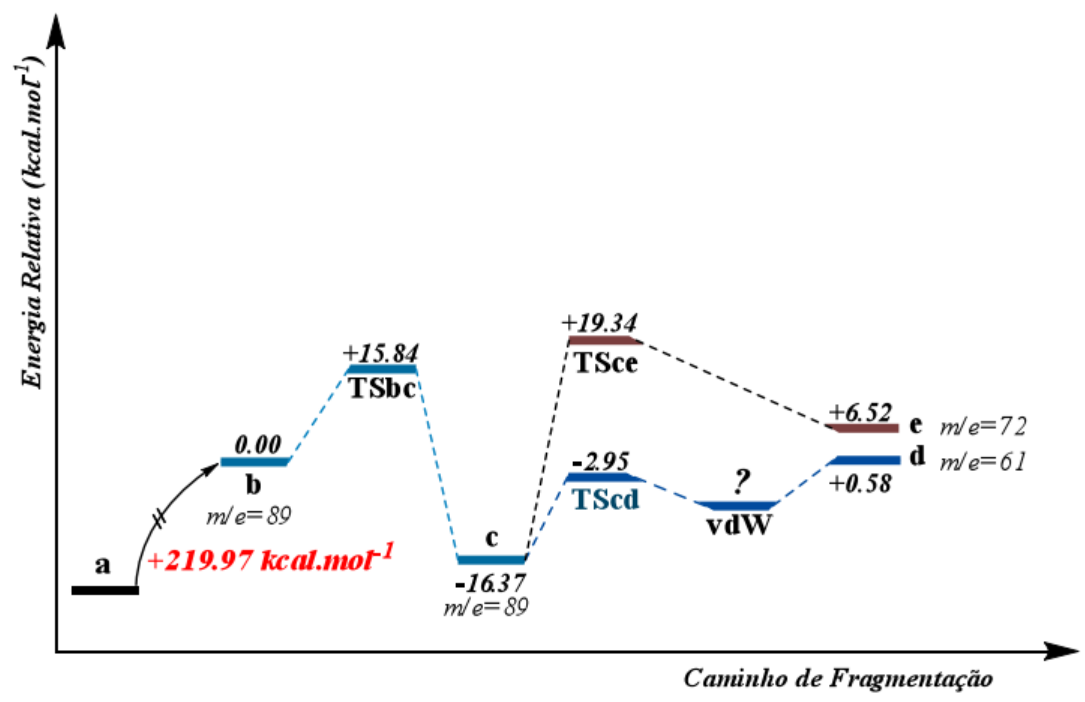

Figura A. 15. Comparação entre os caminhos de fragmentação que levam aos fragmentos $\boldsymbol{e}$ e $\boldsymbol{d}$. Fonte: autor. 
A mesma metodologia foi aplicada para a descrição do mecanismo de rearranjo concertado, entretanto essa descrição não foi possível pois a estrutura referente ao estado de transição para o mecanismo concertado não obteve convergência do cálculo. A não convergência indica que o mecanismo concertado não é favorecido, assim como observado para os outros sistemas. 


\section{Referências}

1. (a) Soriano-Moro, G.; Percino, J.; Cerón, M.; Castro, M. E.; Chapela, V. M., Physicochemical study by multi-angle light scattering of water-soluble methacryloylaminophenylarsonate copolymers. Journal of Polymer Research 2014, 21 (8), 111; (b) Brown, T. L.; LeMay, H. E.; Bursten, B. E.; Burdge, J. R., Quimica. Pearson Educación: 2004.

2. (a) Li, Z.; Zhi, Y.; Feng, X.; Ding, X.; Zou, Y.; Liu, X.; Mu, Y., An Azine-Linked Covalent Organic Framework: Synthesis, Characterization and Efficient Gas Storage. Chemistry - A European Journal 2015, 21 (34), 12079-12084; (b) Zhang, Y.; Lai, S.-L.; Tong, Q.-X.; Chan, M.-Y.; Ng, T.-W.; Wen, Z.-C.; Zhang, G.-Q.; Lee, S.-T.; Kwong, H.-L.; Lee, C.S., Synthesis and characterization of phenanthroimidazole derivatives for applications in organic electroluminescent devices. Journal of Materials Chemistry 2011, 21 (22), 8206-8214; (c) Kaur, I.; Kumari, V.; Dhiman, P. K., Synthesis, characterization and use of polymersupported phase transfer catalyst in organic reactions. Journal of Applied Polymer Science 2011, 121 (6), 3185-3191; (d) Keerthi, K.; Rajapakse, A.; Sun, D.; Gates, K. S., Synthesis and characterization of a small analogue of the anticancer natural product leinamycin. Bioorganic \& Medicinal Chemistry 2013, 21 (1), 235-241; (e) Lane, A. L.; Nam, S.-J.; Fukuda, T.; Yamanaka, K.; Kauffman, C. A.; Jensen, P. R.; Fenical, W.; Moore, B. S., Structures and Comparative Characterization of Biosynthetic Gene Clusters for Cyanosporasides, EnediyneDerived Natural Products from Marine Actinomycetes. Journal of the American Chemical Society 2013, 135 (11), 4171-4174.

3. (a) Clegg, L. E.; Mac Gabhann, F., Molecular mechanism matters: Benefits of mechanistic computational models for drug development. Pharmacological Research 2015, 99, 149-154; (b) Mechanism matters. Nat Med 2010, 16 (4), 347-347.

4. (a) de Broglie, L. Recherches sur la Théorie des Quantas. PhD, University of Paris, Paris, 1924; (b) de Broglie, L., Recherches sur la Théorie des Quantas. Ann. Phys. 1925, 3, 22 128.

5. Einstein, A., Über einen die Erzeugung und Verwandlung des Lichtes betreffenden heuristischen Gesichtspunkt. Annalen der Physik 1905, 322 (6), 132-148.

6. (a) Bader, R. F. W., A quantum theory of molecular structure and Its appllcatlons. Chem. Rev. 1991, 91, 893-928; (b) Bader, R. F. W., Atoms in Molecules: A Quantum Theory. 22 ed.; Oxford University Press, Incorporated: 1994; Vol. 22; (c) Bader, R. F. W., Bond Paths Are Not Chemical Bonds. The Journal of Physical Chemistry A 2009, 113 (38), 10391-10396.

7. (a) Thomson, J. J., XXIV. On the structure of the atom: an investigation of the stability and periods of oscillation of a number of corpuscles arranged at equal intervals around the circumference of a circle; with application of the results to the theory of atomic structure. Philosophical Magazine Series 6 1904, 7 (39), 237-265; (b) Thomson, J. J., LXX. On the number of corpuscles in an atom. Philosophical Magazine Series 6 1906, 11 (66), 769-781; (c) Thomson, J. J., XL. Cathode Rays. Philosophical Magazine Series 5 1897, 44 (269), 293-316. 8. Rutherford, E., The scattering of $\alpha$ and $\beta$ particles by matter and the structure of the atom. Philosophical Magazine 2012, 92 (4), 379-398.

9. Bohr, N., I. On the constitution of atoms and molecules. Philosophical Magazine Series 6 1913, 26 (151), 1-25.

10. (a) Schrödinger, E., An Undulatory Theory of the Mechanics of Atoms and Molecules. Physical Review 1926, 28 (6), 1049-1070; (b) Schrödinger, E., Quantisierung als Eigenwertproblem. Annalen der Physik 1926, 384 (4), 361-376.

11. (a) Bohm, D., A Suggested Interpretation of the Quantum Theory in Terms of "Hidden" Variables. I. Physical Review 1952, 85 (2), 166-179; (b) Bohm, D., Proof That Probability 
Density Approaches $|\mathrm{psi}|^{2}$ in Causal Interpretation of the Quantum Theory. Physical Review 1953, 89 (2), 458-466.

12. (a) Romero, S. N. T., Estado da arte, desafios e perspectiva para os próximos cinco anos. 1 ed.; Chris McHilliard Editora: São Paulo, 2011; p 173; (b) José Luis P. B. Silva, M. B. d. M. C. Para compreender o modelo atômico quântico XIV Encontro Nacional de Ensino de Química [Online], 2008. (accessed 17/11/2015).

13. (a) LEVINE, I. R. A. N., FISICO-QUIMICA. LTC; (b) Eisberg, R. M.; Resnick, R., Fisica quantica: atomos, moleculas, solidos, nucleos e particulas. Campus: 1979.

14. Hameka, H. F., Quantum Mechanics: A Conceptual Approach. Wiley: 2004.

15. (a) Pavia, D. L.; Lampman, G. M.; Kriz, G. S.; Vyvyan, J. A., Introduction to Spectroscopy. Cengage Learning: 2008; (b) LAMPMAN, G. M.; PAVIA, D. L.; KRIZ, G. S.; VYVYAN, J. R., INTRODUÇAO A ESPECTROSCOPIA. CENGAGE.

16. (a) Gross, J. H., Mass Spectrometry: A Textbook. Springer Berlin Heidelberg: 2004; (b) Souza, R. Y.; Bataglion, G. A.; Ferreira, D. A. C.; Gatto, C. C.; Eberlin, M. N.; Neto, B. A. D., Insights on the Petasis Borono-Mannich multicomponent reaction mechanism. RSC Advances 2015, 5 (93), 76337-76341; (c) Medeiros, G. A.; da Silva, W. A.; Bataglion, G. A.; Ferreira, D. A. C.; de Oliveira, H. C. B.; Eberlin, M. N.; Neto, B. A. D., Probing the mechanism of the Ugi four-component reaction with charge-tagged reagents by ESI-MS(/MS). Chemical Communications 2014, 50 (3), 338-340; (d) Cleveland, M. J.; Ziemba, L. D.; Griffin, R. J.; Dibb, J. E.; Anderson, C. H.; Lefer, B.; Rappenglück, B., Characterization of urban aerosol using aerosol mass spectrometry and proton nuclear magnetic resonance spectroscopy. Atmospheric Environment 2012, 54, 511-518; (e) Tfaily, M. M.; Chu, R. K.; Tolić, N.; Roscioli, K. M.; Anderton, C. R.; Paša-Tolić, L.; Robinson, E. W.; Hess, N. J., Advanced Solvent Based Methods for Molecular Characterization of Soil Organic Matter by High-Resolution Mass Spectrometry. Analytical Chemistry 2015, 87 (10), 5206-5215; (f) Danger, G.; OrthousDaunay, F. R.; de Marcellus, P.; Modica, P.; Vuitton, V.; Duvernay, F.; Flandinet, L.; Le Sergeant d'Hendecourt, L.; Thissen, R.; Chiavassa, T., Characterization of laboratory analogs of interstellar/cometary organic residues using very high resolution mass spectrometry. Geochimica et Cosmochimica Acta 2013, 118, 184-201.

17. (a) Smith, R. M., Understanding Mass Spectra: A Basic Approach. Wiley: 2004; (b) McLafferty, F. W.; Tureček, F., Interpretation of Mass Spectra. University Science Books: 1993.

18. Diniz, M. E. R. Uso da técnica de espectrometria de massas com ionização por eletrospray ( ESI-MS ) para o estudo do mecanismo de reações orgânicas e avaliação do perfil de fragmentação de bis-hidroxiiminas aromáticas Uso da técnica de espectrometria de massas com ioniza. Universidade Federal de Minas Gerais, Belo Horizonte, 2011.

19. Moraes, M. C. B.; Lago, C. L. d., Espectrometria de massas com ionização por "electrospray" aplicada ao estudo de espécies inorgânicas e organometálicas. Química Nova 2003, 26, 556-563.

20. Dass, C., Fundamentals of Contemporary Mass Spectrometry. Wiley: 2007.

21. (a) Takayama, M., Metastable McLafferty rearrangement reaction in the electron impact ionization of stearic acid methyl ester. International Journal of Mass Spectrometry and Ion Processes 1995, 144 (3), 199-204; (b) Norberg, D.; Salhi-Benachenhou, N., McLafferty rearrangement of the radical cations of butanal and 3-fluorobutanal: A theoretical investigation of the concerted and stepwise mechanisms. Journal of Computational Chemistry 2008, 29 (3), 392-406; (c) Van Stipdonk, M. J.; Kerstetter, D. R.; Leavitt, C. M.; Groenewold, G. S.; Steill, J.; Oomens, J., Spectroscopic investigation of $\mathrm{H}$ atom transfer in a gas-phase dissociation reaction: McLafferty rearrangement of model gas-phase peptide ions. Physical Chemistry Chemical Physics 2008, 10 (22), 3209-3221; (d) Dalmázio, I. APLICAÇÃO DA ESPECTROMETRIA DE MASSAS COM IONIZAÇÃO ELECTROSPRAY NO 
MONITORAMENTO DE PROCESSOS OXIDATIVOS AVANÇADOS DE INTERESSE AMBIENTAL: DEGRADAÇÃO DE FÁRMACOS, AVALIAÇÃO DE SISTEMAS OXIDATIVOS E OXIDAÇÃO DO ISOPRENO. Universidade Federal de Minas Gerais, Belo Horizonte, 2007; (e) Vessecchi, R.; Galembeck, S. E.; Lopes, N. P.; Nascimento, P. G. B. D.; Crotti, A. E. M., Aplicação da química quântica computacional no estudo de processos químicos envolvidos em espectrometria de massas. Química Nova 2008, 31, 840-853; (f) de Hoffmann, E.; Stroobant, V., Mass Spectrometry: Principles and Applications. Wiley: 2013.

22. (a) Laulhé, S.; Bogdanov, B.; Johannes, L. M.; Gutierrez, O.; Harrison, J. G.; Tantillo, D. J.; Zhang, X.; Nantz, M. H., Fragmentation of oxime and silyl oxime ether odd-electron positive ions by the McLafferty rearrangement: new insights on structural factors that promote $\alpha, \beta$ fragmentation. Journal of Mass Spectrometry 2012, 47 (6), 676-686; (b) Boer, F. P.; Shannon, T. W.; McLafferty, F. W., Electronic structure of the six-membered cyclic transition state in some .gamma.-hydrogen rearrangements. Journal of the American Chemical Society 1968, 90 (26), 7239-7248; (c) Liu, R.; Pulay, P., Ab initio evidence for the stepwise mechanism of the McLafferty rearrangement of the butanal radical cation. Journal of Computational Chemistry 1992, 13 (2), 183-186; (d) Ha, T. K.; Radloff, C.; Nguyen, M. T., An ab initio study on the McLafferty-type rearrangement in the butanal radical cation (CHOCH2CH2CH3+.cntdot.). The Journal of Physical Chemistry 1986, 90 (13), 2991-2994; (e) Olah, G. A.; Mathew, T.; Goeppert, A.; Rasul, G.; Prakash, G. K. S.; Esteves, P. M., Carbocationic rearrangement of pivaloyl cation and protonated pivalaldehyde in superacid medium: A novel solution equivalent of the McLafferty rearrangement. Journal of the American Society for Mass Spectrometry 2004, 15 (7), 959-965.

23. (a) Nibbering, N. M. M., The mclafferty rearrangement: a personal recollection. Journal of the American Society for Mass Spectrometry 2004, 15 (7), 956-958; (b) Osterheld, T. H.; Brauman, J. I., Infrared multiple photon dissociation of butyrophenone cation. A stepwise McLafferty rearrangement. Journal of the American Chemical Society 1990, 112 (5), 20142016; (c) Kercher, J. P.; Sztáray, B.; Baer, T., On the dissociation of the 2-pentanone ion studied by threshold photoelectron photoion coincidence spectroscopy. International Journal of Mass Spectrometry 2006, 249-250, 403-411.

24. $\quad$ NIST Mass Spec Data Center, S.E. Stein, director, "Butyrophenone Mass Spectra". In NIST Chemistry WebBook, NIST Standard Reference Database Number 69, Mallard, P. J. L. a. W. G., Ed. National Institute of Standards and Technology, Gaithersburg MD, 20899: 2016.

25. (a) Biemann, K., Mass spectrometry: organic chemical applications. McGraw-Hill: 1962; (b) Rose, M. E.; Chemistry, R. S. o., Mass Spectrometry. Royal Society of Chemistry: 1989; (c) Stevenson, D. P., Mass Spectrometry and its Applications to Organic Chemistry. Journal of the American Chemical Society 1961, 83 (12), 2787-2787.

26. Dickschat, J. S., Capturing volatile natural products by mass spectrometry. Natural Product Reports 2014, 31 (6), 838-861.

27. Jasinski, J. M.; Rosenfeld, R. N.; Meyer, F. K.; Brauman, J. I., Infrared photochemistry of $[(\mathrm{C} 2 \mathrm{H} 5) 2 \mathrm{O}] 2 \mathrm{H}+$ and $\mathrm{C} 3 \mathrm{~F} 6+$. A comparison of pulsed and continuous-wave laser photodissociation methods. Journal of the American Chemical Society 1982, 104 (3), 652-658. 28. (a) Coutinho, N. H. M. K., Métodos de Química Teórica E Modelagem Molecular. Editora Livraria da Física: 2007; (b) Szabo, A.; Ostlund, N. S., Modern Quantum Chemistry: Introduction to Advanced Electronic Structure Theory. Dover Publications: 2012.

29. (a) Hartree, D. R., The Wave Mechanics of an Atom with a Non-Coulomb Central Field. Part I. Theory and Methods. Mathematical Proceedings of the Cambridge Philosophical Society 1928, 24 (01), 89-110; (b) Hartree, D. R., The Wave Mechanics of an Atom with a nonCoulomb Central Field. Part III. Term Values and Intensities in Series in Optical Spectra. Mathematical Proceedings of the Cambridge Philosophical Society 1928, 24 (03), 426-437; (c) Hartree, D. R., The Wave Mechanics of an Atom with a Non-Coulomb Central Field. Part II. 
Some Results and Discussion. Mathematical Proceedings of the Cambridge Philosophical Society 1928, 24 (01), 111-132; (d) Hartree, D. R., The Wave Mechanics of an Atom with a Non-Coulomb Central Field. Part IV. Further Results relating to Terms of the Optical Spectrum. Mathematical Proceedings of the Cambridge Philosophical Society 1929, 25 (03), 310-314; (e) Fock, V., Näherungsmethode zur Lösung des quantenmechanischen Mehrkörperproblems. $Z$. Physik 1930, 61 (1-2), 126-148; (f) Fock, V., „Selfconsistent field“ mit Austausch für Natrium. Z. Physik 1930, 62 (11-12), 795-805.

30. Slater, J. C., The Self-Consistent Field for Molecular and Solids, Quantum Theory of Molecular and Solids. McGraw-Hill: New York, 1974; Vol. 4.

31. Silva, A. L. B. B. e. Introdução a Química Quântica. http://bliblioteca.yolasite.com/resources/Introdu\%C3\%A7\%C3\%A3o\%20a\%20Qu\%C3\%AD mica\%20Qu\%C3\%A2ntica.pdf (accessed 17/11/2015).

32. C. C. J. Roothaan, C. C. J., New Developments in Molecular Orbital Theory. Rev. Mod. Phys. 1951, 23, 69.

33. (a) Hohenberg, P.; Kohn, W., Inhomogeneous Electron Gas. Phys. Rev. 1964, 136, B864-B871; (b) Kohn, W.; Sham, L. J., Self-Consistent Equations Including Exchange and Correlation Effects. Phys. Rev. 1965, 140, A1133-A1138.

34. (a) Morgon, N. H.; Custódio, R., Teoria do Funcional de Densidade. Química Nova 1995, 18 (1), 12; (b) Parr, R. G.; Yang, W., Density-Functional Theory of Atoms and Molecules. Oxford University Press, USA: 1989.

35. (a) Gillespie, R. J.; Popelier, P. L. A., Chemical Bonding and Molecular Geometry: From Lewis to Electron Densities. Oxford University Press: 2001; (b) Koch, U.; Popelier, P. L. A., Characterization of C-H-O Hydrogen Bonds on the Basis of the Charge Density. The Journal of Physical Chemistry 1995, 99 (24), 9747-9754; (c) Popelier, P. L. A., Characterization of a Dihydrogen Bond on the Basis of the Electron Density. The Journal of Physical Chemistry A 1998, 102 (10), 1873-1878; (d) Popelier, P. L. A., Quantum Molecular Similarity. 1. BCP Space. The Journal of Physical Chemistry A 1999, 103 (15), 2883-2890.

36. (a) Collins, J. B.; Schleyer, P. v. R.; Binkley, J. S.; Pople, J. A., Self-Consistent Molecular Orbital Methods. 17. Geometries and binding energies of second-row molecules. A comparison of three basis sets. J. Chem. Phys. 1976, 64, 5142-5151; (b) Hay, J.; Wadt, W. R., $\mathrm{Ab}$ initio effective core potentials for molecular calculations - potentials for the transition-metal atoms Sc to Hg J. Chem. Phys. 1985, 82, 270-283; (c) Hay, P. J.; Wadt, W. R., Ab initio effective core potentials for molecular calculations - potentials for $\mathrm{K}$ to Au including the outermost core orbitals. J. Chem. Phys. 1985, 82, 299-310; (d) Hehre, W. J.; Stewart, R. F.; Pople, J. A., Self-Consistent Molecular Orbital Methods. 1. Use of Gaussian expansions of Slater-type atomic orbitals. J. Chem. Phys. 1969, 51, 2657-2664.

37. (a) Walker, M.; Harvey, A. J. A.; Sen, A.; Dessent, C. E. H., Performance of M06, M062X, and M06-HF Density Functionals for Conformationally Flexible Anionic Clusters: M06 Functionals Perform Better than B3LYP for a Model System with Dispersion and Ionic Hydrogen-Bonding Interactions. The Journal of Physical Chemistry A 2013, 117 (47), 1259012600; (b) Zhao, Y.; Truhlar, D., The M06 suite of density functionals for main group thermochemistry, thermochemical kinetics, noncovalent interactions, excited states, and transition elements: two new functionals and systematic testing of four M06-class functionals and 12 other functionals. Theoretical Chemistry Accounts 2008, 120 (1-3), 215-241; (c) Zhao, Y.; Truhlar, D. G., The M06 suite of density functionals for main group thermochemistry, thermochemical kinetics, noncovalent interactions, excited states, and transition elements: two new functionals and systematic testing of four M06-class functionals and 12 other functionals. Theoretical Chemistry Accounts 2008, 120 (1), 215-241. 
38. McLean, A. D.; Chandler, G. S., Contracted Gaussian basis sets for molecular calculations. I. Second row atoms, $\mathrm{Z}=11-18$. The Journal of Chemical Physics 1980, 72 (10), 5639-5648.

39. (a) Eyring, H., The activated complex in chemical reactions. J. Chem. Phys. 1935, 3 (2), 107; (b) Evans, M. G.; Polanyi, M., Some applications of the transition state method to the calculation of reaction velocities, especially in solution. Trans. Faraday Soc. 1935, 31 (0), 875894.

40. (a) Mulyava, M. P.; Shevchuk, V. U., Calculation of the preexponential factors of freeradical and molecular reactions based on the principle of bond entropy additivity. Theoretical and Experimental Chemistry 1972, 5 (4), 323-328; (b) Mulyava, M. T.; Shevchuk, V. U., Calculation of pre-exponential factors for radical substitution reactions on the basis of the additivity principle. Theoretical and Experimental Chemistry 1967, 1 (6), 482-485.

41. Morais, S. F. d. A.; Mundim, K. C.; Ferreira, D. A. C., An alternative interpretation of the ultracold methylhydroxycarbene rearrangement mechanism: cooperative effects. Physical Chemistry Chemical Physics 2015, 17 (11), 7443-7448.

42. Tsallis, C., Possible generalization of Boltzmann-Gibbs statistics. Journal of Statistical Physics 1988, 52 (1-2), 479-487.

43. (a) Hirschfelder, J. O.; Meath, W. J., The Nature of Intermolecular Forces. In Advances in Chemical Physics, John Wiley \& Sons, Inc.: 2007; pp 3-106; (b) Kim, C.; Kim, S. J.; Lee, Y. P.; Kim, Y., Quantum mechanicl study of van der Waals complex. I. The $\mathrm{H}_{2}$ dimer using the DFT and multi-coefficient G2/G3 methods. Bull. Korean Chem. Soc. 2000, 21, 510-514.

44. (a) Ditchfield, R.; Hehre, W. J.; Pople, J. A., Self-Consistent Molecular Orbital Methods. 9. Extended Gaussian-type basis for molecular-orbital studies of organic molecules. J. Chem. Phys. 1971, 54, 724; (b) Hariharan, P. C.; Pople, J. A., Accuracy of AH equilibrium geometries by single determinant molecular-orbital theory. Mol. Phys. 1974, 27, 209-214; (c) Hehre, W. J.; Ditchfield, R.; Pople, J. A., Self-Consistent Molecular Orbital Methods. 12. Further extensions of Gaussian-type basis sets for use in molecular-orbital studies of organicmolecules. J. Chem. Phys. 1972, 56, 2257; (d) Rassolov, V. A.; Pople, J. A.; Ratner, M. A.; Windus, T. L., 6-31G* basis set for atoms K through Zn. J. Chem. Phys. 1998, 109, 1223-1229. 45. Frisch, M. J.; Trucks, G. W.; Schlegel, H. B.; Scuseria, G. E.; Robb, M. A.; Cheeseman, J. R.; Scalmani, G.; Barone, V.; Mennucci, B.; Petersson, G. A.; Nakatsuji, H.; Caricato, M.; Li, X.; Hratchian, H. P.; Izmaylov, A. F.; Bloino, J.; Zheng, G.; Sonnenberg, J. L.; Hada, M.; Ehara, M.; Toyota, K.; Fukuda, R.; Hasegawa, J.; Ishida, M.; Nakajima, T.; Honda, Y.; Kitao, O.; Nakai, H.; Vreven, T.; Montgomery Jr., J. A.; Peralta, J. E.; Ogliaro, F.; Bearpark, M. J.; Heyd, J.; Brothers, E. N.; Kudin, K. N.; Staroverov, V. N.; Kobayashi, R.; Normand, J.; Raghavachari, K.; Rendell, A. P.; Burant, J. C.; Iyengar, S. S.; Tomasi, J.; Cossi, M.; Rega, N.; Millam, N. J.; Klene, M.; Knox, J. E.; Cross, J. B.; Bakken, V.; Adamo, C.; Jaramillo, J.; Gomperts, R.; Stratmann, R. E.; Yazyev, O.; Austin, A. J.; Cammi, R.; Pomelli, C.; Ochterski, J. W.; Martin, R. L.; Morokuma, K.; Zakrzewski, V. G.; Voth, G. A.; Salvador, P.; Dannenberg, J. J.; Dapprich, S.; Daniels, A. D.; Farkas, Ö.; Foresman, J. B.; Ortiz, J. V.; Cioslowski, J.; Fox, D. J. Gaussian 09, Gaussian, Inc.: Wallingford, CT, USA, 2009.

46. Keith, T. A. AIMAll (Version 14.10.27), TK Gristmill Software (aim.tkgristmill.com): Overland Park KS, USA, 2014.

47. Adrienko, G. A. ChemCraft, 1.8 (build 445); www.chemcraftprog.org: 2015.

48. (a) Montgomery Jr, J. A.; Frisch, M. J.; Ochterski, J. W.; Petersson, G. A., A complete basis set model chemistry. VII. Use of the minimum population localization method. J. Chem. Phys. 2000112 6532-6542; (b) Ochterski, J. W.; Petersson, G. A.; Montgomery Jr., J. A., A complete basis set model chemistry. V. Extensions to six or more heavy atoms. J. Chem. Phys. 1996, 104, 2598-2619. 